University of Louisville

ThinkIR: The University of Louisville's Institutional Repository

Electronic Theses and Dissertations

$12-2010$

\title{
Inflammatory cell tumor necrosis factor signaling modulates post-infarction left ventricular remodeling.
}

Robert K. Lewis 1977-

University of Louisville

Follow this and additional works at: https://ir.library.louisville.edu/etd

\section{Recommended Citation}

Lewis, Robert K. 1977-, "Inflammatory cell tumor necrosis factor signaling modulates post-infarction left ventricular remodeling." (2010). Electronic Theses and Dissertations. Paper 820.

https://doi.org/10.18297/etd/820

This Doctoral Dissertation is brought to you for free and open access by ThinkIR: The University of Louisville's Institutional Repository. It has been accepted for inclusion in Electronic Theses and Dissertations by an authorized administrator of ThinkIR: The University of Louisville's Institutional Repository. This title appears here courtesy of the author, who has retained all other copyrights. For more information, please contact thinkir@louisville.edu. 
INFLAMMATORY CELL TUMOR NECROSIS FACTOR SIGNALING MODULATES POST-INFARCTION LEFT VENTRICULAR REMODELING

\author{
by \\ Robert K. Lewis \\ B.A., University of Louisville, 1999 \\ M.B.A., University of Louisville, 2002 \\ M.D., University of Louisville, 2004 \\ M.S., University of Louisville, 2008

\begin{abstract}
A Dissertation
Submitted to the Faculty of the

Graduate School of the University of Louisville

In Partial Fulfillment of the Requirements

For the Degree of
\end{abstract} \\ Doctor of Philosophy \\ Department of Physiology and Biophysics \\ University of Louisville \\ Louisville, KY
}

December, 2010 



\title{
INFLAMMATORY CELL TUMOR NECROSIS FACTOR SIGNALING MODULATES POST-INFARCTION LEFT VENTRICULAR REMODELING
}

\author{
by \\ Robert K. Lewis \\ B.A., University of Louisville, 1999 \\ M.B.A., University of Louisville, 2002 \\ M.D., University of Louisville, 2004 \\ M.S., University of Louisville, 2008 \\ A Dissertation Approved on \\ December 7, 2010 \\ By the following Dissertation Committee: \\ Sumanth D. Prabhu, MD \\ William B. Wead, PhD \\ \begin{tabular}{c} 
Steven P.Jones, PhD \\
\hline Stanley E. D'Souza, RhD \\
Suresh C. Tyagi, PhD
\end{tabular}
}




\section{DEDICATION}

I would like to dedicate this dissertation to my mother and father who encouraged and at times forced me to live up to my ability. To my wife who allowed me to dedicate the time and money necessary to complete this project. To my friend and research partner Dr. Justin Kingery. Lastly, to my mentors Dr. William Wead and Dr. Sumanth D. Prabhu who have provided guidance and encouragement throughout this process. 


\title{
ABSTRACT \\ INFLAMMATORY CELL TUMOR NECROSIS FACTOR SIGNALING MODULATES POST-INFARCTION LEFT VENTRICULAR REMODELING
}

\author{
Robert Kenneth Lewis \\ December, 2010
}

The fundamental question of the exact nature of the role played by TNF in the failing myocardium remains one of contention. Many preclinical studies have demonstrated beneficial effects with TNF antagonism and recently the dichotomous role played by the two TNF receptors in chronic ischemic injury has come to light. The failing heart has also been determined to have low levels of inflammatory cell infiltration. As these cells are known to be potent producers of inflammatory cytokines, we hypothesized that inflammatory cell localized TNF receptors play an important role in the progression of $L V$ remodeling following ischemic injury. To isolate the in vivo effects of inflammatory cell TNF receptors, we generated chimeric mice. Wild-type (WT, C57BL/6) mice underwent radiationinduced bone marrow (BM) ablation followed by reconstitution with BM from WT mice (WTc control, $n=30)$, TNFR $1-/-$ mice $(R 1-/-c, n=30)$ or TNFR2 -/- mice $(R 2-/-c, n=30)$. Six weeks later, WTc, R1-/-c, and R2-/-c mice were subjected to 
coronary ligation to induce heart failure (HF) or sham operation. Our results demonstrated that compared to WTC sham, 4 weeks after surgery, WTc HF hearts exhibited significantly $(p<0.05)$ : 1 ) increased LV size (EDV $96.7 \pm 13.7$ vs. $26.6 \pm 8.2 \mu \mathrm{L}$ ) and dysfunction (LVEF $25.5 \pm 7.5$ vs. $69.8 \pm 4.5 \%$ ); 2) greater hypertrophy (LV/tibia length [TL] $3.91 \pm 0.53$ vs. $2.9 \pm 0.4, \sim 4$-fold greater atrial natriuretic factor [ANF] mRNA); 3) increased fibrosis $(16.10 \pm 8.16 \%$ vs. $1.4 \pm$ $0.4 \%$ ) and connective tissue growth factor (CTGF) mRNA expression, and 4) increased ( 2 -fold) mRNA levels of TNF, interleukin (IL)-1 $\beta$, and IL-6. WTc HF mice also had markedly reduced survival (60\% vs. $100 \%)$ and increased blood levels of activated F4/80+/CD11b+ monocytes vs. WTc sham mice. In contrast, compared to WTc HF, R1 $/-c$ HF mice exhibited significantly $(p<0.05)$ : 1) improved survival $(80 \%), 2)$ less LV dilatation and improved LVEF $(42.9 \pm 4.2 \%)$, 3) less cardiac hypertrophy (LV/TL $3.14 \pm 0.2$ ) and ANF mRNA expression, 4) less cardiac fibrosis $(5.48 \pm 2.26 \%)$ and CTGF mRNA expression, and 5$)$ less cardiac TNF and IL-1 $1 \beta$ mRNA expression. Also, compared to WTc HF, R2-/-c HF mice exhibited significantly $(p<0.05)$ greater circulating $F 4 / 80+/ C D 11 b+$ monocytes $(15.32 \pm 4.41$ vs. $12.1 \pm 1.24 \%)$, and greater cardiac fibrosis $(21.92 \pm$ 10.81\%). Also noted was an increase, although not significant, in EDV and ESV. In parallel in vitro studies, the contribution of inflammatory cell TNFR1 and TNFR2 (i.e., macrophage-derived) to cardiac contractile dysfunction was investigated. Macrophages isolated from WT mice with HF 4 week postinfarction, when co-cultured with naïve cardiomyocytes induced contractile dysfunction and myocyte reactive oxygen species (ROS) generation in a 
juxtacrine but not paracrine maner $(p<0.001)$. Interestingly the effect on contractile dysfunction was diminished with the loss of TNFR1 in the HF macrophages but remained unchanged upon loss of TNFR2. Of note, ROS production in these groups followed a similar pattern in that loss of TNFR1 resulted in significantly attenuated myocyte ROS production upon HF macrophage contact with naïve myocytes. We therefore conclude that inflammatory cell-localized TNF receptor signaling has fundamental yet dichotomous, roles in post-infarction LV remodeling. In that inflammatory cell TNFR1 is required for the production of the pro-inflammatory state in failing myocardium and exacerbates post-infarction remodeling. Moreover, TNFR1 signaling in macrophages in HF augments macrophage-induced contractile dysfunction and ROS generation. Inflammatory cell-localized TNFR2 signaling has modest antifibrotic effects in the failing heart. TNF-dependent inflammatory cell responses are critical for the progression of pathological remodeling in HF. 


\section{TABLE OF CONTENTS}

PAGE

TITLE PAGE

SIGNATURE PAGE

...i

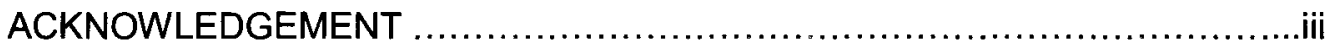

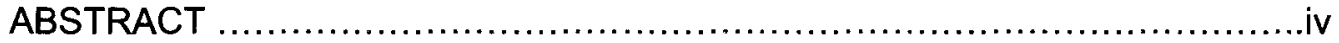

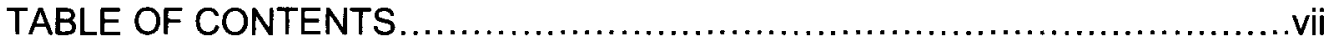

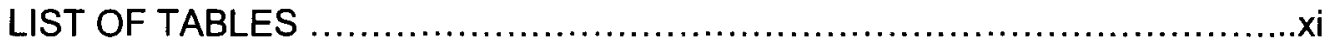

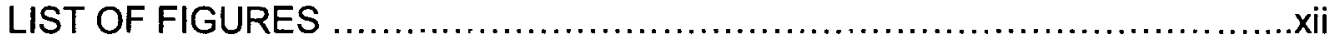

CHAPTER I:

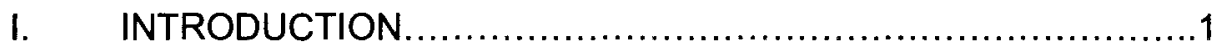

CHAPTER II: Background and Literature Review

I. Why Would TNF Matter in Heart Failure?....................................4

II. Clinical Trials: What Happened?............................................

III. The Complicated Nature of TNF.......................................6

IV. Unraveling the Mystery......................................10

CHAPTER III: Fundamental question

I. Proposed concepts...........................................12

II. Hypothesis and specific aims..................................13 
CHAPTER IV: Aim \#1: ABLATION OF TNFR1 IN THE INFLAMMATORY COMPARTMENT IS BENEFICIAL IN THE CHRONICALLY FAILING HEART

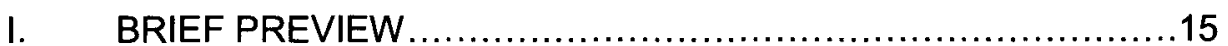

II. INTRODUCTION ................................................... 19

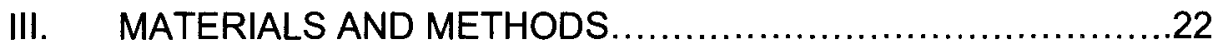

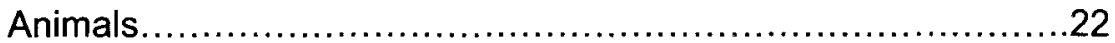

Coronary ligation.....................................................

Echocardiography................................................

Immunohistochemical analysis...................................24

Wheat Germ Agglutin..........................................25

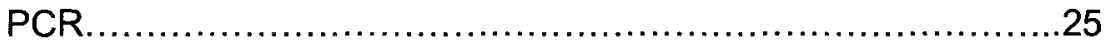

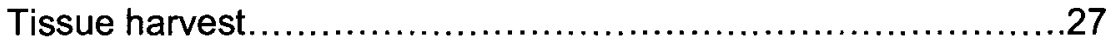

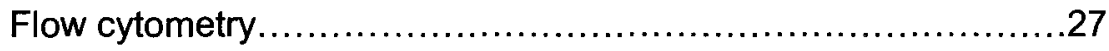

Statistical analysis..............................................

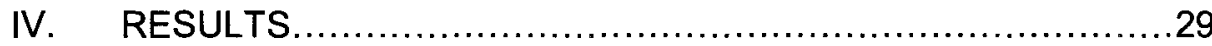

Generation of the Chimeric Animals Imparts no Difference in Cardiac Phenotypes between the Three Study Groups.............29

Proof of Concept: Monocytes/ Macrophages are Activated in the Peripheral Blood in Chronic Heart Failure..........................31

Proof of Concept: Activated Macrophages Infiltrate the Failing Myocardium Producing Inflammatory Cytokines.

Selective Loss of Either TNF Receptor in the Inflammatory Compartment Yields a Pro-Survival Benefit...

The Initial Level of Injury was Equivalent Between all HF Study Groups. 
LV Remodeling and Dilatation post Infarction is Attenuated by the Selective Loss of TNFR1 in the Inflammatory Compartment.......39

In vivo Measurements of Chamber Dilatation and Performance...41

Post Mortem Tissue Weights.....................................42

Myocyte Area and Atrial Natuiretic Factor (ANF) .................45

Decreased Fibrosis Seen in R1 HF Group.......................48

Myocardial Expression of Connective Tissue Growth Factor.......52

Flow Cytometric Analysis.....................................54

Myocardial cytokine expression...............................57

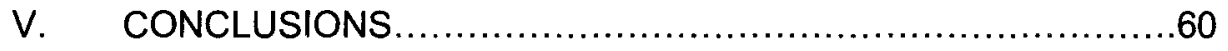

CHAPTER V: Aim \#2: HEART FAILURE-DERIVED MACROPHAGES INDUCE MYOCYTE OXIDATIVE STRESS AND CONTRACTILE DYSFUNCTION IN A JUXTACRINE AND TNF-DEPENDENT MANNER

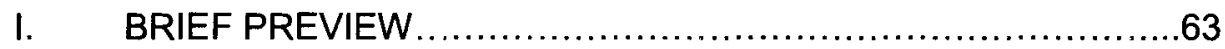

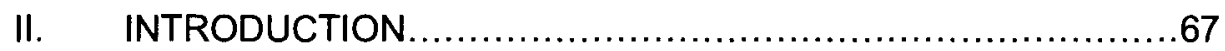

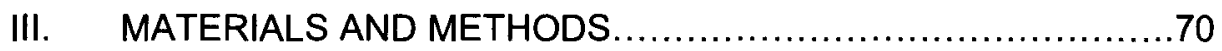

Animals........................................................

Coronary ligation and experimental protocol......................70

Isolation of mouse cardiomyocytes.............................71

Isolation of peritoneal macrophages............................72

Co-culture experimental protocol ..............................72

Flow cytometric analysis........................................

Statistical Analysis.............................................75

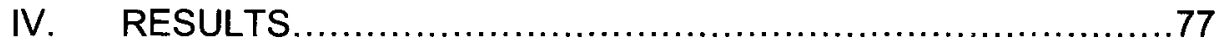


Proof of Concept: Thioglycollate Elicited Peritoneal Macrophages are Positive for the Macrophage Marker F4/80 ..................77

LPS-Stimulated Macrophages Induce Contractile Dysfunction.....80

LPS-Stimulated Macrophages cause Myocyte Dysfunction in a Juxtacrine but not Paracrine Manner.................................81

Heart Failure-Derived Macrophages are Sufficiently Activated to Induce Cardiomyocyte Contractile Depression......................83 HF-Derived Macrophage-Myocyte Physical Interaction Induces Contractile Dysfunction in a TNFR-Divergent Manner..............85

Heart Failure-Derived Macrophages Stimulate Cardiomyocyte Free Radical Production................................................. 87

Wild Type, TNFR1 ${ }^{+-}$, and TNFR2 ${ }^{-/-}$Macrophages Attach to Myocytes in Equivalent Numbers................................93

V. CONCLUSIONS .................................................

CHAPTER VI: Summary and future research directions

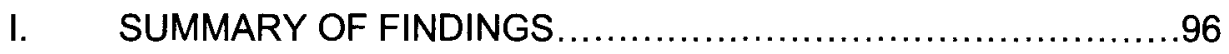

II. FUTURE DIRECTIONS ......................................99

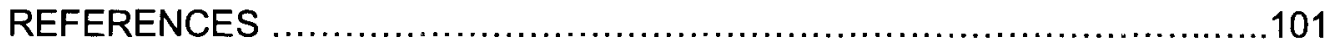

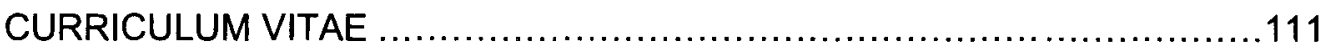




\section{LIST OF TABLES}

TABLE PAGE

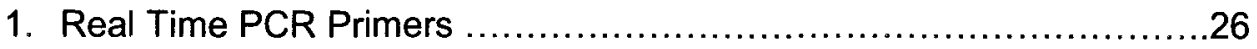




\section{LIST OF FIGURES}

FIGURE PAGE

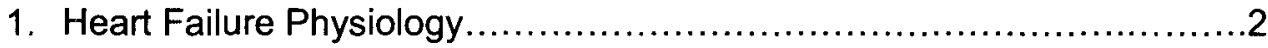

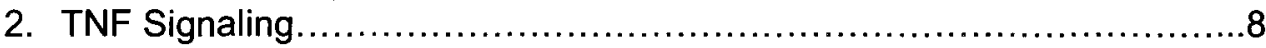

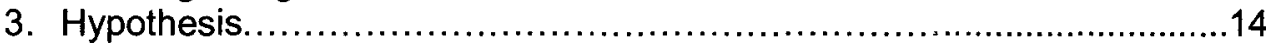

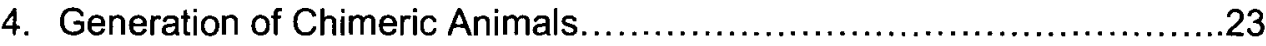

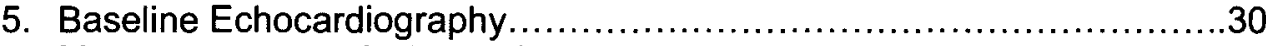

6. Macrophages are Activated in HF....................................32

7. Activated Macrophages in the Failing Heart............................. 35

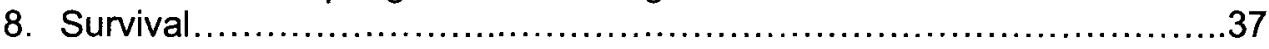

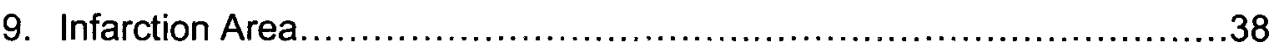

10. LV Cross Sections and M-mode ....................................... 40

11. Echocardiographic Parameters..........................................42

12. Tissue Weights............................................................. 44

13. Representative Wheat Germ Agglutin..................................46

14. Myocyte Area and ANF Expression....................................47

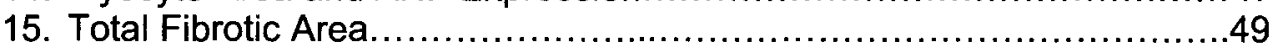

16. Border Zone and Remote Zone Fibrosis................................51

17. Myocardial CTGF Expression........................................53

18. Baseline Monocyte Activation.......................................... 54

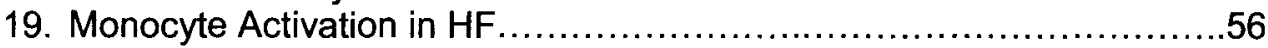

20. Myocardial Cytokine Expression in HF ..................................59

21. Aim \#2 Experimental Design.......................................... 74

22. Peritoneal Macrophages................................................. 78

23. Function of Isolated Macrophages and Myocytes..........................79

24. Macrpohage Attachment Causes Myocyte Dysfunction ...................80

25. Group Data: Macrophage Attachment Causes Myocyte Dysfunction....882

26. HF Derived Macrophages Equivalent to LPS Stimulation..................84

27. Comparison of WT, TNFR1 $1^{-1-}$ and TNFR2 ${ }^{-1-}$ Macrophages $\ldots \ldots \ldots \ldots \ldots . \ldots 6$

28. Representative DCF Fluorescent Imaging..............................88

29. DCF Fluorescent Color Map...........................................90

30. Comparison of DCF Fluorescence in WT, TNFR1 $1^{-1-}$, and TNFR2 ${ }^{-1-}$

Macrophage/Myocyte Interactions......................................91

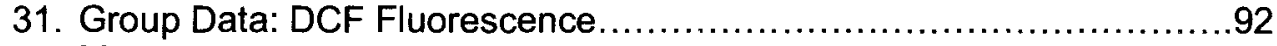

32. Macrophage Attachment is Equal..................................... 94 


\section{CHAPTER I}

\section{INTRODUCTION}

Several complex pathophysiologic mechanisms influence the process of left ventricular (LV) remodeling in chronic heart failure (HF). These include changes in mechanical forces, such as wall stress and increases in systemic vascular resistance, creating afterload mismatches, inflammatory cytokine production particularly TNF, IL-1, and IL-6, and activation of neurohormonal signaling pathways, most importantly the renin-angiotensin system and the sympathetic nervous system [1-8]. (Figure 1)

These responses initially help compensate for the acute phase of myocardial injury and its physiological consequences. For example, increased salt and fluid retention mediated by angiotensin and increases in systemic vascular resistance and heart rate driven by the sympathetic nervous system serve to maintain blood pressure and cardiac output, facilitating organ perfusion. In the chronic HF state, however, these responses become detrimental, creating a milieu that precipitates the undesirable consequences of myocyte apoptosis, mitochondrial dysfunction, 
myocyte hypertrophy, and contractile dysfunction [9-12]. This ultimately results in LV remodeling grossly evident by chamber dilatation [2-6]. On the molecular level, the phenotype of HF includes activation of the fetal gene program $[1,13]$, abnormalities of calcium handling [14-18], uncoupling of $\beta$-adrenergic receptor ( $\beta-A R)$ signaling [19-21], reactive oxygen species (ROS) production [10,22-26], and activation of inflammatory pathways. These pathological changes are characteristic phenotypic features of $\mathrm{HF}$, and thus can be used as physiological indices of the severity of cardiac dysfunction and remodeling.

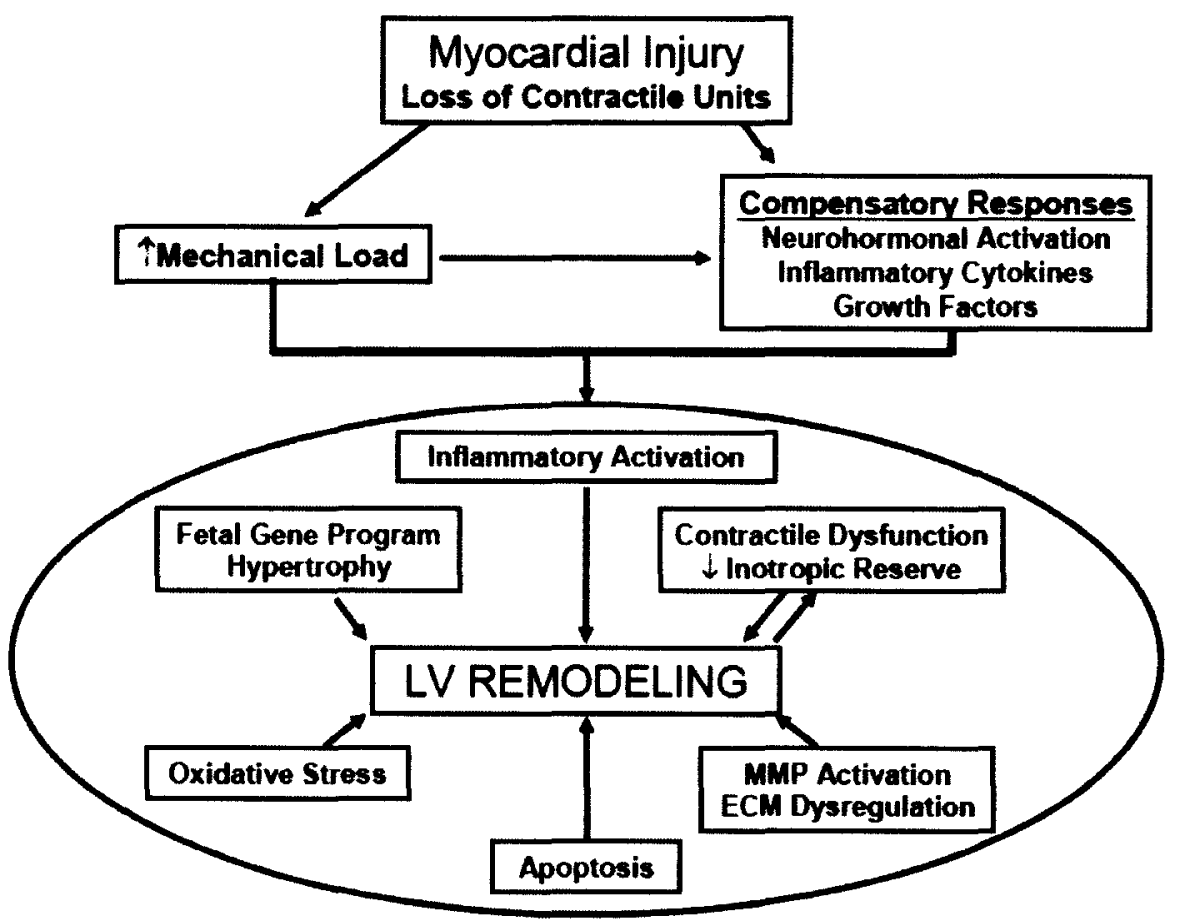

Fig1: Pathological mechanisms of LV remodeling after myocardial injury [13]

As mentioned above, inflammation is a hallmark of chronic HF $[27,28]$. Elevated levels of pro-inflammatory cytokines such as TNF, interlukin-1 $\beta$ (IL- $1 \beta$ and 
interlukin-6 (IL-6) are present at high levels in the plasma of HF patients. Interestingly, the level of these cytokine correlates inversely with survival [29-31]. Moreover, levels of the anti-inflammatory cytokine interleukin-10 (IL-10) have been observed to be significantly reduced in chronic HF patients [32-35]. Elevated levels of pro-inflammatory cytokines have not only been observed systemically but in the injured myocardium as well. Together these findings delineate the pro-inflammatory imbalance in patients with chronic HF [29,36-38]. 


\section{CHAPTER II}

\section{BACKGROUND}

\section{Why would TNF matter in Heart Failure?}

Several lines of evidence point to TNF as a potential target of therapeutic interest in chronic HF. First, elevated plasma levels of TNF and IL-6, as well as soluble TNF receptor 1 (TNFR1) and TNF receptor 2 (TNFR2) function as independent predictors of mortality in HF patients $[31,39,40]$. Secondly, in experimental animal models, TNF via infusion or over expression, can reproduce many of the phenotypic responses noted in HF, specifically depressed contractile function [41-43], myocyte hypertrophy [28,44], $\beta-A R$ uncoupling [43], apoptosis [45], and ROS production [46] indicating that TNF in sufficient levels, even in the absence of antecedent injury, can decrease myocardial performance. Third, mice with cardiac-specific TNF over expression suffer a premature death with a dilated cardiomyopathy, characterized by many of the same pathologic findings seen in chronic ischemic HF [47-49]. Fourth, while it is true that several proinflammatory cytokines are up regulated in the setting of HF, TNF is a foundation

cytokine, that has the ability to modify the expression of others such as IL-1 $\beta$ and 
IL-6 [50,51]. Lastly, antagonism of TNF in several animal models including TNF infusion [5], cardiac specific TNF over expression [52], and in post infarction HF [53-57] ameliorates the deleterious effects of pro-inflammatory milieu seen with the preceding conditions.

\section{Clinical Trials: What Happened?}

The findings of the above mentioned animal studies created a great deal of enthusiasm in the HF community. Hurried enthusiasm led to the initiation of clinical studies to test the effectiveness of TNF antagonism in chronic HF. Two forms of TNF antagonism where used. The first was etanercept, a previously FDA-approved drug for use in the chronic inflammatory condition of rheumatoid arthritis, consisting of two TNFR2 receptors linked to human IgG1:Fc. The second drug was infliximab, composed of anti-TNF murine Fab linked to human $\operatorname{lgG1:Fc.~This~drug~was~also~FDA-approved~for~human~usage~prior~to~the~HF~}$ trials for the same indication as entanercept. The four clinical trials where named RECOVER, RENAISSANCE, RENEWAL, AND ATTACH. Each independently reached conclusions that put the HF community in flux. Interestingly these trials showed no beneficial effect from TNF antagonism and concluded that both increased deaths and HF hospitalizations occur in a time and dose dependent manner in response to TNF antagonists $[28,50,58]$. This of course was quite surprising given the promising nature of the pre-clinical data, and begged the question, why the dichotomous results? Why did the clinical trials prove to be such a disappointment? While the true reason is yet undefined, several 
hypotheses have been proposed $[28,50,58]$ to explain the surprising findings. The most popular of the possible explanations is poor study design. While this always seems to be the first criticism put forth when things don't go as planned, there is likely some validation for this claim. Many investigators argue that these trials were plagued by the selection of patients with disease so advanced they where unlikely to recover, improper drug dosing both in quantity given and timing, and poorly defined end points. A second possible explanation is that the side effects of the drugs used were not completely understood, and that some of the toxicity observed had nothing to do with myocardial TNF interaction, but was related to the inherent pharmacologic properties of the drugs themselves. Lastly and perhaps most intriguing is that role of TNF in HF is more complicated and diverse than previously believed, and a deeper and more profound understanding of the complex and wide ranging interactions of TNF was needed before we could understand the proper use of TNF antagonism in chronic HF.

\section{The complicated nature of TNF}

It is known that TNF, along with other pro-inflammatory cytokines, is an evolutionarily well-conserved stress response molecule. From an intuitive standpoint, the highly-conserved nature implies an element of usefulness. In the myocardium, TNF provides protection during the acute phase of ischemic injury $[59,60]$, and during infective myocarditis $[61,62]$. TNF may have multi-faceted effects in the heart that produce either adaptive or maladaptive responses based on a delicate balance of cytokine and receptor expression. Previous work, 
discussed later, has shown that there is a dichotomous effect in the failing myocardium that is TNF receptor dependent [63].

To fully grasp the effects of TNF, it is important to understand its signaling mechanisms. TNF is expressed as both a soluble molecule (STNF) and in a membrane bound form (mTNF) [64-69]. Likewise, TNF signaling occurs through two cell surface receptors, TNF receptor 1 (TNFR1) and TNF receptor 2 (TNFR2). Neither receptor possesses enzymatic activity, and as a result signaling involves recruitment of additional intracellular proteins. TNFR1 binding and activation results in the recruitment of: 1) TNF receptor associated death domain (TRADD) ultimately resulting in the activation of caspase dependent apoptosis, and 2) TNF receptor-associated factor 2 (TRAF2) through the TRADD leading to the activation of nuclear factor- kappa B (NF-kB), c-Jun N-terminal kinase (JNK) phosphorylation leading to activation of activator protein-1 (AP-1), and p38 mitogen activated protein kinase (MAPK) activation. There is a significant amount of cross talk between the two receptors and their downstream signals [64-67]. However, TNFR2 does not bind to the TRADD but instead directly activates TRAF2 resulting in the same activation of NF- $\mathrm{kB}, \mathrm{AP}-1$, and p38 MAPK. (Figure 2) TNFR1 and TNFR2 also differ in their response to the different forms of TNF that serves to activate these receptors. Whereas TNFR1 is activated equally by both sTNF and mTNF forms, TNFR2 is activated predominantly by mTNF $[64,65,67,70]$. Most of the in-vitro studies that define cell signaling use sTNF, and under these conditions TNFR2 is not activated to any 
significant extent. Because of this, TNFR2 intracellular mechanisms are not as clear as those of TNFR1, and hence the benefits and consequences of its signaling mechanisms are not as well delineated.

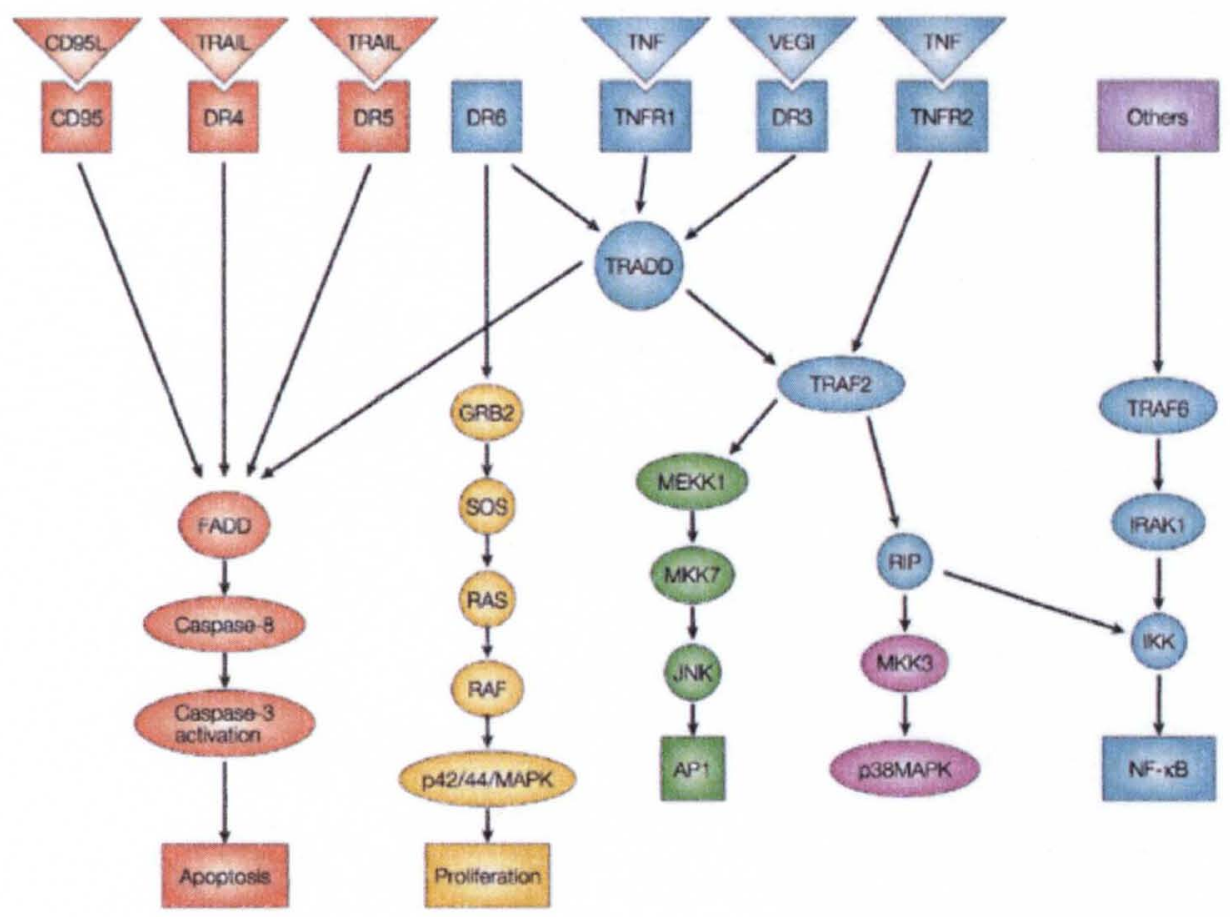

Figure 2: TNFR1 and TNFR2 signaling mechanisms. [66]

The heart normally expresses equal amounts of TNFR1 and TNFR2. However, during the normal homeostatic state, there is no constitutive myocardial expression of TNF in either the membrane bound or soluble form [29,71]. In the failing heart, however, there is significant expression of TNF and a substantial but equal down regulation of both TNF receptors to approximately one-half of their constitutive expression [29]. This is, of course, not an uncommon response to a dramatic and chronic increase in receptor stimulation. There is also a 
substantial increase in soluble TNF receptor levels in the serum of HF patients, possibly indicating a mechanism by which TNF responses are modulated [29].

In vivo, TNF can produce its effects in a juxtracrine manner, i.e. cell-to-cell physical contact. These interactions are more dependent on mTNF than the soluble form. Moreover, the dichotomy in the functional activation of the two TNF receptors in experimental models suggests either mTNF or sTNF over expression. In models of cardiac specific mTNF over-expression, resulting in primarily TNFR2 activation, concentric hypertrophy LV occurs, whereas in sTNF over-expression models, the animals develop a dilated cardiomyopathy [72]. Further evidence of divergent phenotypic responses is seen in disease states involving organ systems other than the myocardium. In a model of retinal ischemia, signaling through TNFR1 results in a worse phenotype [73]. On the other hand TNFR2 is primarily responsible for the detrimental effects of TNF in inflammatory arthritis as well as inflammatory bowel disease (IBD) [74].

Inflammatory cells are the major source of TNF production in the baseline state [64]. These cells also serve as an important source of pro-inflammatory cytokines during chronic HF, producing significantly elevated levels of TNF [75]. There is also progressive macrophage infiltration observed in the failing myocardium that positively correlates with disease severity $[36,76-80]$. Furthermore, co-localization of $\mathrm{IL}-1 \beta$ and TNF occur in these infiltrating cells $[36,76,78]$ demonstrating their active nature. These cells not only invade the 
failing myocardium but are activated, producing pro-inflammatory cytokines and exerting detrimental effects in the heart. Furthermore, in an ischemic HF model, the administration of an inhibitor of monocyte/ macrophage activation dramatically reduced myocardial expression of TNF, demonstrating the significant contribution of these cells to cardiac TNF production in HF [81]. To this point, differential cell-type specific responses occur with cytokine stimulation $[64,66]$. Inflammatory cells release a host of cytotoxic mediators with cytokine stimulation $[82,83]$ that may affect adjacent cells [84]. One example is the release of nitric oxide (NO) from stimulated macrophages leading to superoxide generation and peroxnitrite formation [85-88]. To further support the importance of the inflammatory cell's interaction with the heart, studies of endotoxemia show that inducible NO synthase (iNOS) from inflammatory cells, and not myocytes, is responsible for myocardial dysfunction in sepsis [84,89].

\section{Unraveling the mystery}

Previous work in the Prabhu lab further delineate the possibility of a dichotomous relationship between the two TNF receptors in chronic HF that is apparent in extracardiac disease processes. This work shows that somatic TNFR1 and TNFR2 null mice exhibit disparate effects on many of the hallmark phenotypical findings in chronic HF, specifically LV remodeling and myocyte hypertrophy, when subjected to permanent coronary ligation [63]. 
To obtain this initial data, TNFR1-/- and TNFR2-/- mice were compared to C57BL6 mice after undergoing either permanent left coronary artery ligation to induce HF or sham operation. As expected, the C57BL6 mice exhibited significant LV dilatation and dysfunction. However, these detrimental effects were alleviated in TNFR1--mice (unopposed TNFR2 stimulation). Interestingly, TNFR2-/- mice (unopposed TNFR1 stimulation) demonstrated an exaggerated remodeling response to chronic ischemic injury [63].

The above observations suggest that TNFR1 and TNFR2 have divergent effects on the pathological remodeling in HF, in that TNFR1 augments and TNFR2 attenuates this process. Furthermore, as activated inflammatory cells impart significant toxic cytokine-mediated responses on adjacent tissues, it is also likely that the TNFRs would demonstrate divergent and opposing phenotypic responses in $\mathrm{HF}$ if modulated in the inflammatory compartment.

I seek to define an integrated model of TNFRs and activated macrophages in the failing myocardium. I propose, as shown in Fig 3, a hypothesis that in activated macrophages infiltrating the failing heart, TNFR1 increases whereas TNFR2 opposes, or at least does not exacerbate, cellular activation as well as toxic metabolites and cytokine production. These changes serve to affect, in a dichotomous manner based on TNFRs, adjacent myocyte function and LV remodeling in response to ischemic injury. 


\section{CHAPTER III}

\section{FUNDAMENTAL QUESTION}

Phenomenon: Several pre-clinical and clinical studies have been undertaken to delineate the role of TNF in chronic HF. While the pre-clinical animal studies of TNF antagonism have been overwhelmingly positive, the clinical studies with TNF antagonist proved not only negative, but demonstrated an increase in morbidity and mortality. Hence, the precise role of TNF as a therapeutic target in HF remains yet undetermined.

Proposed concepts: Fundamental questions remain regarding the role of TNF in chronic HF. Previously the Prabhu lab demonstrated a dichotomous role for TNF in chronic murine HF dependent on the receptor stimulated, TNF receptor 1 or receptor 2. This could perhaps explain some of the conflicting data observed in the pre-clinical and clinical studies. Given, however, that a substantial percentage of the TNF produced during an inflammatory state is a product of inflammatory cells, and that pro-inflammatory cytokines have been determined to play a substantial role in the pathology of HF, it is possible that TNF exhibits both 
temporal, i.e. early vs. late HF, and spatial, i.e. somatic vs. inflammatory cell differences, that further determine the complex nature of TNF in chronic HF.

Experimental design: To determine the role of TNF in HF, an experimental protocol was designed to test the following hypothesis.

\section{Hypothesis:}

TNF has complex and dichotomous effects based on the TNF receptor stimulated. Likewise, inflammatory cells and their products play an important and deleterious role in the propagation of the pathology associated with chronic HF. I propose that selective modulation of the TNFRs in the inflammatory compartment will result in phenotypic differences in chronic ischemic heart failure. The ablation of TNFR1 will result in beneficial changes and the loss of TNFR2 will serve to further worsen the HF phenotype or possibly have no effect, if the primary detrimental effects are mediated by TNFR1. (Figure 3)

Aim \#1: To define the in vivo role of the inflammatory cell, as opposed to the myocyte, with regards to the divergent TNFR-specific effects in post-infarction LV remodeling.

Aim\#2: To delineate the role of the TNF receptor in in vitro macrophage-myocyte interactions in the setting of heart failure. 


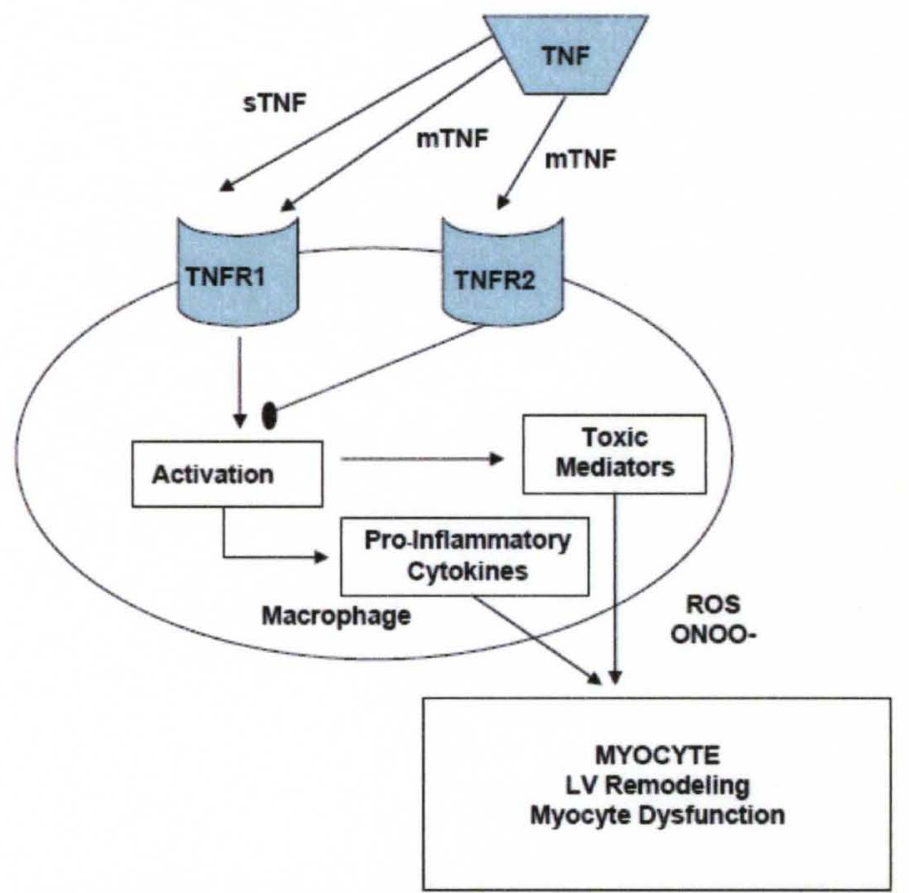

Figure 3: Graphical representation of the hypothesis for AIM 1. In response to ischemic injury activated macrophages infiltrate the myocardium. These macrophages assert their effects in a TNF dependent manner based on a dichotomous relationship between TNFR1 and TNFR2. TNFR1 increases whereas TNFR2 opposes cellular activation as well as toxic metabolite and cytokine production. These changes serve to effect adjacent myocyte function and LV remodeling in response to ischemic injury. 


\section{CHAPTER IV}

\section{AIM \#1: TO DEFINE THE IN VIVO ROLE OF THE INFLAMMATORY CELL, AS OPPOSED TO THE MYOCYTE, WITH REGARDS TO THE DIVERGENT TNFR- SPECIFIC EFFECTS IN POST-INFARCTION LV REMODELING.}

\section{BRIEF PREVIEW}

Background: Elevated myocardial and systemic levels of inflammatory mediators are hallmarks of chronic heart failure (HF) and predictors of mortality. Tumor necrosis factor- $\alpha$ (TNF), a "foundation" cytokine that influences other inflammatory mediators, is considered to play a detrimental role in the pathogenesis of LV remodeling. However, large multi-center clinical trials of biological anti-TNF therapy in HF have been negative, demonstrating no effects or even increased mortality with such therapy. This suggests that the effects of TNF are not homogeneous, and are more complex than an all-or-none toxic response in the failing heart. TNF signals through two cell-surface receptors, TNFR1 and TNFR2. TNF induces divergent inflammatory and remodeling responses in the failing heart that are TNF-receptor specific: TNFR1 signaling is detrimental and promotes these effects, whereas TNFR2 signaling is beneficial 
and opposes these effects. Importantly, in addition to myocyte-specific effects, TNF also activates immune and inflammatory cells that are potential sources of cytokines and cellular toxicity in HF. However, the importance of inflammatory cell-localized TNF responses in the pathogenesis of LV remodeling is unknown

Hypothesis: Inflammatory cell-localized TNFR1 and TNFR2-signaling play important and divergent roles in the progression of post-infarction LV remodeling in chronic HF. My study objective was to evaluate the effects of selective inflammatory/immune cell TNFR1 or TNFR2 ablation on LV remodeling

Methods: In order to delineate the role of immune cell TNFR1 and TNFR2 in LV remodeling chimeric mice were generated. Recipient WT C57BL/6 mice underwent lethal bone marrow irradiation followed by reconstitution with bone marrow from either TNFR1 -/- or TNFR2 -/- mice. Reconstituted with bone marrow from C57BL/6 were used as a control. Mice were quarantined for 30 days post-transplant to ensure adequate resident cell turnover, and chimerism was confirmed via flow cytometery of donor CD45.2 and recipient CD45.1. All mice exhibited more than $90 \%$ marrow chimerism. Mice were evaluated at baseline and sequential time points via echocardiography and flow cytometry. Phenotypic assessment with a variety of physiologic, histologic, and molecular techniques was performed as discussed in detail in the Methods section. 
Results: These mice, which exhibit loss of either TNFR1 (R1-/-c) or TNFR2 $(\mathrm{R} 2-/-\mathrm{c})$ or loss of neither receptor (WTc) in inflammatory cells, underwent coronary ligation to induce HF or sham operation. Compared to WTc sham, 4 weeks after surgery, WTc HF hearts exhibited significantly $(p<0.05)$ : 1) increased LV size (EDV $96.7 \pm 13.7$ vs. $26.6 \pm 8.2 \mu \mathrm{L}$ ) and dysfunction (LVEF $25.5 \pm 7.5$ vs. $69.8 \pm 4.5 \%$ ); 2) greater hypertrophy (LV/tibia length [TL] $3.91 \pm$ 0.53 vs. $2.9 \pm 0.4, \sim 4$-fold greater atrial natriuretic factor [ANF] mRNA); 3) increased fibrosis $(16.10 \pm 8.16 \%$ vs. $1.4 \pm 0.4 \%)$ and connective tissue growth factor (CTGF) mRNA expression, and 4) increased ( 2-fold) mRNA levels of TNF, interleukin (IL)-1 $\beta$, and IL-6. WTC HF mice also had markedly reduced survival (60\% vs. $100 \%)$ and increased blood levels of activated F4/80+/CD11b+ monocytes vs. WTc sham mice. In contrast, compared to WTc HF, R1-/-c HF mice exhibited significantly $(p<0.05)$ : 1) improved survival $(80 \%)$, 2) less LV dilatation and improved LVEF $(42.9 \pm 4.2 \%), 3)$ less cardiac hypertrophy (LV/TL $3.14 \pm 0.2 \mathrm{mg} / \mathrm{mm})$ and ANF mRNA expression, 4) less fibrosis $(5.48 \pm 2.26 \%$ area) and CTGF mRNA expression, and 5) less cardiac TNF and IL-1 $1 \beta$ mRNA expression. Also, compared to WTc HF, R2-/-c HF mice exhibited significantly (p $<0.05)$ greater circulating F4/80+/CD11b+ monocytes $(15.32 \pm 4.41$ vs. 12.1 $\pm 1.24 \%$ gate), and greater cardiac fibrosis (21.92 $\pm 10.81 \%$ area). Also noted was an increase, although not significant, in EDV and ESV.

Conclusion: Inflammatory cell-localized TNFR1 signaling exacerbates inflammation and cardiac remodeling in HF, whereas inflammatory cell TNFR2 
signaling has modest anti-fibrotic and anti-inflammatory effects. Modulation of global inflammatory cell function induces profound localized alterations in LV remodeling; TNFR1/R2 signaling plays an important role in these effects. 


\section{INTRODUCTION}

It is well established that inflammation is one of the key mediators of the deleterious effects seen in chronic HF $[27,28]$. Elevated levels of proinflammatory cytokines such as TNF are present in the plasma and myocardium of HF patients. Interestingly, levels of these cytokines correlate inversely with survival in chronic HF [29-31]. Collectively, these findings delineate that there is a pro-inflammatory imbalance in chronic HF, and that this imbalance plays a substantial role in the progression of disease [29, 36-38].

Several lines of evidence point to TNF as a potential target of therapeutic interest in chronic HF. First, as mentioned above, elevated plasma levels of TNF function as independent predictors of mortality in $\operatorname{HF}$ patients $[31,39,40]$. Secondly, in experimental animal models, TNF infusion or over-expression reproduces many of the phenotypic responses noted in $\mathrm{HF}[28,41-46]$. Also, TNF has been shown to be a foundation cytokine in that has the ability to modify the expression of the other pro-inflammatory cytokines such as IL-1 $\beta$ and IL-6 $[50,51]$. Lastly, antagonism of TNF in several animal models, including TNF infusion [5], cardiac specific TNF over-expression [52], and in post-infarction HF [53-57], ameliorate the deleterious effects of the pro-inflammatory milieu seen in these conditions. 
The above findings led to the initiation of clinical studies of TNF antagonism in chronic HF patients. Interestingly these trials not only failed to show beneficial effects, but also that TNF antagonism increased death and HF hospitalization in a time and dose dependent manner $[28,50]$. This of course was quite surprising given the robust pre-clinical data showing the very promising possibilities for TNF modulation. These results raised the question as to why the clinical trials prove to be such a disappointment? Perhaps the role of TNF in HF is more complicated and diverse than previously believed. TNF may in fact have multi-faceted effects in the heart that can produce either adaptive or maladaptive responses based on a delicate balance of cytokine and receptor expression. Previous work has proven that in fact there is a dichotomous effect in the failing myocardium which is TNF receptor dependent [63].

The primary sources of TNF in the quiescent state are monocytes and macrophages [64]. Likewise, these cells also serve as an important source of pro-inflammatory cytokines in HF, producing significantly elevated levels of TNF and other mediators of inflammation [75]. There is progressive macrophage infiltration observed in the failing myocardium that positively correlates with disease progression $[36,77-80]$. Furthermore, co-localization of IL-1 $\beta$ and TNF has been demonstrated in these infiltrating cells $[36,78]$. Likewise in an ischemic HF model, administration of an inhibitor of monocyte/macrophage activation dramatically reduced myocardial expression of TNF, demonstrating the significant contribution of these cells to cardiac TNF production in HF [81]. 
Previous work in our lab has shown that TNFR1 and TNFR2 whole body knock out $(-/-)$ animals exhibit disparate effects on post-infarction LV remodeling, hypertrophy, inflammation, and apoptosis [63]. This would suggest that TNFR1 and TNFR2 have divergent effects in HF in regards to the primary responses mediated by TNF, namely inflammation and myocardial dysfunction, in that TNFR1 augments while TNFR2 attenuates these processes. Furthermore, as activated inflammatory cells impart significant toxic cytokine medicated responses on adjacent tissues, it is possible that the TNFRs could impart analogous divergent and opposing phenotypic responses in HF if modulated in the inflammatory compartment.

I seek to define an integrated model of TNFRs and activated macrophages in the failing myocardium. I propose, as shown in Figure 3, a hypothesis that in cardiac macrophages, TNFR1 increases whereas TNFR2 opposes, or at least does not exacerbate, cellular activation as well as toxic metabolite and cytokine production. These changes serve to affect, in a dichotomous manner based on TNFRs, adjacent myocyte function and LV remodeling in response to ischemic injury. 


\section{MATERIALS AND METHODS}

Animals and Generation of Chimeric Mice. Recipient C57BL/6 mice (8-12 wks, 20-25 grams) were irradiated overnight (950 cGy) in an irradiation chamber to ablate the bone marrow compartment (Figure 4). The following day, femur bone marrow was harvested from donor green fluorescent protein (GFP) expressing transgenic (Tg) mice, WT C57BL/6 control, TNFR1 ${ }^{-1-}$, or TNFR2 ${ }^{-1-}$ (Jackson Labs) mice. $15 \times 10^{6}$ cells of donor bone marrow were injected via tail vein into recipient mice. Mice were quarantined for 30 days to ensure adequate resident cell turnover. Post-quarantine, flow cytometric analysis of donor CD45.2 fluorescein isothiocyanate (FITC) vs recipient CD45.1 phycoerythrin (PE) was performed to determine percent chimerism. All study mice exhibited greater than $90 \%$ chimerism. Briefly, for GFP Tg mice, a bacterial artificial chromosome (BAC) encoding the mouse Rag1 and Rag2 sequence was modified by the insertion of an enhanced green fluorescent protein gene into exon 1 of Rag2. TNFR $^{-/-}$was achieved via insertion of a neomycin cassette at position 535 of the coding sequence on chromosome 6 [90]. For TNFR2-1- generation, homologous recombination techniques to target the Tnfr2 gene where used. Specifically, a construct containing a neomycin resistance gene under the control of the Pgk promoter was inserted into the second exon of the Tnfr2 gene resulting in loss of gene function [91]. 
A] Recipient
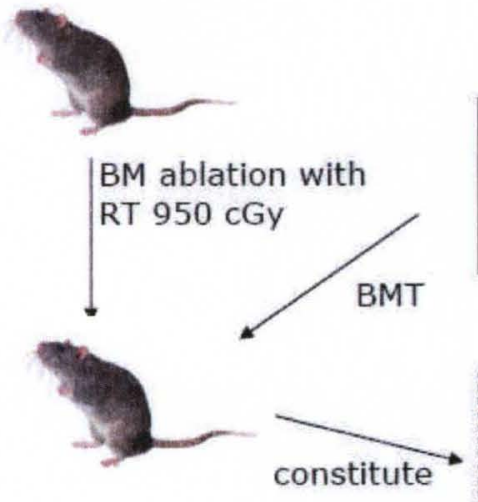

BM ablation with

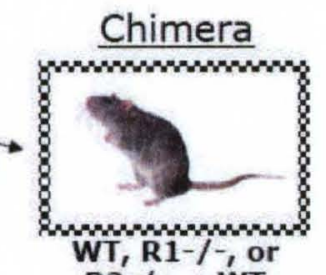

R2 $-1-\rightarrow$ WT
B]

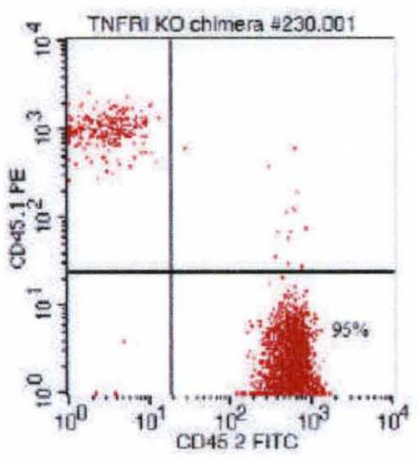

Figure 4. A: Bone marrow chimeric mice were generated by ablation of donor C57BL/6 mouse marrow via overnight irradiation followed by reconstitution with either TNFR1-1-, TNFR2-1- or C57BL/6 marrow. B: Chimerism was confirmed by flow cytometric analysis of donor CD45.2-FITC and recipient CD45.1-PE demonstrating greater then $90 \%$ chimerism.

Coronary ligation and experimental protocol. All studies were performed in compliance with the NIH Guide for the Care and Use of Laboratory Animals (DHHS publication No. [NIH] 85-23, revised 1996). Permanent coronary ligation was performed as previously described $[63,92]$ Anesthesia was induced in mice with tribromoethanol $(0.25 \mathrm{mg} / \mathrm{g} \mathrm{IP})$. After induction, the mice were intubated and supported with a MiniVent Mouse Ventilator (Type 845, Harvard Apparatus) at $125-150$ breaths/minute depending on body weight (tidal volume $6.4 \mu \mathrm{L} / \mathrm{g}$, PEEP 5-7 cm H2O). Anesthesia was maintained with $1 \%$ isoflurane. Heat lamps and heating pads were used to maintain body temperature at $37^{\circ} \mathrm{C}$. Under sterile conditions, a left thoracotomy was performed in the 4th intercostal space, the heart exposed, and the pericardium opened. An 8.0 prolene ligature was passed and tied around the proximal left coronary artery, $1 \mathrm{~mm}$ distal to the left atrial 
appendage border. Successful occlusion was confirmed by the production of pallor and dyskinesia in the distal myocardium. In sham animals, the suture was passed but not tied. The chest was then closed in layers using 5.0 silk, and the mice were allowed to recover. The total mice used for these studies were as follows: WTc $n=30 ; R 1-/-c n=30 ; R 2-/-c n=30$. Mice were followed for 4 weeks following operation.

Echocardiography. Under tribromoethanol $(0.25 \mathrm{mg} / \mathrm{g}$ IP $)$ sedation, echocardiography (M-mode, 2D, and Doppler) was performed at baseline and 4 weeks post-operatively using a Philips Sonos $5500,15 \mathrm{MHz}$ linear array transducer, $120 \mathrm{~Hz}$ frame rate. Measured variables included the short-axis enddiastolic (ED) and end-systolic (ES) diameter (D) and wall thickness (WT), and long-axis end-diastolic and end-systolic volume (EDV and ESV) using the modified Simpson's method. LV systolic function was indexed by either fractional shortening $(F S=E D D-E S D / E D D)$ or single plane planimetered $L V$ ejection fraction (EF = EDV-ESV/EDV).

Histomorphometry and immunohistochemical analysis. Paraffin embedded tissue sections $(5 \mu \mathrm{m})$ were de-paraffinized, rehydrated, and stained with Masson Trichrome (for collagen) using standard histologic techniques $[63,92]$. The degree of tissue fibrosis (blue-green stain) was assessed using Metamorph Imaging Software. 
Wheat Germ Agglutin (WGA) staining. Paraffin embedded tissue sections (5 $\mu \mathrm{m})$ were de-paraffinized and rehydrated. They were then stained with WGA solution diluted to $5 \mu \mathrm{g} / \mathrm{ml}$ in PBS for 1 hour in a dark room at room temperature. The slides were washed and fixed with DAPI Antifade Reagent and sealed. Epifluorescent microscopy (Nikon TE 200) was used for analysis.

Real-time PCR and mRNA quantitation. Total RNA was isolated from LV tissue using TRIzol reagent (Invitrogen), and cDNA was synthesized from $1 \mu \mathrm{g}$ RNA using the iScript ${ }^{\mathrm{TM}}$ cDNA Synthesis kit (BioRad). Relative levels of mRNA transcripts for atrial natriuretic factor (ANF), connective tissue growth factor (CTGF), TNF, interleukin (IL)-1ß, IL-6, and IL-10were quantified by real-time PCR using Fast SYBR® Green (Applied Biosystems). GAPDH mRNA expression was used to normalize the data. Expression level of each targeted gene was normalized by subtracting the corresponding GAPDH threshold cycle (CT) values using the $\triangle \triangle C T$ comparative method [93]. The primer pairs used are detailed in Table 1. 
Table 1. Primers Used for Real-Time PCR

\begin{tabular}{|c|c|c|}
\hline Gene & Forward Primer & Reverse Primer \\
\hline ANF & 5'-CCTGTGTACAGTGCGGTGTC -3' & 5'-AAGCTGTTGCAGCCTAGTCC -3' \\
\hline CTGF & 5'-AAGACACATTTGGCCCAGAC-3' & 5-TTACGCCATGTCTCCGTACA-3' \\
\hline TNF & 5'-ACGGCATGGATCTCAAAGAC -3' & 5-TGGAAGACTCCTCCCAGGTA-3' \\
\hline IL-1B & 5'-TCATTGTGGCTGTGGAGAAG '3' & 5-AGGCCACAGGTATTTTGTCG -3' \\
\hline IL-6 & 5'-GTTCTCTGGGAAATCGTGGA-3' & 5-GGAAATTGGGGTAGGAAGGA -3' \\
\hline IL-10 & 5'-TGCTATCCTGCCTGCTCTTA-3' & 5'-TCATTTCCGATAAGGCTTGG -3' \\
\hline GAPDH & 5'-TGATGACATCAAGAAGGTGGTGAAG-3' & 5'-TCCTGGAGGCCATGTGGGCCAT-3' \\
\hline
\end{tabular}

ANF, atrial netriuretic fector: CTGF, comective tissue growth fector; TNF, tumor necrosis factor-a; IL, imerieukin; GAPDH, glycerreldehydes phosphate dehydrogenase. 
Tissue harvest. Following the final echocardiographic or hemodynamic study, mice were given additional anesthesia with sodium pentobarbital (50 mg/kg IP), diastolic-arrested with I.V. KCL, and the heart was rapidly excised and rinsed in ice-cold physiological saline. Ventricles and atria were dissected and weighed separately. Liver, kidneys, spleen, and lungs were dissected and weighed as well. Lungs were subsequently dried for $48 \mathrm{hrs}$ at $60^{\circ} \mathrm{C}$ and weighed to yield wet-dry ratios. Tibia length was taken for tissue weight normalization. A shortaxis section of the LV was formalin fixed for $16 \mathrm{~h}$, dehydrated in ethanol, and paraffinembedded for subsequent histological studies. The remaining LV tissue was separated into infarcted (scar) and non-infarcted regions, snap-frozen in liquid nitrogen, and stored at $-80^{\circ} \mathrm{C}$ for biochemical and molecular studies. Noninfarcted tissue was used for molecular analyses.

Flow Cytometric Analysis of Peripheral Blood. Approximately 100 uL of peripheral blood was collected via facial vein technique [94] into BD Microtainer tubes with EDTA (BD Biosciences, 365973). Blood was then lysed with $2 \mathrm{~mL}$ RBC lysis buffer (eBiosciences, 00-4333-57) for $5 \mathrm{~min}$ on ice in a $15 \mathrm{~mL}$ conical centrifuge tube followed by PBS quenching via addition of $10 \mathrm{~mL}$ cold PBS. Cells were then centrifuged at $380 \mathrm{~g}$ for $10 \mathrm{~min} / 4^{\circ} \mathrm{C}$ and the supernatant was discarded. The pellet was resuspended in $400 \mathrm{uL}$ of ice cold flow cytometry staining buffer (eBioscience, 00-4222-57) and divided into two plastic flow cytometry tubes yielding two $200 \mathrm{uL}$ tubes for each animal. Each tube was subsequently incubated for $30 \mathrm{~min}$ on ice with fluorescently labeled cell surface 
antibodies $\left(0.6 \mathrm{ug} / 10^{6}\right.$ cells) for the Monocyte Cell Panel: F4/80-Pacific Blue, CD11b-PE. Cells were then centrifuged at $380 \mathrm{~g}$ for $10 \mathrm{~min} / 4^{\circ} \mathrm{C}$, and the pellet was resuspended in $400 \mathrm{uL}$ of ice cold PBS. Samples were immediately analyzed on a BD LSRII flow cytometer equipped with 405,488 , and $633 \mathrm{~nm}$ lasers and appropriate filter sets. A non-debris gate was established on a FSC vs SSC gate and positivity for respective surface markers was determined from subsequent histograms. Unstained and fluorescently labeled respective lg antibodies were analyzed to determine negative populations and set fluorescence threshold. Final analysis was performed using FlowJo software v.7.6. Activated monocytes were taken to be $F 4 / 80^{+} C D 11 b^{+}$. Blood was analyzed on all animals at baseline 1 day, 1 week, and 4 weeks post-infarction.

Statistical analysis. Comparisons of experimental data were made using a repeated measures analysis of variance (ANOVA). Animal survival was evaluated by Kaplan-Meier analysis, and comparisons of survival between groups at specific time points was made by both Cox regression and long-rank statistics. Statistical significance was accepted at $p<0.05$. 


\section{RESULTS}

\section{Chimeric Mice Exhibit Similar Baseline Cardiac Phenotypes}

One of the initial concerns during the planning of this study was whether the generation of the chimeric model would in and of itself alter cardiac structure and/or function differentially between the three experimental groups. It therefore was necessary to determine if chimeric mice, had baseline differences in their cardiac phenotype. The concern was warranted due to the use of lethal doses of radiation during the process of generating the chimeric model and reconstitution of the bone marrow compartment with genetically modified cells. The baseline cardiac phenotype, in terms of myocardial volumes and cardiac performance determined by ejection fraction (EF) for the TNF R1-/- chimera mice thus far referred to as R1-l-c and the TNF R2-l- chimera group hence forth, R2-l-c, was not different from the control C56BL/6 chimera, WTc. On the following page, representative long axis echocardiograms of the baseline studies are shown on the left and graphical demonstration of volumetric data, end diastolic volume (EDV), end systolic volume (ESV) and EF demonstrated on the right (Figure 5).

The overall volumes are smaller universally then expected for naive mice. We believed that this was likely due to the radiation administered. The important fact, however, was that the animals demonstrated no difference amongst the groups at baseline. 

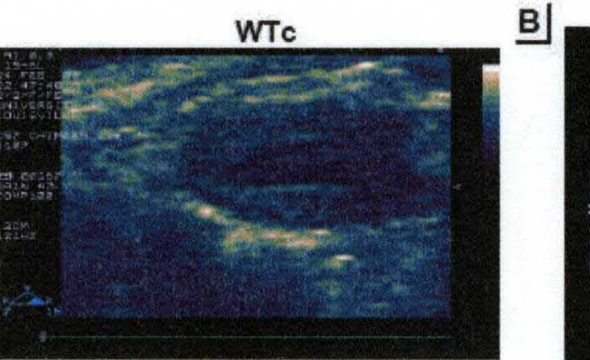

TNFR1 ${ }^{+c} \mathrm{c}$
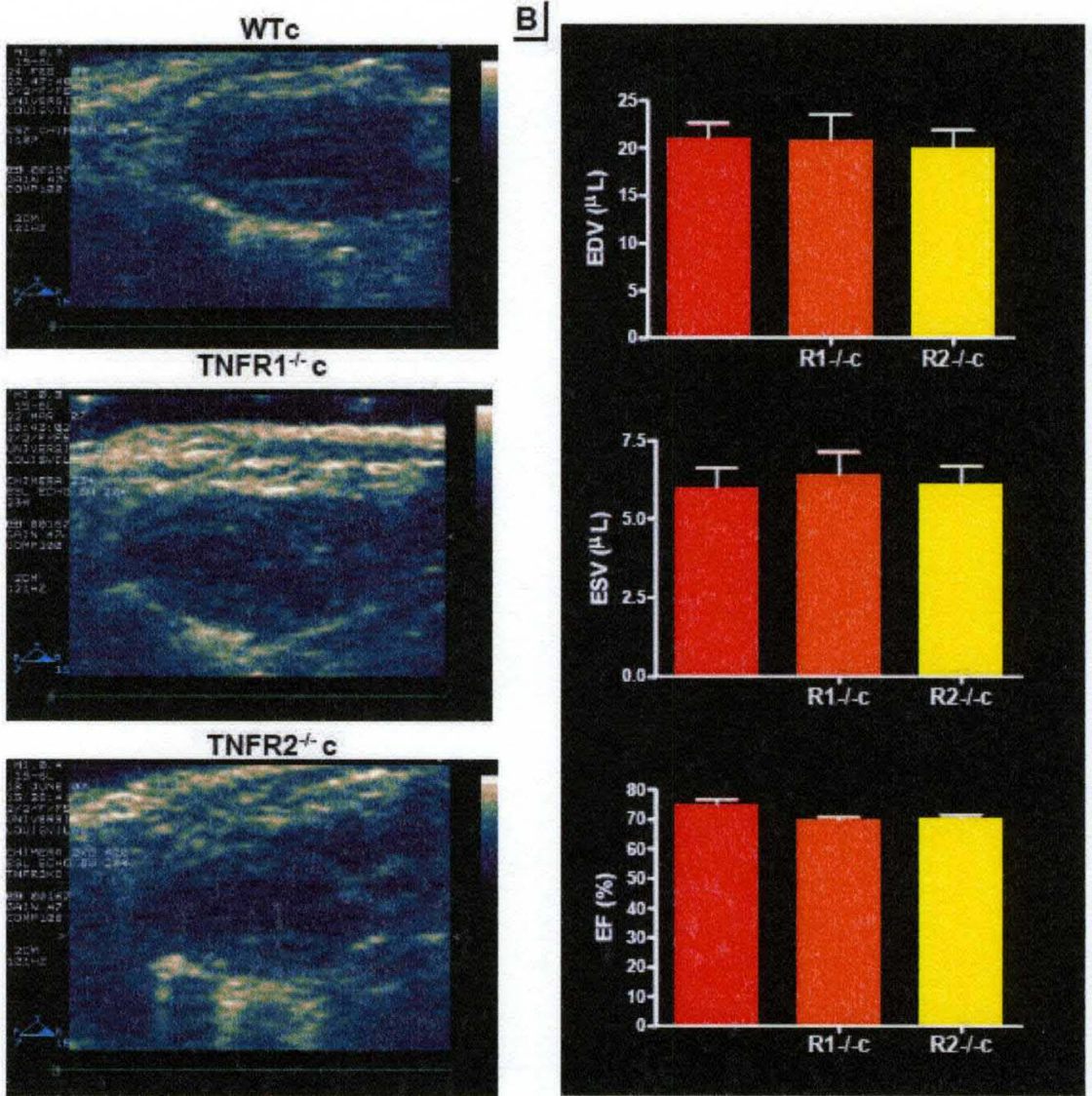

Figure 5. A: Representative long-axis echocardiographs show no change in left ventricular size between WTc, TNFR1-/-c and TNFR2-1-c groups. Quantitative group data confirm this finding. B. Graphical representation of group echo data showing no baseline changes in EDV, ESV, or EF. 
Proof of Concept: Monocytes/ Macrophages are Activated in the Peripheral Blood in Chronic Heart Failure

As the central theme of our hypothesis was that activated inflammatory cells play a detrimental and modifiable role in chronic $\mathrm{HF}$, it was of paramount importance to prove monocytes were activated in a sustained manner in the peripheral blood in response to ischemic injury. In order to determine the level of monocyte activation in HF, WT mice where subjected to permanent coronary ligation. Flow cytometric analysis was performed to evaluate blood monocyte activation. Activated monocytes were identified as $\mathrm{CD} 11 \mathrm{~b}$ and F4/80 dual positive cells. A marked increase in this cell population was noted at 4 weeks post ligation (3.59 \pm 1.1 vs. $9.78 \pm 0.4 \%$ gate), indicating a sustained inflammatory reaction generated by myocardial injury. To insure that this same increase in mononuclear inflammatory cells also occurred in TNFR null animals, TNFR1-/and TNFR2-/- mice were subjected to the same protocol. Flow cytometric analysis of their peripheral blood for dual CD11b and F4/80 positive cells yielded a similar finding with evidence of a pro-inflammatory milieu 4 weeks post injury in TNFR1-/- (4.17 \pm 0.76 vs. $7.74 \pm 0.87 \%$ gate $)$ and TNFR2-/- (4.15 \pm 0.96 vs. $11.0 \pm 1.55 \%$ gate) (Figure 6) 
A]

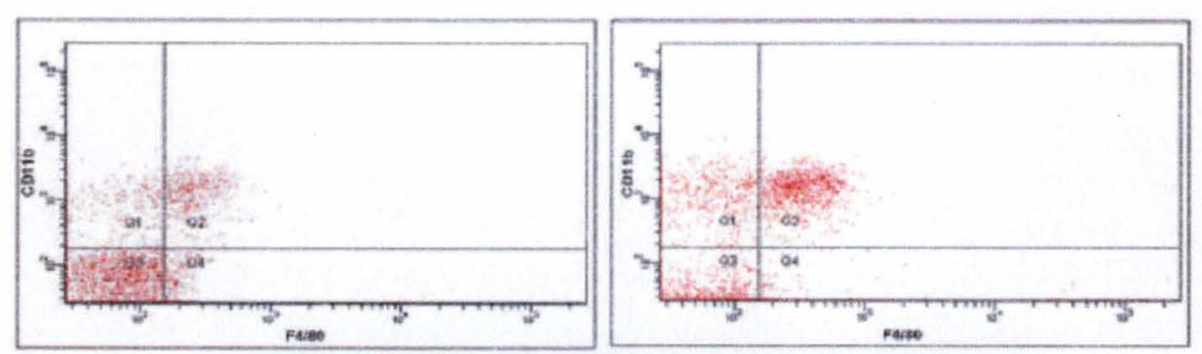

B)

Figure 6. A: Representative flow cytometric analysis of activated blood monocytes at baseline on the left and at four weeks post ligation on the right. B: Graphical representation of each group at baseline and four weeks post infarction. 
Proof of Concept: Activated Macrophages Infiltrate the Failing Myocardium Producing Inflammatory Cytokines

We next performed cardiac tissue analysis looking for infiltration of macrophages into chronically infarcted myocardium. Activated mononuclear cells in the periphery must infiltrate the infarcted myocardium in order to produce significant myocardial damage and dysfunction, given the typical juxtacrine effects of inflammatory cells. We first used green fluorescent protein (GFP) generated chimeric mice (GFPc), i.e. somatic wild type and GFP positive bone marrow, to determine if inflammatory cell infiltration into the infarcted myocardium occurred. GFPc animals were subjected to permanent coronary ligation and followed for four weeks. They were then sacrificed and the myocardial tissue examined with fluorescent microscopy. Interestingly, we found GFP positive cells in and around the area of myocardial injury, since these animals were GFP chimeras, the fluorescent cells could only have been generated in the bone marrow and were therefore, inflammatory cells. We next sought to determine whether the infiltrating cells were in fact activated while in the myocardial tissue. To do this we used C57BL6 WT mice as well as TNFR1 and TNFR2 whole body knockouts. These animals were subjected to either sham operation or coronary ligation. Four weeks post ligation these animals were sacrificed and the myocardial tissue was immunostained with MOMA-2, a marker of macrophage activation, and anti-TNF antibody. Fluorescent microscopy was performed. MOMA-2 analysis revealed enhanced macrophage infiltration in the failing heart, especially in the border 
zone myocardium. Importantly, MOMA-2 positivity was not significantly increased compared to sham in TNFR1 knockout HF hearts (NS) but exaggerated in TNFR2 knockout HF hearts compared to sham animals $(p<0.05)$ (Figure 7). Moreover, dual immunofluorescent staining for MOMA-2 and TNF in failing hearts, revealed strong macrophage TNF expression, further indicative of cell activation. (Figure 7) These results confirmed infiltration of activated inflammatory cells into the failing heart, and suggested that these cells compromised a significant source of inflammatory cytokines. The functional significance of this was determined with further experimentation. 

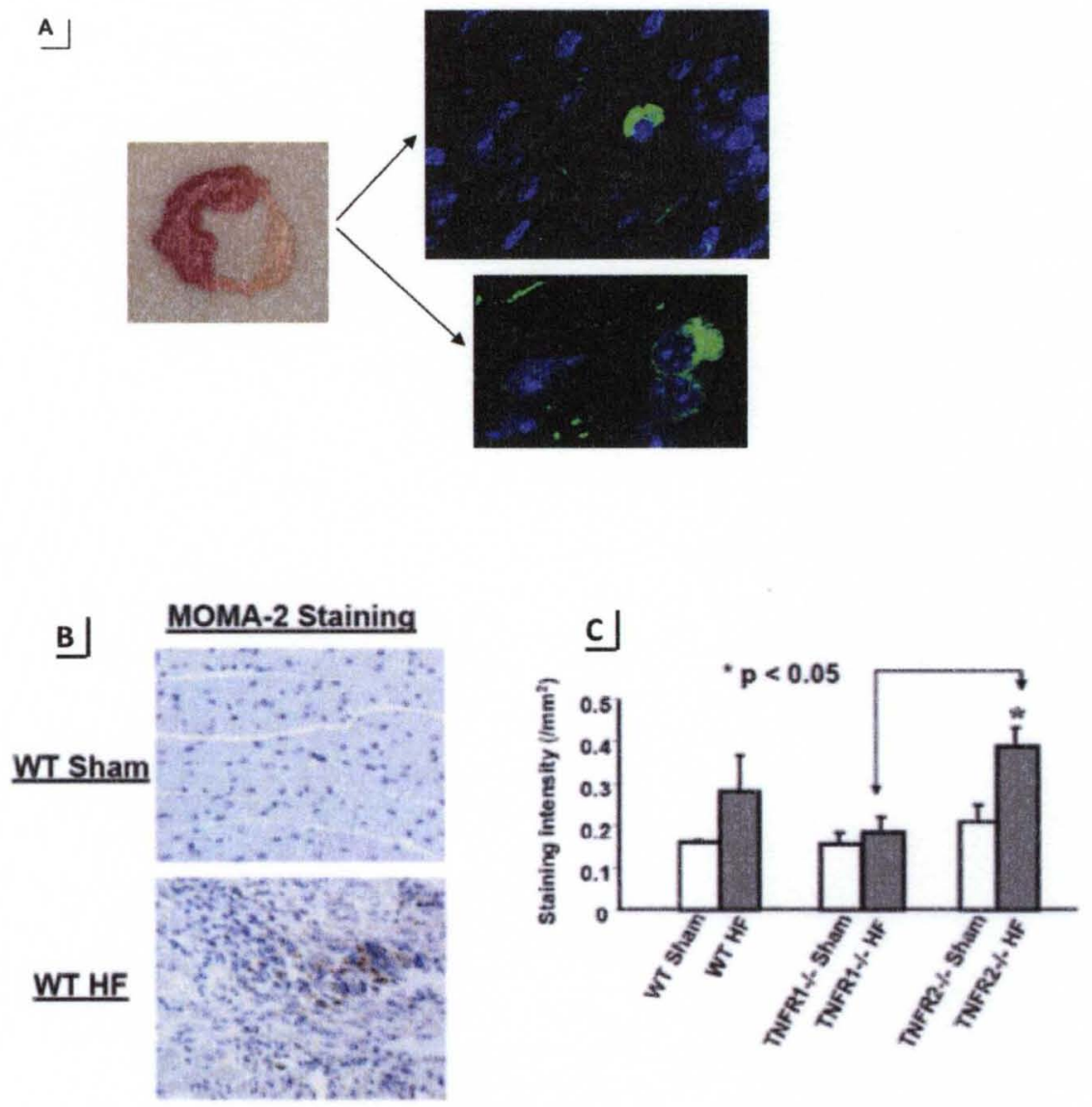

D]

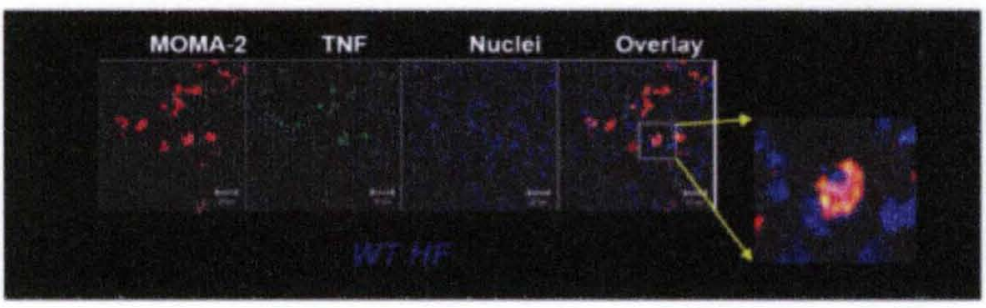

Figure 7. A: In GFP chimeric mice, GFP positive cells infiltrate the infarcted myocardium implying migration from bone marrow. B: Immunohistochemical identification of activated macrophages using anti-MOMA-2 in sham (top) and in failing mouse hearts (bottom). C: Quantification of MOMA-2 staining in WT,

TNFR1-/- and R2-/- hearts. Activated macrophages were increased in WT and TNFR2- $/-$ HF hearts ( ${ }^{*} p<0.05$ vs sham), but not in TNFR1 $/-$ HF. Also, TNFR2 $/-$ $\mathrm{HF}$ had significantly more activated macrophages as compared to TNFR1-/- HF $(p=0.012)$. D: On the left panel, WT HF sections were stained with either antiMOMA-2 for activated macrophages, anti-TNF (green, FITC-labeled secondary antibody), and DAPI to label nuclei (blue), and imaged with confocal microscopy. As seen in the overlay images, there was co-localization of TNF with macrophages. 


\section{Selective Loss of Either TNF Receptor in Inflammatory Cells Yields a Pro- Survival Benefit}

There was no difference observed in the survival between the three chimeric (WTc, R1-/-c, and R2-/-c) sham groups ( $p=N S)$. However, when compared to WTc sham, WTc HF animals showed an approximately $40 \%$ mortality. This is in line with previously observed mortality rates for C57BL/6 permanent coronary ligation models in both our laboratory and others [63,92]. Interestingly, in postinfarction HF, we found that ablation of either TNF receptor in the inflammatory cell compartment improved survival significantly over WTc HF animals ( $80 \%$ vs. $60 \%$ ). This can be seen in the Kaplan-Meier survival curve shown below (Figure 8). This phenomenon of increased survival with ablation of either of the TNF receptors was also previously observed in somatic TNFR1 and R2 null mice [63]. 


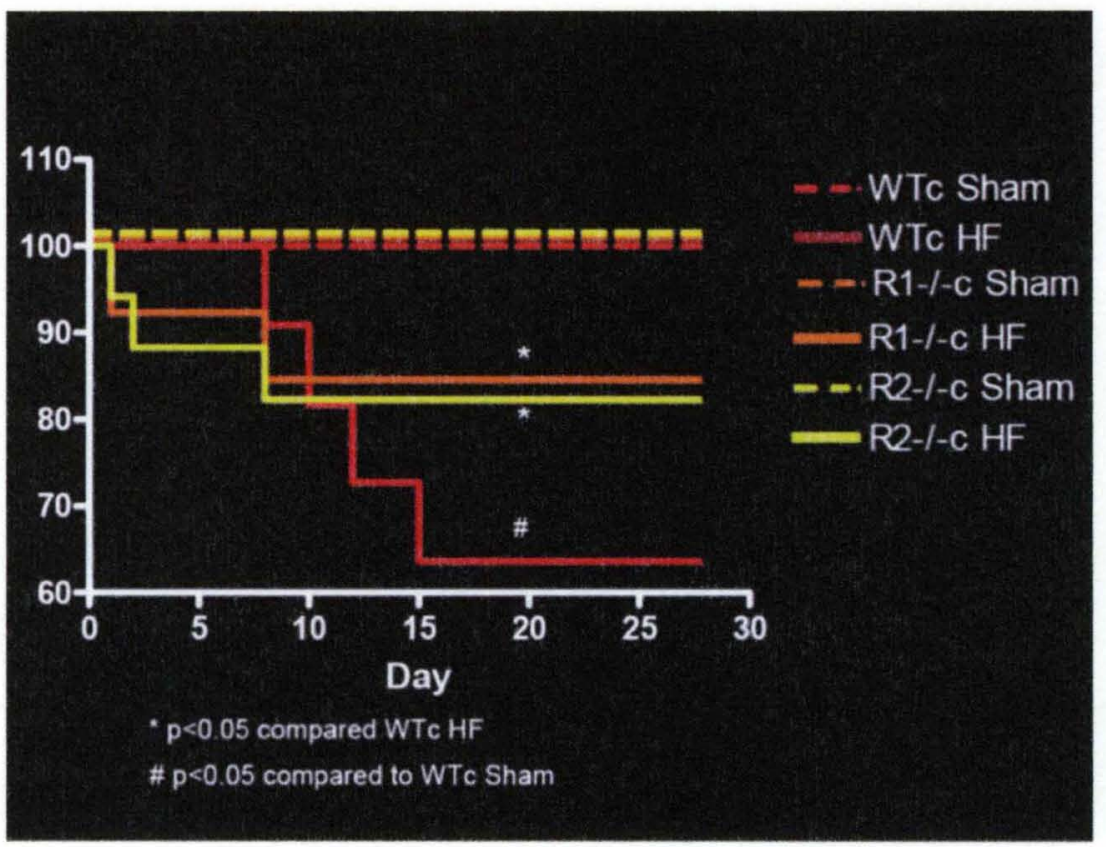

Figure 8: Kaplan-Meier survival curves from WTc, R1-/-c, and $\mathrm{R} 2-\mathrm{l}$-c mice after coronary ligation (HF) or sham operation.

Sham animals demonstrated significant improved survival over their HF counterparts. Interestingly, both R1-/-c and R2-/-c HF groups showed improved survival when compared to the WTC HF group.

The Initial Level of Injury was Equivalent Between all HF Study Groups and not a Reason for the Difference in Survival Noted Between the TNF Receptor Knockout Chimeras and WT Chimeras

To ensure no significant difference was present in the initial myocardial injury that might explain this difference in survival in the HF groups, infarct area as a percent of total LV area at 4 weeks was measured for each animal. This data demonstrated that there was no difference in the infarction area observed in the 
3 groups ( $p=N S$ ) indicating that the survival benefit observed was not from differences in initial injury. (Figure 9)

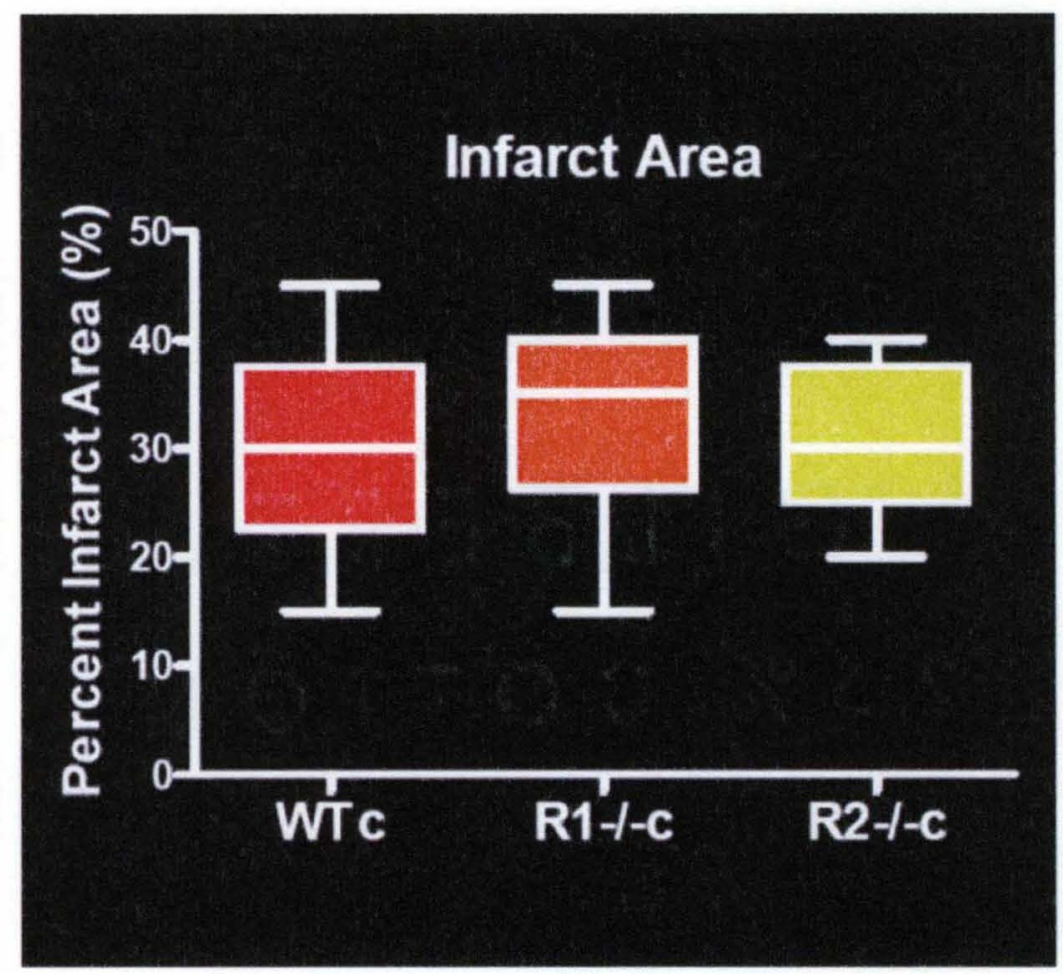

Figure 9: Quantification of infarction area as percent of LV area demonstrating equivalent injury in each of the HF groups. 
LV Remodeling and Dilatation post Infarction is Attenuated by the Selective Loss of TNFR1 in the Inflammatory Compartment, while Similar Loss of TNFR2 Demonstrates no such Benefit

Four weeks following coronary ligation, LV tissue sections were obtained as described in the methods section. Demonstrated below are representative LV short axis tissue sections and M-mode echocardiograms corresponding to WTC sham and WTC HF, again demonstrating that permanent coronary ligation resulted in a substantial level of myocardial injury and LV dilatation. When comparing representative R1-/-c HF images, the magnitude of these changes was attenuated. An obvious decrease in LV dilatation is seen in the gross cross section and improved myocardial performance noted on M-mode. The R2-/-c HF example shows LV dilatation and systolic dysfunction similar to WTC HF. The $\mathrm{R} 1-\mathrm{-c}$ and R2-I-C shams are phenotypically similar to the WTC sham, again demonstrating no significant differences in uninjured myocardium. (Figure 10) 


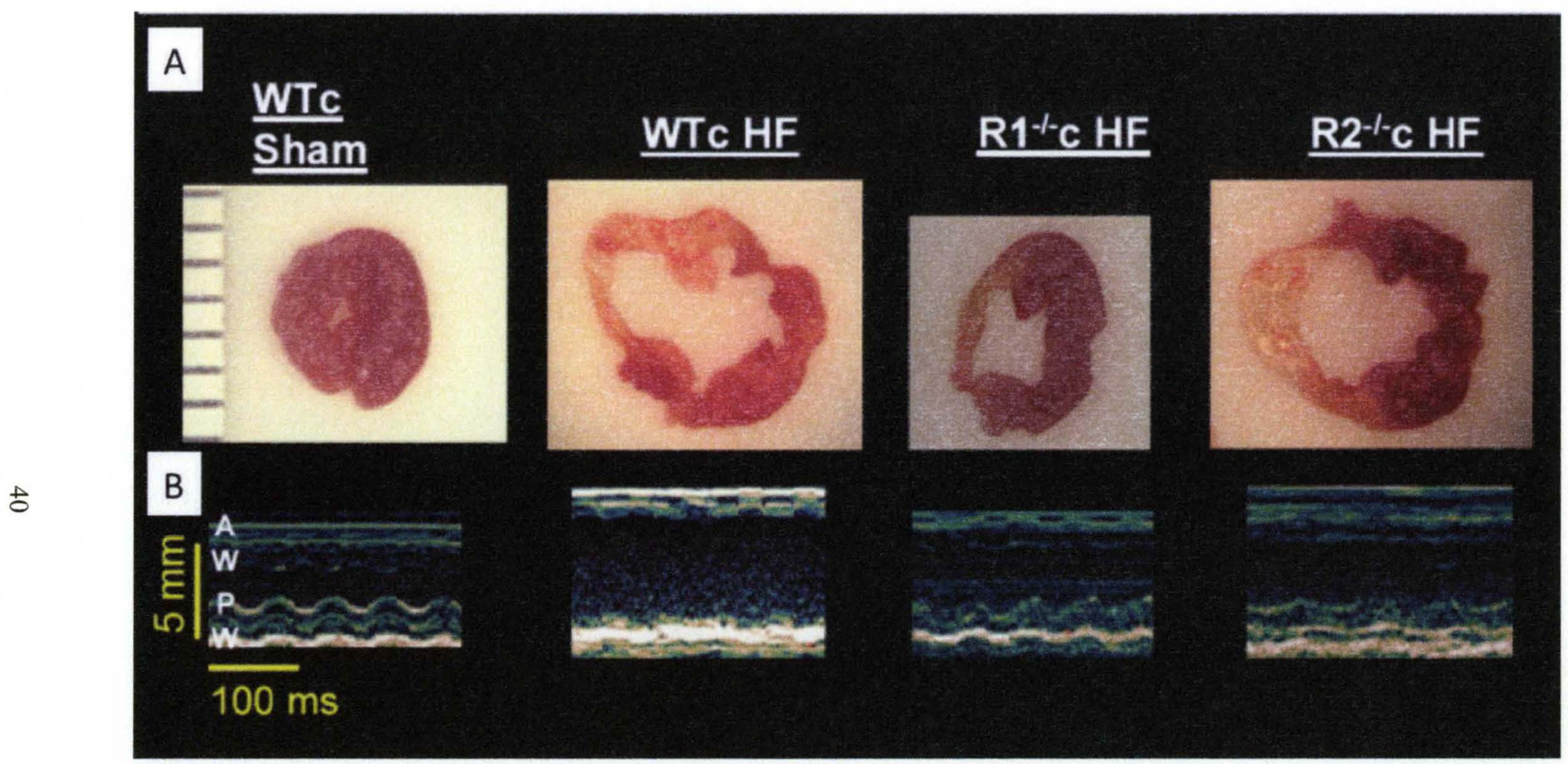

Figure 10. A: Representative left ventricular short-ax-s cross sections. While hearts from all three HF groups were significantly increased in size over sham, gross changes between R2-/-c and WTC HF animals were significantly greater when compared to R1-I-c HF. B: Representative M-mode echocardiograms. As with gross pathology, no apparent differences were observed between the WTc and R2-/-c HF groups, however significantly improved function was noted in the R1-l-c HF animals. R1-/-c and R2-/-c shams are not shown for simplicity but were not different from WTc shams. 
In vivo Measurements of Chamber Dilitation and Performance Demonstrate Improved LV Remodeling and Myocardial Performance with the Loss of TNFR1 in Inflammatory Cells

The observation of exaggerated LV chamber dilatation in WTc HF and R2-/-c HF hearts compared with R1/-c HF hearts were confirmed by group echocardiographic data. LV size was indexed by end diastolic and end systolic volume (EDV and ESV), and systolic function was indexed by LV EF. EDV and ESV were significantly increased in each of the HF groups when compared to respective sham animals. The degree of chamber dilatation, as measured by EDV, however, was attenuated in R1-/-c HF when compared with either WTc HF $(96.7 \pm 13.7$ vs. $65.7 \pm 13.8 \mu \mathrm{L})$ or $\mathrm{R} 2-/ \mathrm{c} \mathrm{HF}(111.1 \pm 28.5$ vs. $65.7 \pm 13.8 \mu \mathrm{L})$

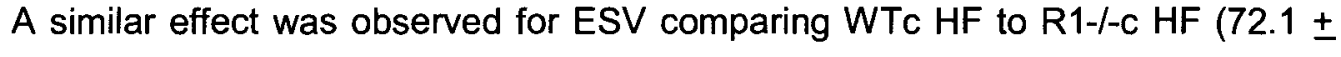
14.6 vs. $37.0 \pm 9.7 \mu \mathrm{L})$ and R1 $\mathrm{R}-\mathrm{c}$ HF and R2-/-c HF groups (37.0 \pm 9.7 vs. 85.6 $\pm 22.9 \mu \mathrm{L}$ ) (Figure 11). The R1 $1-\mathrm{c}$ HF group also demonstrated a much higher EF as compared to either WTc HF (42.9 \pm 4.2 vs. $25.5 \pm 7.5 \%)$ or R2-/-c HF animals $(42.9 \pm 4.2$ vs. $22.3 \pm 4.6 \%$ ) (Figure 11$)$. No significant difference was observed in either LV size or ejection fraction between R2-/-c and WTc HF $(p=N S) . \quad$ (Figure 11) 


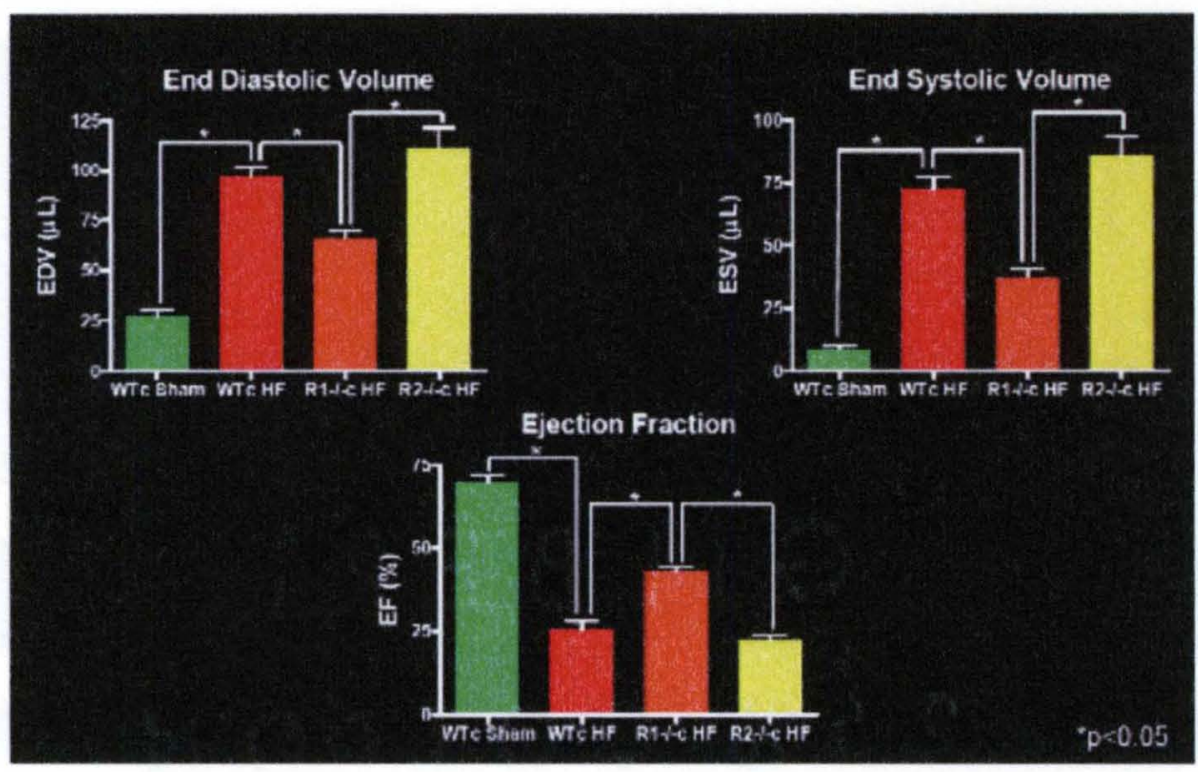

Figure 11: Quantification of echocardiographic parameters of end diastolic volume (EDV), end systolic volume (ESV), and ejection fraction (EF). All HF groups had significantly increased volumes both EDV and ESV and reduced EF compared to sham indicative of LV dilatation and impaired systolic function, however the R1-/-c HF group demonstrated less change from the sham groups In all three parameters compared to the WTc and R2-I-c HF. R1-/-c and R2-/-c sham groups are not shown for simplicity but are not different from WTc sham

\section{Mice with Deletion of TNFR1 in Inflammatory Cells Demonstrated Less Pulmonary and Systemic Congestion and Myocardial Mass in HF Consistent with Improved HF Physiology}

Following animal sacrifice, analysis of tissue weights was performed as described in the methods section. An increase in LV mass and increased lung and liver weights consistent with LV hypertrophy and increased lung and liver water were seen in all HF groups compared to sham $(p<0.05)$. In accordance with the echocardiography data showing less LV remodeling and improved performance in R1-/-c failing hearts (Figure 11) there was a decrease in heart 
size normalized to tibia length in R1-/-c HF when compared with either WTc HF $(4.79 \pm 0.64$ vs. $6.39 \pm 0.44 \mathrm{mg} / \mathrm{mm})$ or $\mathrm{R} 2-/-\mathrm{c} \mathrm{HF}(4.79 \pm 0.64$ vs. $6.85 \pm 1.05$ $\mathrm{mg} / \mathrm{mm}$ ) groups. When analyzing LV mass individually, again normalized to tibial length, a similar trend was noted upon comparing R1-/-c HF with either WTc HF ( $3.14 \pm 0.20$ vs. $3.91 \pm 0.53 \mathrm{mg} / \mathrm{mm})$ or R2-/-c HF groups $(3.14 \pm 0.20$ vs. $4.07 \pm$ $0.27 \mathrm{mg} / \mathrm{mm}$ ). Additionally, R1-/-c HF had reduced lung and liver weights, compared with either WTc HF or R2-/-c HF $(p<0.05)$. R2 HF and WTc HF demonstrated no significant differences in heart, LV, lung or liver weight $(p=N S)$ (Figure 12). Pulmonary and systemic congestion, hallmarks of the pathophysiology of HF are indexed here by lung and liver weights mentioned previously. The R2-/-c and WTc HF groups had significantly higher lung and liver weights then the R1-/-c HF mice, demonstrating an attenuated HF physiology in the R1-I-c mice. 

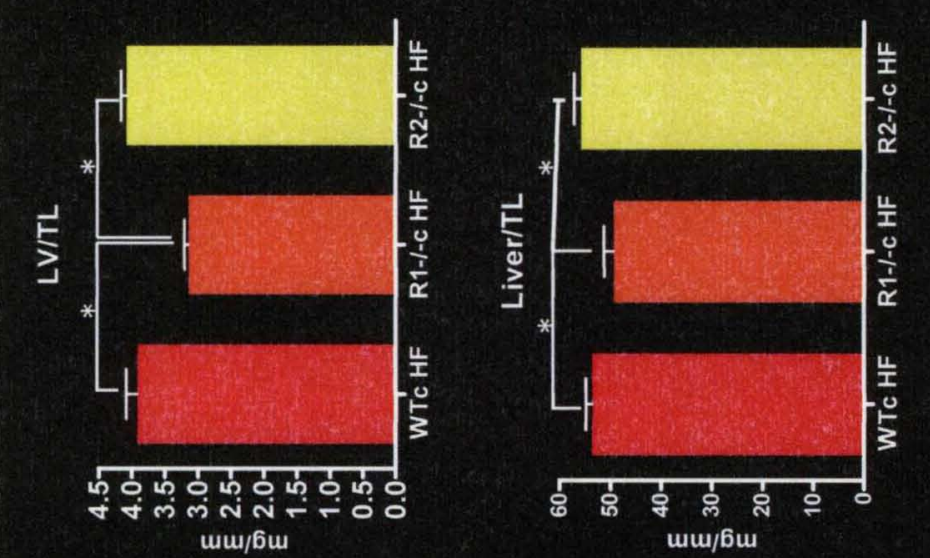

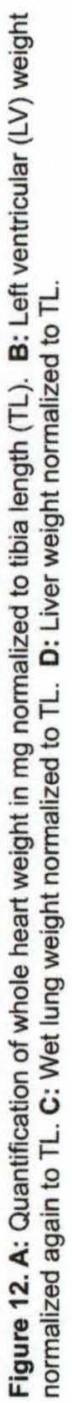
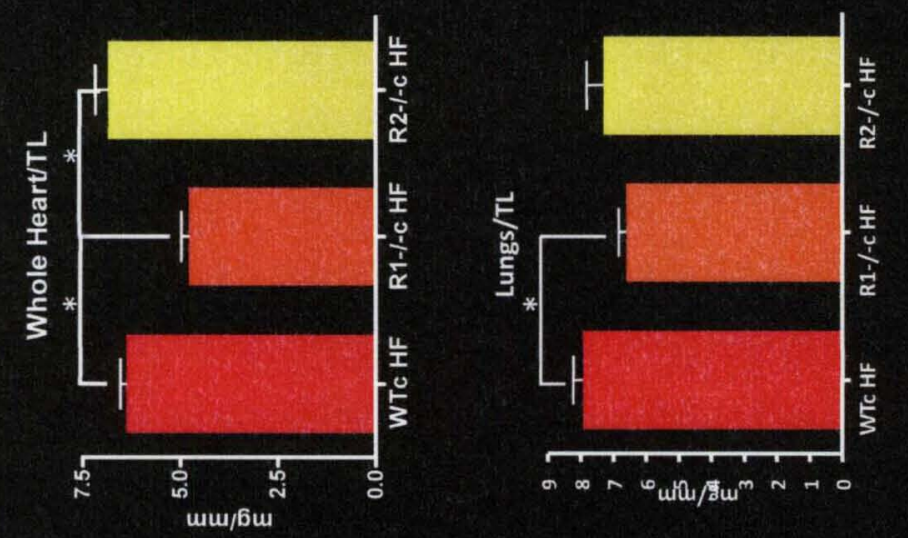


\section{Myocyte Area and Atrial Natuiretic Factor (ANF) Expression were Significantly Attenuated in R1-/-c HF Mice Compared to Either R2-/-c or WTc HF Mice}

Myocyte area was assessed using wheat germ agglutin (WGA) staining and representative images are shown in Figure 13. In each HF group there was an increase in myocyte size compared to sham, as is expected with a significant level of injury subsequently resulting in pathological hypertrophy. However, in the R1 $1-\mathrm{c}$ HF group this increase in size was attenuated when compared to either WTc HF $\left(255.64 \pm 64.98\right.$ vs. $\left.325 \pm 73.45 \mu \mathrm{m}^{2}\right)$ or R2-l-c HF $(255.64 \pm$ 64.98 vs. $331.89 \pm 71.87 \mu \mathrm{m}^{2}$ ). This pattern was further supported by evaluation expression of ANF, a protein marker of myocyte hypertrophy. ANF expression was significantly increased in WTc HF hearts and R2-l-c HF hearts over sham (WTc HF $5.14 \pm 1.34$ fold increase; and R2 - -c HF $4.26 \pm 2.04$ fold increase), however, no significant increase was noted in the R1-/-c HF hearts compared to sham (1.19 \pm 0.9 fold change) consistent with the decrease in myocyte hypertrophy observed with histological analysis (Figure 14). 


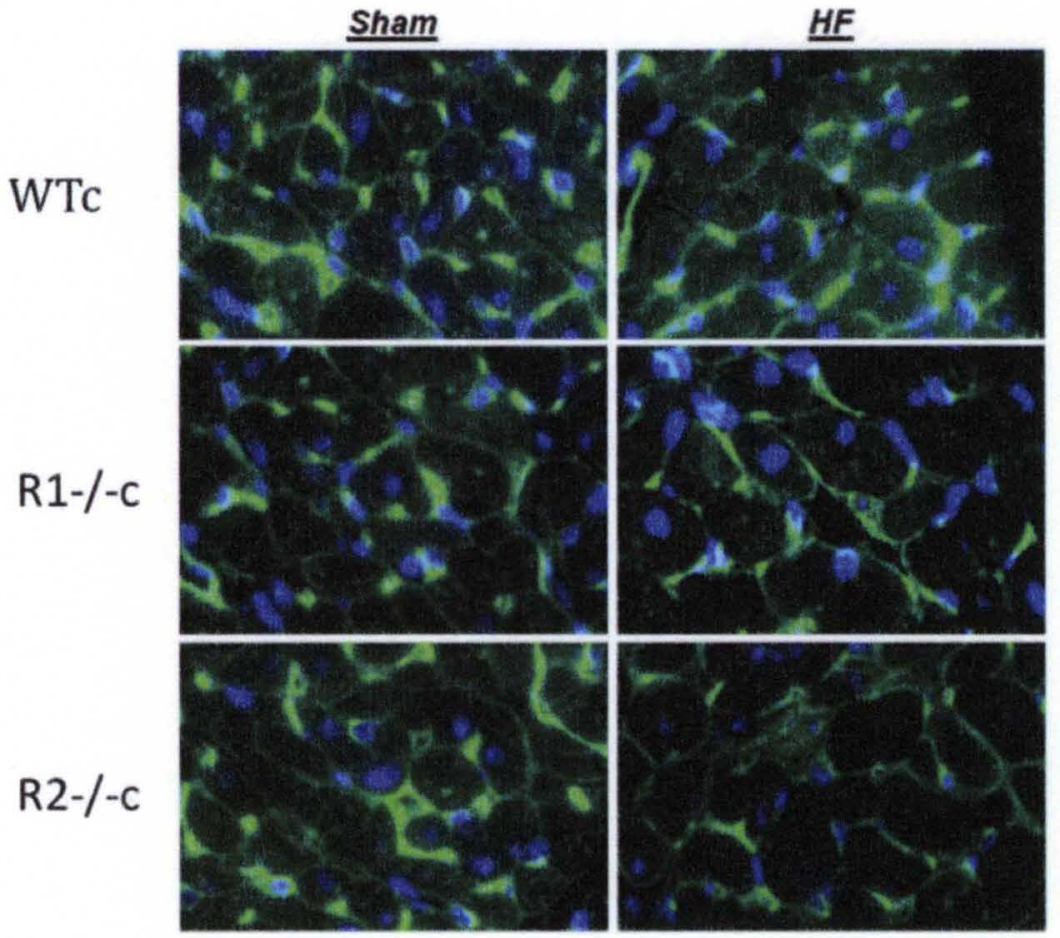

Figure 13: Representative images of wheat germ agglutin staining (WGA). Shown are WTc, R1-/-c, and R2-/-c sham and HF. All HF groups demonstarted Myocyte hypertrophy compared to the sham groups. However, the R1-/-c HF group had significantly less hypertrophy compared to either the WTc or $\mathrm{R} 2-/-\mathrm{c} \mathrm{HF}$ animals. 


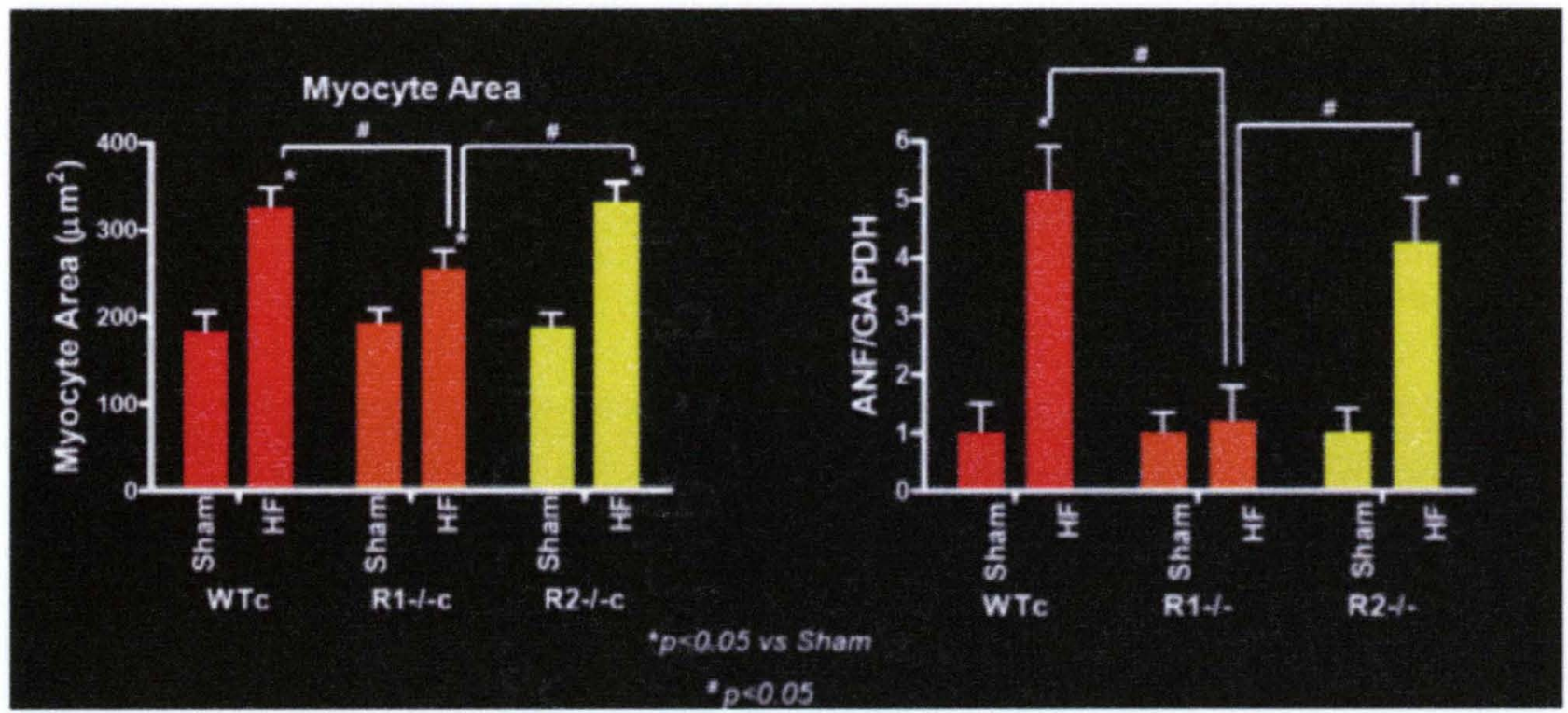

Figure 14. A: Graphical quantification of myocyte area as measured by wheat germ agglutin syaining (WGA). All HF groups demonstrated significantly increased myocyte area when compared to their corresponding shams. However, the R1-/-c HF group had significantly less hypertrophy compared to the other two HF groups. B: Quantified RT-PCR of atrial naturetic factor (ANF), confirming the hypertrophy data, the level of ANF in R1-/-c HF hearts was significantly less then either the WTc or R2-I-c HF groups. 
Decreased Total Fibrotic Area Seen in R1 HF Group Compared to Both R2 HF and WTc HF groups

Total LV fibrorotic area was assed using Trichrome staining. Shown in Figure 15 are representative histomicrographs of non-infarcted, and remodeled myocardium, and the corresponding group quantitation of fibrotic area (Figure 15). There was a significant increase in collagen deposition in all three HF groups when compared to their respective sham groups $(p<0.05)$. However, this was most pronounced in the WTc and R2-/-c, and was less in R1/-c HF compared to either WTc HF (5.48 \pm 2.26 vs. $16.10 \pm 8.16 \%$ area) and R2-/-c HF $(5.48 \pm 2.26$ vs. $21.92 \pm 10.81 \%$ area). (Figure 15$)$ 


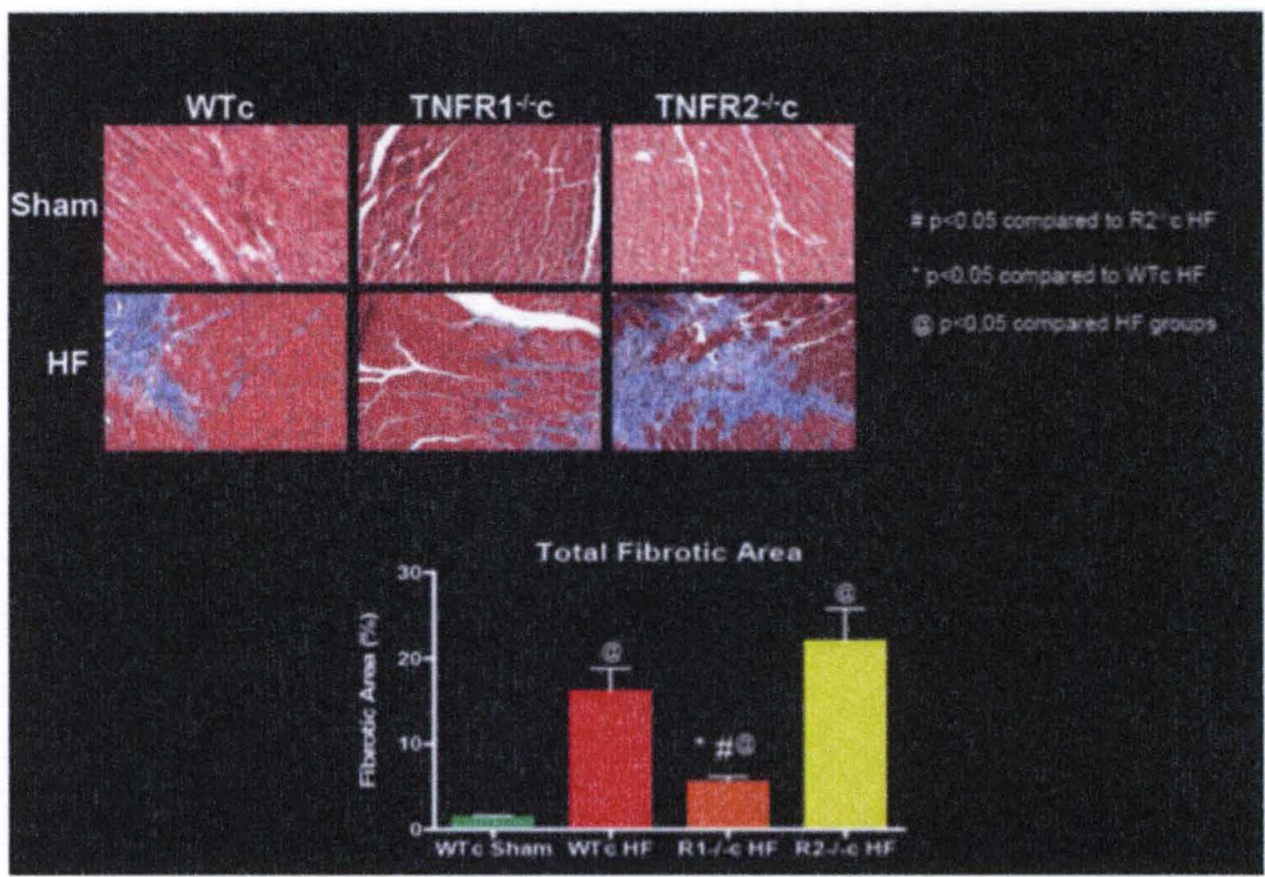

Figure 15. A: Representative Trichrome staining of sham and HF hearts. Significant levels of fibrosis (blue) are seen in all HF groups compared to sham. B: Quantification of total myocardial fibrotic area demonstrates significant increased fibrosis in all HF groups compared to sham, however, R1-/-c HF had significantly less fibrosis following infarction then either WTc or R2-1-c HF groups.

\section{Attenuated Fibrosis was Observed in the R1 -c HF Hearts in the Region Immediately Adjacent to the Infarction as well as Areas Remote to the Injury}

Trichrome analysis to delineate fibrotic burden of the border zone, the area immediately adjacent to the infarcted myocardium, and the remote zone, the area of LV uninvolved by infarction, demonstrated a similar pattern with regard to total fibrotic area. Specifically, in the border zone significantly increased fibrosis was 
noted in all HF groups as compared with sham $(p<0.05)$. However, there was significantly less borderzone fibrosis noted in R1-/-c HF compared to either R2 - -c HF or WTc HF $(5.48 \pm 2.26$ vs. $16.10 \pm 8.16$ vs. $21.92 \pm 10.81 \%$ area, respectively). In the remote zone, no significant differences in fibrosis were noted between sham and R1-l-c HF ( $p=N S)$. The remaining HF groups, R2-/-c HF and WTc HF, both demonstrated increased fibrosis compared to sham. However, no significant differences were noted between R1--c HF and WTc HF $(p=N S)$. There was however a significant increase in fibrosis in the remote zone in the R2-/-c HF group compared to either WTc HF (4.78 \pm 2.02 vs. $2.6 \pm 1.62 \%$ area) and $\mathrm{R} 1-/-\mathrm{c} \mathrm{HF}(4.78 \pm 2.02$ vs. $1.80 \pm 1.34 \%$ area) (Figure 16$)$. 


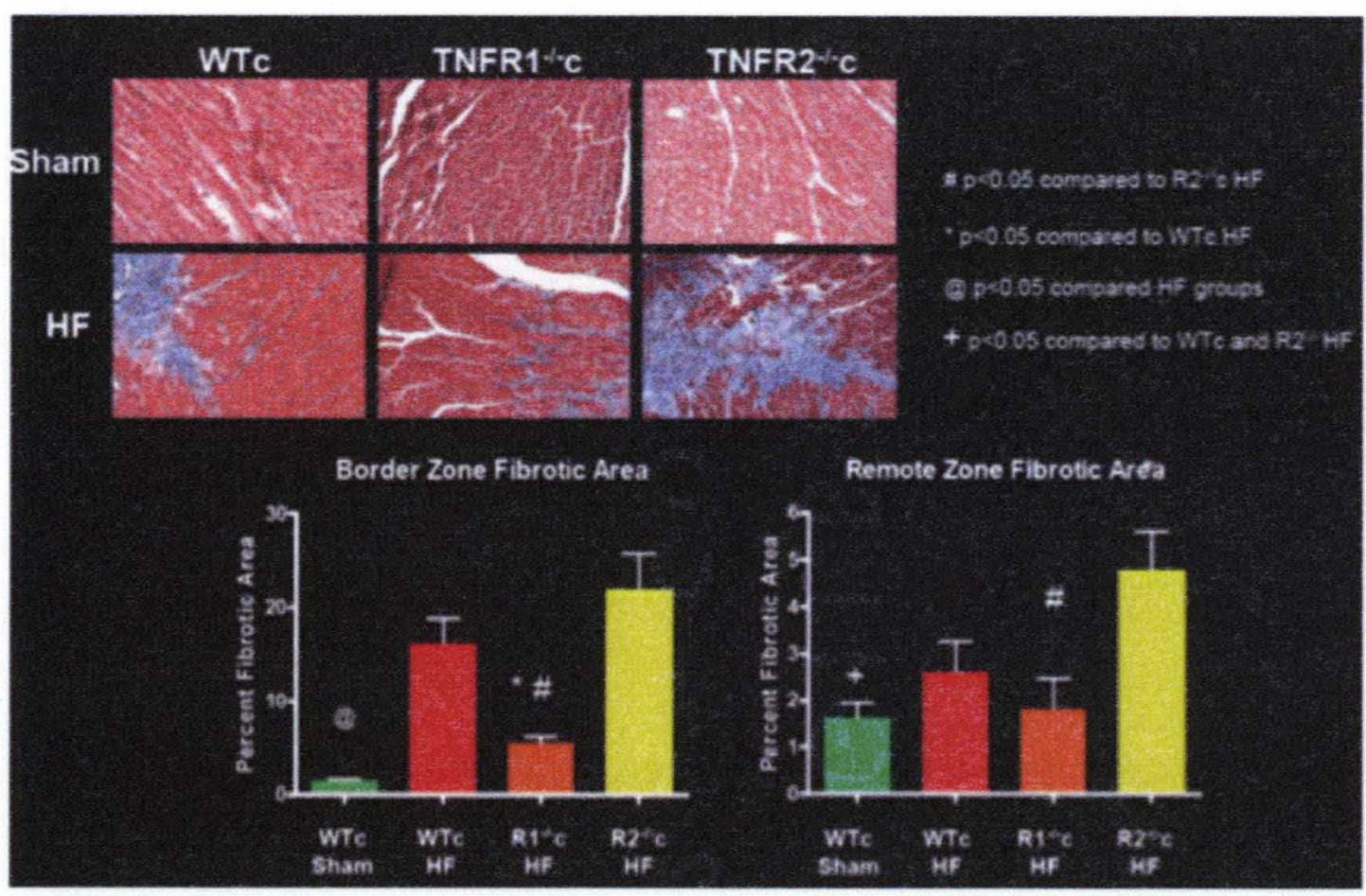

Figure 16. A: Representative Trichrome staining of sham and HF hearts. Significant levels of fibrosis (blue) are seen in all HF groups compared to sham. B: Quantification of myocardia border zonel

Fibrosis. All HF groups had significantly increased border zone fibrosis. R1-/-c HF animals had significantly less fibrosis than either WTC or R2 $/-c$ HF. C: The Remote zone, demonstrated significantly increased fibrosis in all HF groups compared to sham; however, R1-/-c HF had significantly less fibrosis following infarction than R2-/-c HF. 
Myocardial Expression of Pro-Fibrotic Connective Tissue Growth Factor (CTGF) Parallels the Changes in LV Fibrosis Post Infarction

RT-PCR was used to measure myocardial expression of connective tissue growth factor (CTGF) a pro-fibrotic protein. The pattern of post infarction LV fibrosis demonstrated in WTc, R1-/-c, and R2-/-c HF groups discussed previously was supported by analysis of CTGF gene expression, which exhibited reponses analogous to the change in tissue fibrosis. Specifically, all HF groups demonstrated significantly increased cardiac expression of CTGF compared to sham $(p<0.05)$. Interestingly, R1-/-c HF hearts showed a significant fold decrease in CTGF expression compared to either WTc HF (1.66 \pm 0.50 vs. 2.28 \pm 0.62 fold increase) and R2-l-c HF hearts $(1.66 \pm 0.50$ vs. $2.61 \pm 1.22$ fold increase) (Figure 17). 


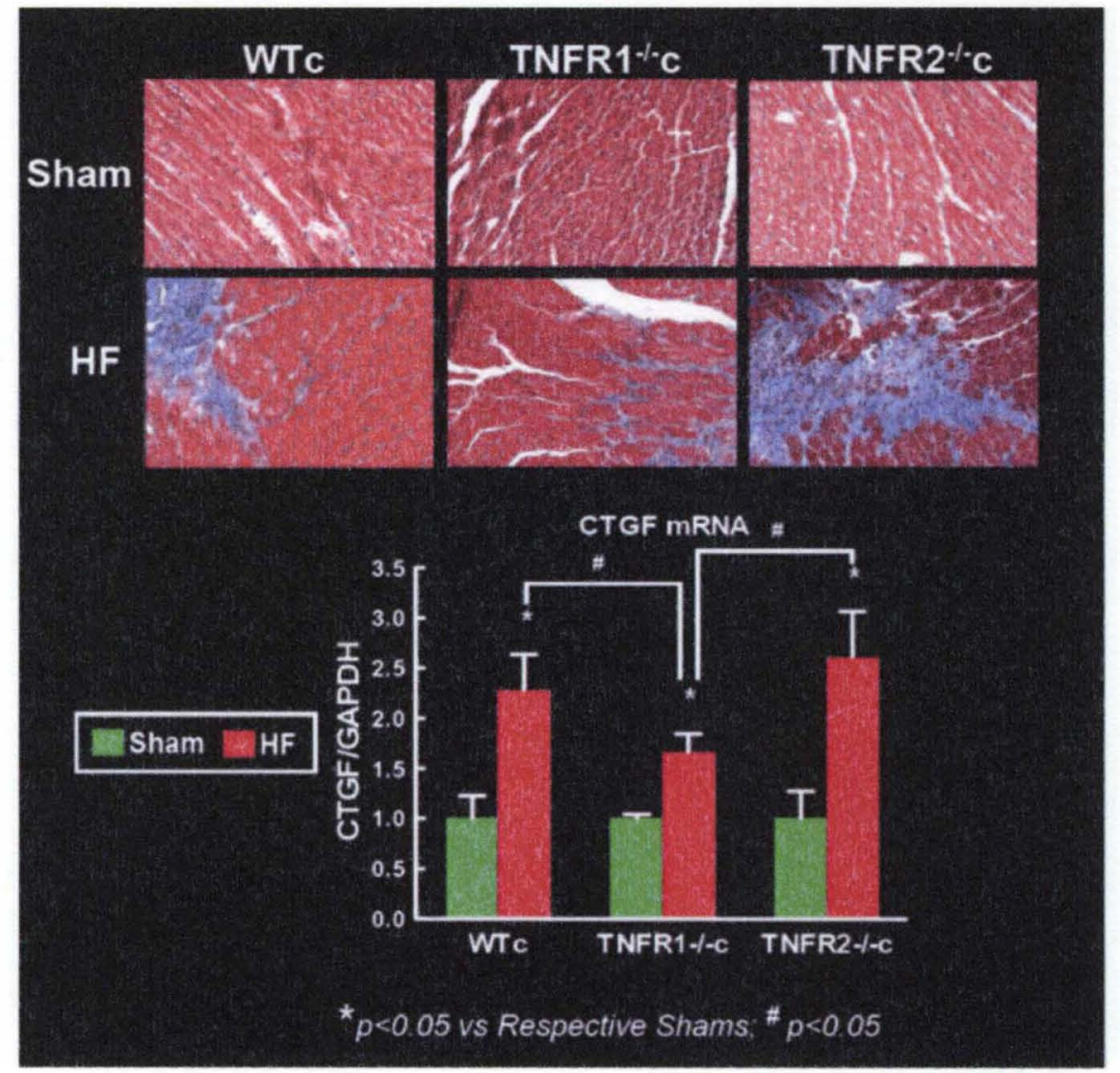

Figure 17. A: Representative Trichrome staining of sham and $\mathrm{Hf}$ hearts in the WTc, R1-/-c, and R2-/-c groups. B: Quantified RTPCR values of myocardial expression of connective tissue growth factor (CTGF). CTGF was increased in all HF groups over their respective shams. Compared to R2-/-c HF and WTc $H F, R 1-/-c$ HF had significantly lower levels of CTGF expression. 


\section{No Significant Difference was noted in Activated Peripheral Monocytes $(\mathrm{F} 4 / 80+/ \mathrm{CD} 11 \mathrm{~b}+)$ Amongst the Three Study Groups in Naïve Animals}

Flow cytometric analysis was performed on peripheral blood samples obtain from naive mice in each of the three study groups, WTc, R1-/-c, and R2-/-c. Activated monocytes were identified as dual positive F4/80 and CD11b cells. No significant difference was noted between any of the three groups at baseline $(p=N S) . \quad$ (Figure 18)

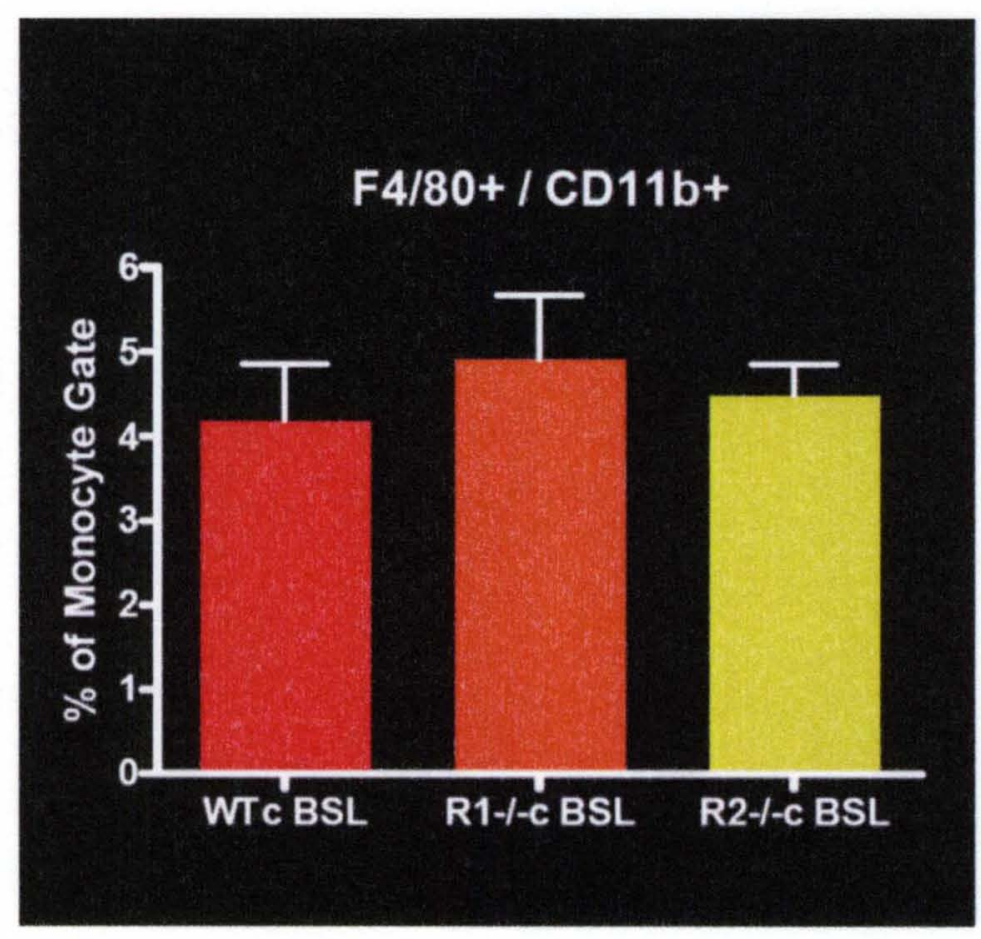

Figure 18: Activated momocytes as defined by dual positivity of $\mathrm{F} 4 / 80$ and CD11b by flow cytometry in the peripheral blood of Naïve WTc, R1-/-c, and R2-/-c mice. No significant difference was noted between any of the groups. 


\section{An Exaggerated Level of Activated Monocytes (F4/80+/ CD11b+) was Demonstrated by Flow Cytometry in the Peripheral Blood of R2 - -c HF Mice in Response to Myocardial Injury}

Activated monocytes, identified as cells dual positive for F4/80 and CD11b by flow cytometric analysis, were significantly increase in all HF groups compared to their respective baselines and shams at all time points observed, with the exception of R1-/-c HF at 1 week post infarction. Interestingly the R2-/-c HF group demonstrated significantly higher levels of circulating activated monocytes compared to WTc HF at 1 day $(15.32 \pm 4.41$ vs. $12.10 \pm 1.24 \%$ gate $)$ and 4 weeks ( $12.06 \pm 1.73$ vs. $5.90 \pm 0.75 \%$ gate $)$ post infarction, and at all observed timepoints compared to R1-/-c HF 1 day (15.32 \pm 4.41 vs. $8.19 \pm 3.08 \%$ gate), 1 week $(10.40 \pm 1.67$ vs. $5.81 \pm 2.27 \%$ gate), and 4 weeks $(12.06 \pm 1.73$ vs. 6.68 $\pm 0.94 \%$ gate). This supports an important role for TNFR1 in the activation of monocytes in HF (Figure 19). 


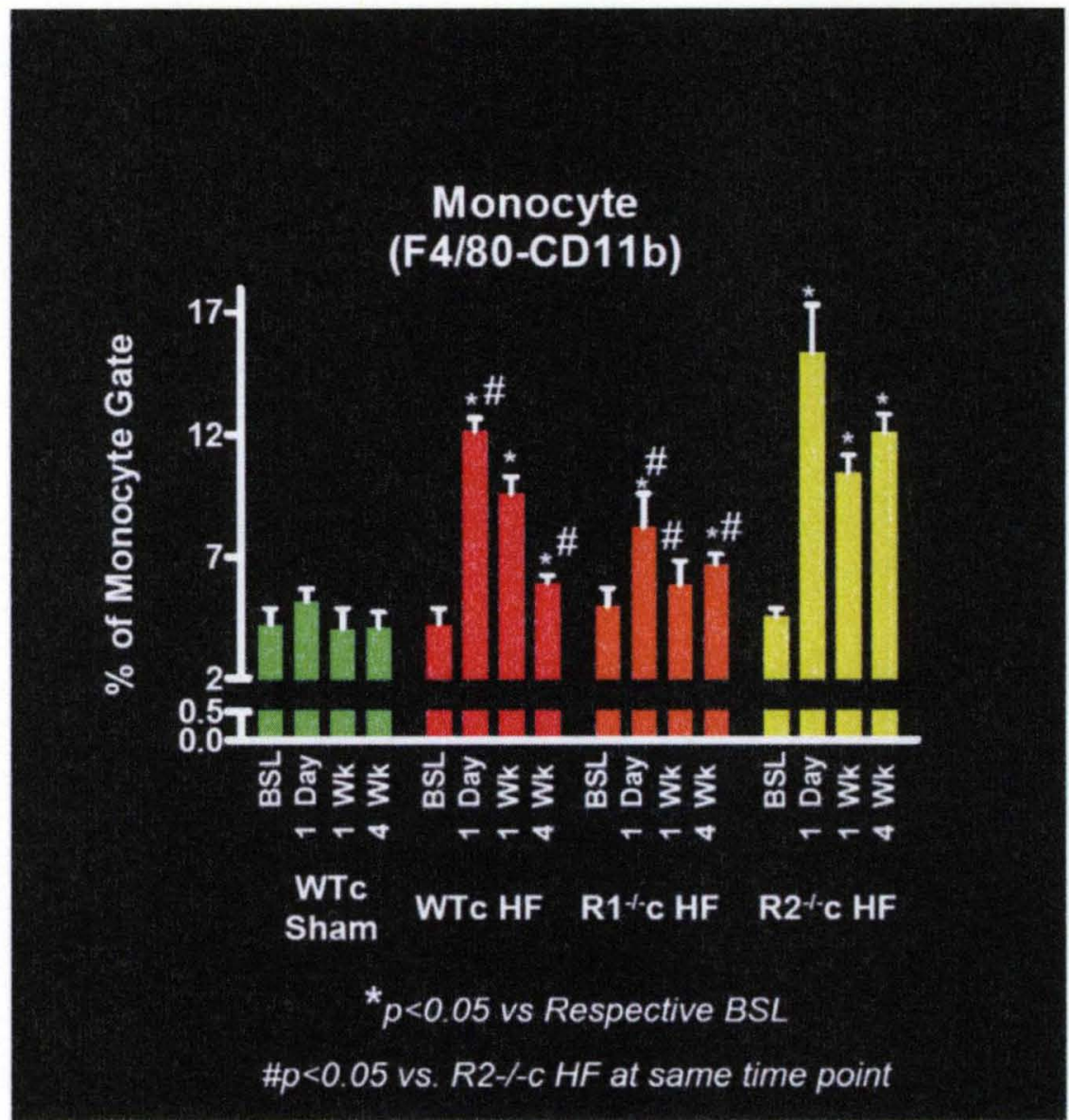

Figure 19: Quantified values of activated monocytes, identified as dual positive cells (F4/80 and CD11b) by flow cytometry, in the peripheral blood of WTc sham, WTc HF, R1-l-c HF, and R2-l-c HF. R1-l-c and R2-l-c shams not shown, but were not different from WTc sham. R2-/-c HF demonstrated an exaggerated increase in activated monocytes compared to the WTc and R1-/-c HF groups at all time points post infarction with the exception of WTc HF at 1 week post infarction. 
Loss of Inflammatory Cell TNFR1 Attenuates Myocardial Inflammation in the Failing Heart

RT-PCR was used to measure cardiac expression of the pro-inflammatory TNF $\alpha$, $I L-1 \beta$, and IL -6 , as well as the anti-inflammatory cytokine IL-10. TNF $\alpha$ expression was significantly increased in WTC HF over sham (1.64 \pm 0.33 fold increase). Interestingly, there was no TNF $\alpha$ upregulation, as compared to sham, in either $\mathrm{R} 1$ - $\mathrm{c}$ HF $(0.42 \pm 1.95$ fold change $)$ or $\mathrm{R} 2-1-\mathrm{c}$ HF $(1.02 \pm 0.75$ fold change $)$ (Figure 20). These findings indicated that both TNFRs need to be functional in the inflammatory compartment to induce TNF expression in the failing myocardium. R1-/-c HF also showed non-significant fold changes in the levels of IL-1 $\beta(0.53 \pm 1.88$ fold change $)$ and IL-6 $(1.50 \pm 1.2$ fold change $)$ compared to the R1-/-c sham. The absolute fold change in IL-1 $\beta$ in the R1-/-c HF group was significantly lower than in the R2-/-c HF $(0.53 \pm 1.88$ vs. $1.72 \pm 1.31$ fold change $)$ and WTc HF (0.53 \pm 1.88 vs. $1.86 \pm 0.55$ fold change) groups. This indicates less myocardial inflammation in the R1 $1-\mathrm{c}$ HF hearts as compared to both WTc and R2-/-c HF, indicating that TNFR1 signaling in inflammatory cells is required for myocardial cytokine expression. The R2-/-c HF group demonstrated a predictable and significant increase in both IL-1 $\beta(1.72 \pm 1.31$ fold increase $)$ and IL-6 $(2.13 \pm 1.24$ fold increase $)$ gene expression relative to sham. The WTc HF hearts exhibited similar IL-1 $\beta$ and IL-6 expression as compared with R2-/-c HF hearts. Myocardial expression of IL-10, a well-established anti-inflammatory cytokine, was increased in the R1-/-c HF group compared to sham $(1.57 \pm 0.80$ 
fold increase), but not in WTc or R2-I-c HF, consistent with the observed blunted inflammatory response in R1-/- chimeras (Figure 20). 


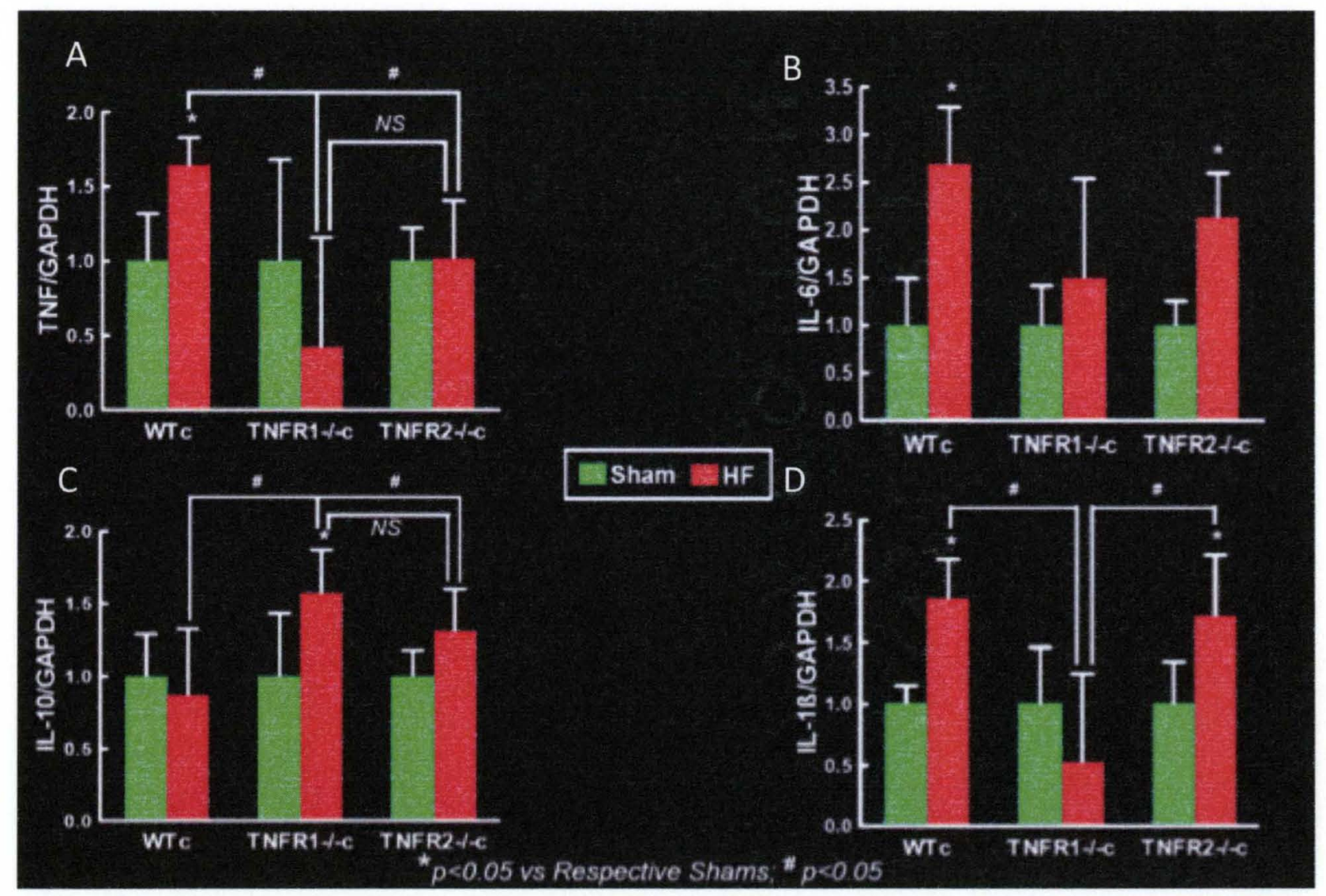

Figure 20. A: RTPCR quantified myoycardial expression of tumor necrosis factor alpha (TNF), B: interleukin (IL) 6 (IL-6), C: IL-10, and D: IL-1B. 


\section{Conclusions}

The data in this chapter demonstrated that selective loss of TNFR1 in inflammatory cells profoundly influences post-infarction cardiac remodeling and protects the failing myocardium from many of the deleterious processes that define the pathology of HF. Specifically, deletion of TNFR1 in the inflammatory compartment alleviated contractile dysfunction and chamber dilatation, LV and myocyte hypertrophy, interstitial fibrosis, peripheral monocyte activation, and myocardial inflammation with significant reductions in TNF, IL-6, and IL-1 $1 \beta$ expression and increases in IL-10 expression.

Conversely, selective loss of TNFR2 in inflammatory cells did not significantly influence post-infarction cardiac remodeling in that the LV performance and dimensions measured by echocardiography were not significantly different from the WTC HF group. It did, however, modestly augment interstitial fibrosis, compared to WTc, and reduce TNF expression.

Nonetheless loss of either TNFR1 or TNFR2 in inflammatory cells improved survival over WTc HF mice. This is an interesting finding in that, even though loss of TNFR2 did not significantly change the phenotypic picture of chronic HF with regards to LV function, inflammatory cytokine production (with the exception of TNF $\alpha$ ), and myocyte hypertrophy, it offered a survival benefit. This is even more interesting in that it correlated with previously reported data [63] indicating 
a similar survival benefit in TNFR -/- HF mice despite seemingly unimproved myocardial dysfunction post coronary ligation. Possible explanations for this include scar stabilization, decreased electrical abnormalities, and decreased systemic effects of HF, all likely the result of more complex intercellular and intracellular TNF related signaling mechanisms then are currently appreciated. Myocardial rupture is a prominent cause of death early in the time course of post infarction remodeling in mice. While a slight increase in myocardial fibrosis was noted in the R2-/-c HF hearts, we can not fully determine the level of scar stability, i.e. its resistance to mechanical forces. Improved tensile strength would certainly better resist myocardial rupture. Sudden cardiac death (SCD), a product of malignant ventricular arrhythmias, is common in the sub acute infarction period. While this is difficult to monitor in an animal model it is likely this represents, as it does in humans, a significant cause of mortality. Differences in scar formation and fibrosis are well known to influence these electrical abnormalities. While differences in remodeling were evident in the R1I-c HF mice, it was less so with the R2-/-c HF animals. More sophisticated analysis of the fibrotic areas and electrical behavior of these animals would be needed to determine the likelihood of this explanation. Likewise, worsening systemic HF physiology can contribute to mortality. The observed requirement of both TNF receptors to induce myocardial TNF $\alpha$ production could play a role in improved HF physiology from the R2-/-c group, although from the analysis of liver and lung weights, along with echocardiographic data, it appears this is unlikely to be the case. 
It is apparent from this work that modulation of global inflammatory cell function induces significant localized changes in cardiac remodeling, and that TNF receptor signaling plays an important role in these effects. Inflammatory celllocalized TNFR1 exacerbates post-infarction LV remodeling and is required for the genesis of a pro-inflammatory state in failing myocardium. Inflammatory celllocalized TNFR2 imparts modest beneficial anti-fibrotic effects in the remodeling heart. Independent of the myocyte-specific effects of TNF, TNF-dependent inflammatory cell responses are critical for the progression of post-infarction remodeling in HF. 


\section{CHAPTER V}

\section{AIM \#2: TUMOR NECROSIS FACTOR SIGNALING IN MACROPHAGES MODULATES JUXTACRINE MACROPHAGE-MYOCYTE INTERACTIONS IN HEART FAILURE}

\section{BRIEF PREVIEW}

Background: While our previous findings indicated that selective ablation of bone marrow TNF Receptor 1 is beneficial, and that ablation of TNF Receptor 2 yields modest detrimental effects in $\mathrm{HF}$, the exact underlying cellular mechanisms of these effects are still unknown. In this aim, we will discuss potential mechanisms whereby infiltrating macrophages can interact with myocytes. To date it is unknown whether induction of myocardial dysfunction is a paracrine, cytokine mediated event or if actual cell-to-cell interaction is necessary; therefore, we will determine both paracrine and juxtacrine interactions between the macrophage and cardiomyocyte.

Methods: Heart failure was induced by permanent coronary artery ligation in C57BL/6, TNFR1 -, and TNFR2-/- mice (Jackson Labs) as described previously. The HF mice were then treated with an intraperitoneal injection of the 
macrophage attractant thioglycollate. Five days later, peritoneal macrophages were collected via peritoneal lavage and placed in co-culture with freshly isolated naïve cardiomyocytes. Macrophages isolated from sham operated animals served as the negative control, whereas, macrophages isolated from sham animals and artificially stimulated with lipopolysaccharide (LPS) served as the positive control. Cardiomyocyte contractile function was measured via videoedge detection (lonOptix) during digital field stimulation $(1 \mathrm{~Hz})$ under various conditions: 1) baseline cardiomyocyte contraction, 2) contraction following addition, but no attachment, of isolated macrophages, and 3) contraction following addition and attachment of macrophage and cardiomyocyte for 15 minutes. In separate experiments, cardiomyocytes were pre-loaded with the general marker of oxidant stress 5-(and-6)-carboxy-2',7'-dichlorofluorescein diacetate (DCFDA), a fluorescent indicator of ROS levels, and subjected to the same experimental conditions.

RESULTS: Upon physical attachment of wild type LPS-stimulated macrophages, cardiomyocytes exhibited significantly depressed sarcomeric shortening $(4.8 \pm$ 1.9 vs. $10.5 \pm 2.1 \%$ shortening). This was determined to be a solely juxtacrine effect since addition of stimulated macrophages, without cardiomyocyte attachment, had no significant impact on sarcomeric shortening $(9.26 \pm 3.54$ vs. $10.5 \pm 2.1 \%$ shortening). This effect was mirrored in macrophages isolated from HF animals without pre-stimulation with LPS $(4.5 \pm 2.8$ vs. $10.5 \pm 2.1 \%$ shortening), implying that macrophages are sufficiently pathologically activated in 
HF for the induction of myocyte dysfunction. Interestingly, while attachment of macrophages isolated from TNFR1 ${ }^{1-}$ HF animals still induced cardiomyocyte contractile depression as compared to wild type controls, the resultant depression was significantly altered as compared with WT HF macrophages (7.06 \pm 1.44 vs. $4.5 \pm 2.8 \%$ shortening). Conversely, TNFR2 ${ }^{-1}$ HF macrophage augmented myocyte contractile dysfunction upon cell-to-cell interaction $(2.80 \pm$ 0.19 vs. $4.5 \pm 2.8 \%$ shortening). Cell contact between macrophages and cardiomyocytes pre-loaded with the oxidant stress indicator DCF-DA, revealed 30 fold increased myocyte oxidant stress 15 minutes following attachment of WT HF macrophages, and abrogation of this response upon attachment of TNFR1 ${ }^{\text {-1 }}$ HF macrophages. Conversley, TNFR2 ${ }^{-t}$ HF macrophage attachment significantly increased myocyte oxidant stress as compared to WT HF macrophages.

CONCLUSIONS: We have provided mechanistic insight into the potential role of tissue macrophages in the production of contractile dysfunction and the first known report that the TNF receptors have divergent roles not only in in vitro single cell line culture models, but in cell-to-cell macrophage/cardiomyocyte interaction and function. In the infarcted animal, peripheral blood macrophages were pathologically activated and infiltrated the myocardium. Our previous data imply that many of the effects of these infiltrating cells may be most pronounced in the infarct border zone (i.e., changes in extracellular matrix components) and may, at least in part, be dependent on the interplay of various inflammatory 
mediators (iNOS, TNF, etc.). The effects of direct interaction between infiltrating macrophages and cardiomyocytes, and the role of TNFR-specific responses, are unknown. Data from this Aim indicates that direct, juxtacrine interactions between activated infiltrating macrophages are sufficient to induce oxidant stress and contractile depression in cardiomyocytes. This process is further influenced by the differential roles of immune cell TNF receptors. Moreover, our data confirm previous studies, in that paracrine (as opposed to juxtacrine) interactions between macrophages and cardiomyocytes were not sufficient to cause contractile dysfunction in the in vitro, co-culture setting. 


\section{INTRODUCTION}

While recent evidence has provided some mechanistic insight into the role of inflammation in the heart failure, much has been left undetermined. The role of the "foundation cytokine" TNF in HF remains unclear. Specifically, while much is known regarding the divergent pathways of generalized TNF receptor 1 and 2 signaling, the possibly critical contribution of cellular source has not been determined until this study. Aim 1 of this project provides the first evidence that the source of TNF receptor is critical for beneficial or detrimental function (i.e. whereas inflammatory cell-specific TNFR1 ablation is beneficial to pathologic remodeling, TNFR2 ablation is modestly detrimental); however, this only further warrants studies into the cellular interactions between infiltrating inflammatory cells and the injured myocardium, specifically the cardiomyocyte itself. Therefore, we extended our studies in Aim 2 to more clearly delineate the underlying mechanisms through which these beneficial or detrimental processes may occur.

While Aim 1 provides insights into the in vivo roles of the inflammatory cell TNF signaling in heart failure $[63,95]$, it remains unknown whether these effects are secondary to changes in the microenvironment, changes in the surrounding and supporting cells in the ischemic areas, or alterations in direct interactions between cardiomyocytes and infiltrating cells. Furthermore, if interactions between myocytes and inflammatory cells are a critical component (as we 
hypothesize), is this effect controlled by the macrophage or other infiltrating bone marrow cells? In this Aim we will attempt to uncover answers to these and other questions.

In addition to cellular source, the downstream effects on cardiomyocyte function are of critical importance as well. Are the observed effects secondary to changes within the cardiomyocyte or localized solely to the extracellular matrix and environment? If localized to the cardiomyocyte one suspect process involves myocardial oxidative stress. Myocardial generation of oxidative stress is a well known effect of the heart failure state [96] and is a known cause of a myriad of pathologic changes in failing myocardium including contractile dysfunction via disruption of contractile proteins [97]. However, the exact mechanism of this oxidant increase and the subsequent changes induced remain elusive. While we and others have suggested that infiltrating inflammatory cells in myocardium may contribute to oxidant stress-induced cardiac dysfunction, to-date only one paper hints at the possible role of the physical interaction of these cell types in the generation of oxidative stress [89]. In this elegant study, it was shown in an in vitro, cell co-culture model of neutrophil-cardiomyocyte interaction that neutrophils from septic animals were sufficiently activated to induce oxidant stress and ensuing contractile dysfunction in cardiomyocytes. 
This important work is consistent with our findings of improved cardiac remodeling and oxidant stress in the in vivo HF model with TNFR1 ${ }^{-1-}$ chimerism. While exciting, it remains unknown whether inflammatory cells, activated in vitro, function in the same manner as chronically activated inflammatory cells in HF. Secondly, it is unknown whether macrophages in HF are sufficiently activated to induce oxidant stress effects in cardiomyocytes in a manner analogous to sepsisactivated neutrophils. While these questions remain unanswered to date, it is notable that macrophages, like neutrophils, produce the foundation cytokine TNF in response various stimulants $[98,99]$. Taken together with our data that macrophages infiltrate the myocardium and are activated during heart failure, we hypothesize that macrophage-cardiomyocyte interaction in the failing heart is sufficient to induce contractile dysfunction via mechanisms related to free radical generation. We investigated this hypothesis using a cell co-culture model of macrophage-cardiomyocyte interaction. 


\section{MATERIALS AND METHODS}

Animals. For these studies, commercially available C57BL/6 (WT), TNFR1 ${ }^{1-}$, and TNFR2 ${ }^{-}$mice (Jackson Labs) were used. The mice were maintained in the University of Louisville Research Resources Center. All studies were performed in compliance with the NIH Guide for the Care and Use of Laboratory Animals (DHHS publication No. [NIH] 86-23, Revised 1996).

Coronary ligation and experimental protocol. Permanent coronary ligation was performed as previously described [63,92]. Anesthesia was induced in mice with tribromoethanol $(0.25 \mathrm{mg} / \mathrm{g} \mathrm{IP})$. After induction, the mice were intubated and supported with a MiniVent Mouse Ventilator (Type 845, Harvard Apparatus) at 125-150 breaths/minute depending on body weight (tidal volume $6.4 \mu \mathrm{L} / \mathrm{g}$, PEEP 5-7 $\mathrm{cm} \mathrm{H}_{2} \mathrm{O}$ ). Anesthesia was maintained with $1 \%$ isoflurane. Heat lamps and heating pads were used to maintain body temperature at $37^{\circ} \mathrm{C}$. Under sterile conditions, a left thoracotomy was performed in the 4th intercostal space, the heart was exposed, and the pericardium was opened. An 8.0 prolene ligature was passed and tied around the proximal left coronary artery, $1 \mathrm{~mm}$ distal to the left atrial appendage border. Successful occlusion was confirmed by the production of pallor and dyskinesia in the distal myocardium. In sham animals, the suture was passed but not tied. The chest was then closed in layers using 5.0 silk, and the mice were allowed to recover and followed for 4 weeks. The total mice used for these studies were as follows: C57BL/6 $(n=10)$, TNFR1 $^{-1-}(n=10)$, 
$\operatorname{TNFR2}^{-1-}(n=10)$. Mice were followed for 4 weeks following operation, and were used for macrophage harvest.

Isolation of mouse cardiomyocytes. Naïve mice were deeply anesthetized with pentobarbital $(80 \mathrm{mg} / \mathrm{kg} \mathrm{IM}$ ) and given heparin $10 \mathrm{U} / \mathrm{g}$ i.p. The heart was rapidly excised, and $\mathrm{Ca}^{2+}$ tolerant mouse ventricular myocytes were isolated by modified Langendorff perfusion and collagenase digestion as previously described $[1,3]$. Briefly, the aorta was cannulated with retrograde perfusion of Tyrode buffer (in $\mathrm{mM}: \mathrm{NaCl}-126, \mathrm{KCl}-4.4, \mathrm{MgCl}_{2}-1, \mathrm{NaHCO}_{3}-18$, Glucose-11, HEPES-4, BDM-10, Taurine-30, Glutathione-10) followed by 12 min collagenase perfusion. Atria were removed, and ventricular tissue was minced in collagenase mince buffer (tyrode buffer supplemented with $0.001 \%$ collagenase and $0.003 \%$ albumin), passed through a 120 um mesh (Whatman) into a $15 \mathrm{~mL}$ conical tube, and allowed to settle for $10 \mathrm{~min}$. Supernatant was discarded, and the remaining cells were mixed with $25 \mathrm{uM} \mathrm{Ca}^{2+}$ supplemented Tyrode buffer. This process was repeated with $50,100,250$, and $500 \mathrm{uM} \mathrm{Ca}^{2+}$ supplemented buffer. Finally, cells were plated at a density of $10^{4}$ rod-shaped cells $/ \mathrm{cm}^{2}$ in serum-free supplemented DMEM medium (with albumin $0.2 \%$, L-carnitine $2 \mathrm{mM}$, creatine $5 \mathrm{mM}$, taurine $5 \mathrm{mM}$, Lglutamine $1.3 \mathrm{mM}$, insulin $0.1 \mathrm{mM}$, triiodothyronine $0.1 \mathrm{nM}$, pyruvate $2.5 \mathrm{mM}$, BDM $10 \mathrm{mM}$, and penicillin/streptomycin $0.1 \%$ (cardiomyocyte media, CMM)) at $37^{\circ} \mathrm{C}$ in $5 \% \mathrm{CO}_{2}$ until experimentation. Cell viability was typically $75-80 \%$, as 
assessed by trypan blue exclusion. Preparations with less than $75 \%$ viability were discarded.

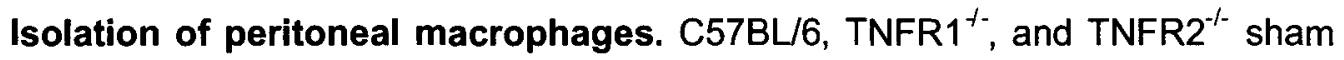
or $\mathrm{HF}$ mice were injected ip with $3 \mathrm{~mL}$ Brewer thioglycollate (TG) medium (Sigma, B2551) 5-7 days prior to harvest. Mice were euthanized with $\mathrm{CO}_{2}$, followed by cervical dislocation, and cells were collected in a $50 \mathrm{~mL}$ conical tube on ice via peritoneal lavage with cardiomyocyte media. Macrophages were then isolated from lavage fluid by density gradient purification followed by washing and resuspension in cardiac myocyte media $(\mathrm{CMM})$ to a final concentration of $2.5 \times 10^{6}$ cells $/ \mathrm{mL}$. The macrophage phenotype was confirmed with FITC tabeled F4/80 cell surface staining in a small aliquot. Approximately $99 \%$ of purified cells were determined to be positive.

Co-culture experimental protocol. Isolated ventricular cardiomyocyte function with and without macrophage attachment was determined using an lonOptix myocyte contractility system (Milton, MA). C57BL/6 cardiomyocytes were utilized for all studies, and macrophages from C57BL/6, TNFR1 ${ }^{-1-}$, and TNFR2 ${ }^{-1}$ sham or HF mice (Jackson Labs, Bar Harbor, ME) were utilized where noted (Figure 21). Approximately 4 hours after isolation, $10^{3}$ cardiomyocytes $\left(10^{4}\right.$ cells $\left./ \mathrm{mL}\right)$ were placed into the contraction system and perfused with HEPES buffer (in $\mathrm{mM}$ : $\mathrm{NaCl}-137, \mathrm{KCl}-4.9, \mathrm{MgSO}_{4} \cdot 7 \mathrm{H}_{2} 0-1.2$, Glucose-15, HEPES-20, $\mathrm{NaH}_{2} \mathrm{PO}_{4}-1.2$, 
$\mathrm{CaCl}_{2}-1.8$ ). Baseline sarcomeric shortening was determined during $1 \mathrm{~Hz}$ field stimulation for 5 minutes. Macrophages (100 uL of $2.5 \times 10^{6}$ cells $/ \mathrm{mL}$ ) were then introduced into the system and allowed to attach for 15 minutes. For HF macrophage studies, cells were harvested from animals 4 weeks post-infarction, and for LPS studies, harvested cells were treated with $5 \mathrm{ug} / \mathrm{mL}$ LPS (Sigma) for 4 hours prior to use. Post-attachment, sarcomeric shortening was again determined via $1 \mathrm{~Hz}$ stimulation for 5 minutes. For in vitro reactive oxygen species production experiments, cardiomyocytes were preloaded with 2 uM 6carboxy-2',7'-dichlorodihydrofluorescein diacetate acetoxymethyl ester (Molecular Probes) followed by washing to ensure no residual DCFDA in media. Preloaded myocytes were then loaded into chambered borosilicate coverglass systems and non-DCFDA loaded macrophages were introduced. Immediately upon macrophage-myocyte interaction, baseline epifluorescent pictures were started and continued every 2 minutes for 15 minutes. After 15 minutes, brightfield images were obtained in order to quantitate number of macrophages attached. All fluorescent studies were preformed on a Nikon Eclipse TE2000-U microscope equipped with a mercury light source. 


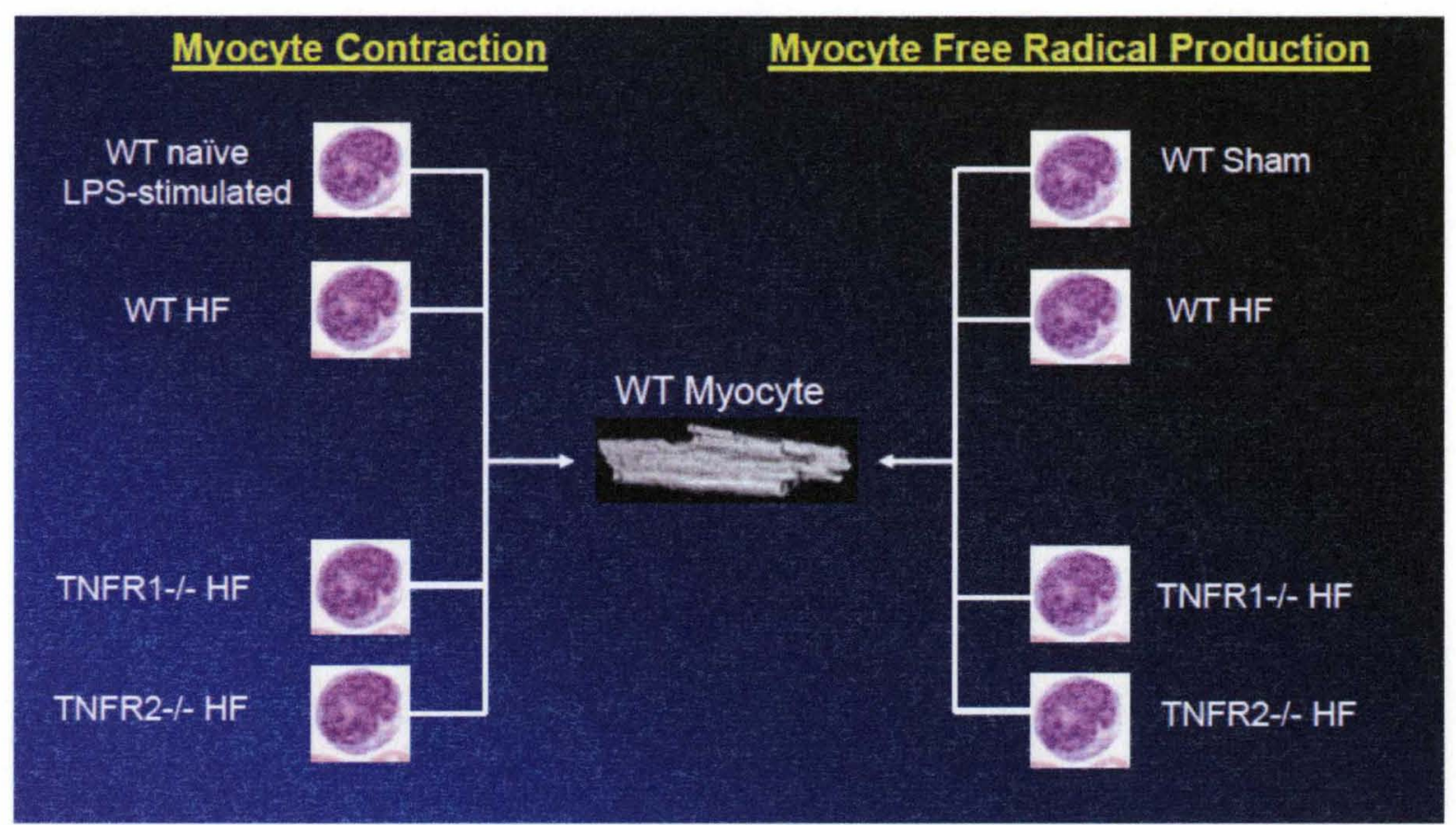

Figure 21. For myocyte contraction studies (left) WT cardiomyocytes were co-cultured with WT LPS stimulated, WT HF-derived, TNFR1- HF-derived, and TNFR2 ${ }^{-1} \mathrm{HF}$-derived and LPS stimulated peritoneal macrophages. For free radical production studies, WT myocytes were co-cultured with WT sham, WT HF, TNFR1 $1^{-1-H F}$, and TNFR2 ${ }^{-1-}$ HF peritoneal macrophages. 
Flow Cytometric Analysis of Peripheral Blood. Approximately 100 uL of peripheral blood was collected via facial vein technique [94] into BD Microtainer tubes with EDTA (BD Biosciences, 365973). Blood was then lysed with $2 \mathrm{~mL}$ RBC lysis buffer (eBiosciences, $00-4333-57$ ) for 5 min on ice in a $15 \mathrm{~mL}$ conical centrifuge tube followed by PBS quenching via addition of $10 \mathrm{~mL}$ cold PBS. Cells were then centrifuged at $380 \mathrm{~g}$ for $10 \mathrm{~min} / 4^{\circ} \mathrm{C}$ and supernatant was discarded. The pellet was resuspended in $400 \mathrm{uL}$ of ice cold flow cytometry staining buffer (eBioscience, 00-4222-57) and divided into two plastic flow cytometry tubes yielding two 200 uL tubes for each animal. Each tube was subsequently incubated for $30 \mathrm{~min}$ on ice with fluorescently labeled cell surface antibodies $\left(0.6 \mathrm{ug} / 10^{6}\right.$ cells) for the Monocyte Cell Panel: F4/80-Pacific Blue, CD11b-PE. Cells were then centrifuged at $380 \mathrm{~g}$ for $10 \mathrm{~min} / 4^{\circ} \mathrm{C}$, and the pellet was resuspended in $400 \mathrm{uL}$ of ice cold PBS. Samples were immediately analyzed on a BD LSRII flow cytometer equipped with 405,488 , and $633 \mathrm{~nm}$ lasers and appropriate filter sets. A non-debris gate was established on a FSC vs SSC gate and positivity for respective surface markers was determined from subsequent histograms. Unstained and fluorescently labeled respective Ig antibodies were analyzed to determine negative populations. Final analysis was performed using FlowJo v.7.6. Activated mononcytes were taken as $\mathrm{F} 4 / 80^{+} \mathrm{CD} 11 \mathrm{~b}^{+}$.

Statistical analysis. Comparisons of experimental data were made using a repeated measures analysis of variance (ANOVA). Animal survival was evaluated by Kaplan-Meier analysis, and comparisons of survival between 
groups at specific time points was made by both Cox regression and long-rank statistics. Statistical significance was accepted at $p<0.05$. 


\section{RESULTS}

Proof of Concept: Thioglycollate Elicited Peritoneal Macrophages are Positive for the Macrophage Marker F4/80 and Functional and Collagenase Disassociated Cardiomyocytes are Viable

Seven days post peritoneal injection of thioglycollate, cells harvested via peritoneal lavage exhibited the morphology (lobed nucleus) and size (10-12um in diameter) characteristics of macrophages (Figure 22A) upon light microscopy. Approximately $10-15 \times 10^{6}$ cells were harvested from each mouse and diluted into cardiomyocyte media. To confirm macrophage identity, immunofluorescent staining was performed for the classical macrophage marker F4/80 (FITClabeled). Nearly all cells were positive (99\%) for the surface marker F4/80. (Figure 22B) While confirmation of macrophage phenotype was important, it was equally critical to assess the ability of these cells to become activated upon stimulation. To this end, we developed a protocol for macrophage stimulation outlined in Figure 23A. One day post LPS stimulation, macrophages produced significantly greater amounts (2.5-fold) of NOx than unstimulated macrophages. Interestingly, these cells continued their stimulated state even 4 hours after withdrawal of the LPS stimulus. (Figure 23B) We also isolated mouse cardiomyocytes via modified Langendorff perfusion with collagenase digestion. The isolated cells were calcium-tolerant and of normal morphological size and 
shape (rod shape, approximately 100-120um) and behaved normally under field stimulation. (Figure 23C)

A
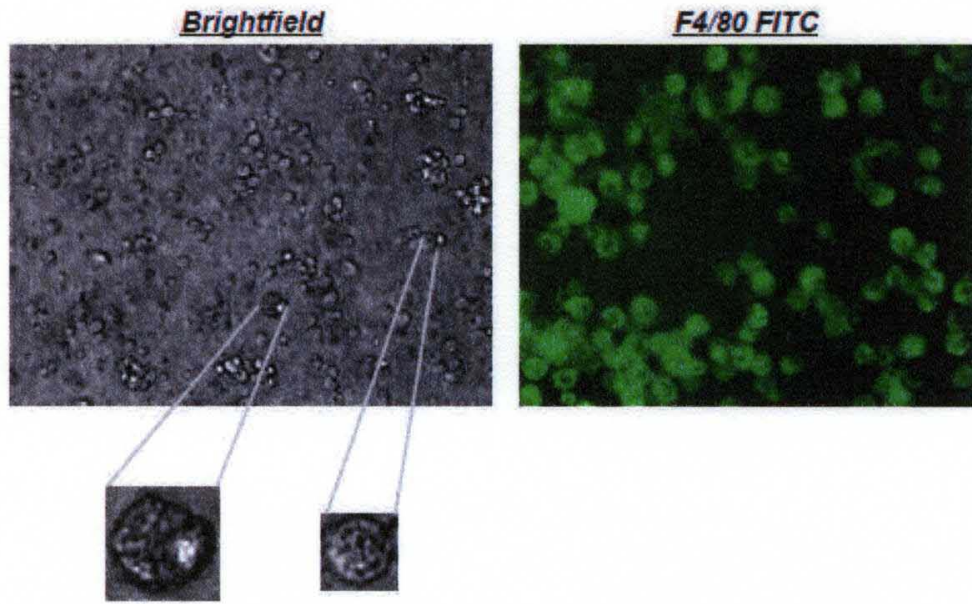

B

Brightfield

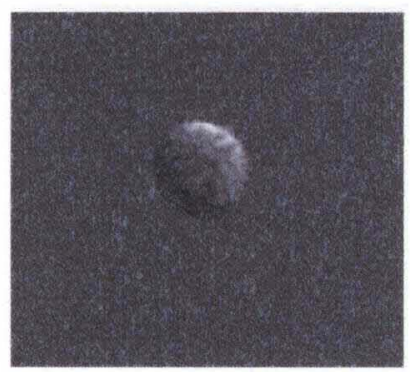

F4/80 FITC

Overlay

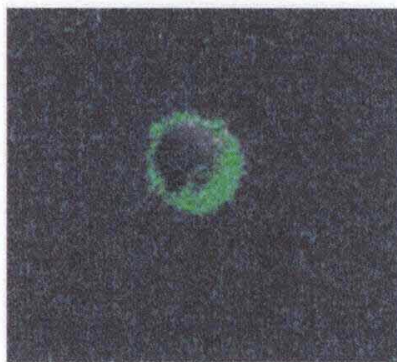

Figure 22. A: 5-7 days post peritoneal thioglycollate injection, peritoneal macrophages were harvested via lavage (left image). Macrophage phenotype was confirmed through FITC labelled F4/80 surface staining (right image). B: Confocal microscopy confirms expected macrophage phenotype (brightfield image at left) and surface F4/80 staining (overlay image at right). 


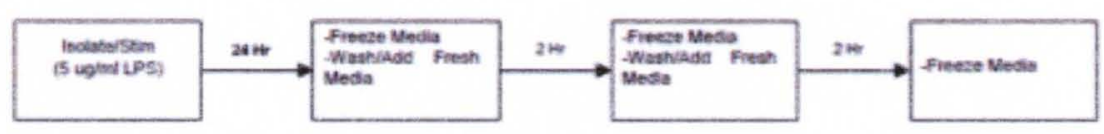

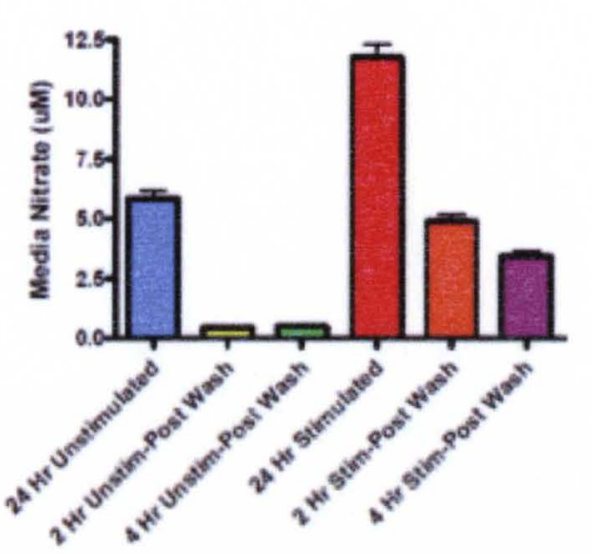

c)

B)

Figure 23: A: Isolated macrophage function was determined via the outlined protocol. B: One day post LPS stimulation, macrophages are active and produced 2.5-fold higher amounts of NOx. This activation continued after withdrawal of the initial stimulus. C: Freshly isolated cardiomyocytes exhibited normal morphological features. 


\section{LPS-Stimulated Macrophages Induce Contractile Dysfunction Upon}

\section{Attachment to Cardiomyocytes}

Upon introduction of LPS-stimulated peritoneal macrophages into the cardiomyocyte co-culture chamber, macrophages settled and attached to the surface of surrounding cardiomyocytes (Movie 1, Figure 24). When stimulated at $1 \mathrm{~Hz}$, the normal myocyte sarcomeric shortening was depressed approximately $50 \%$ from baseline ( $4.8 \pm 1.9$ vs $10.5 \pm 2.1 \%$ shortening $)$ and the duration of contraction increased. (Figure 24 Lower)

\section{Naïve Cardiomyocyte}

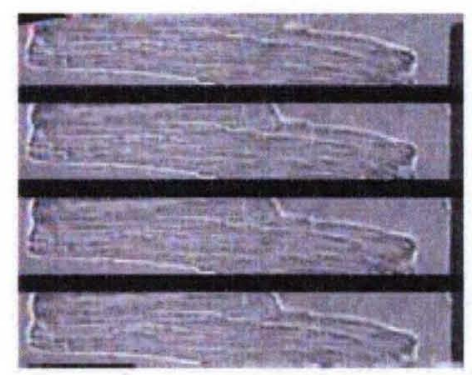

\section{Macrophage Attachment}

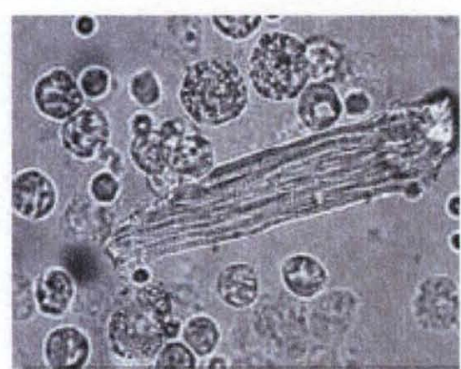

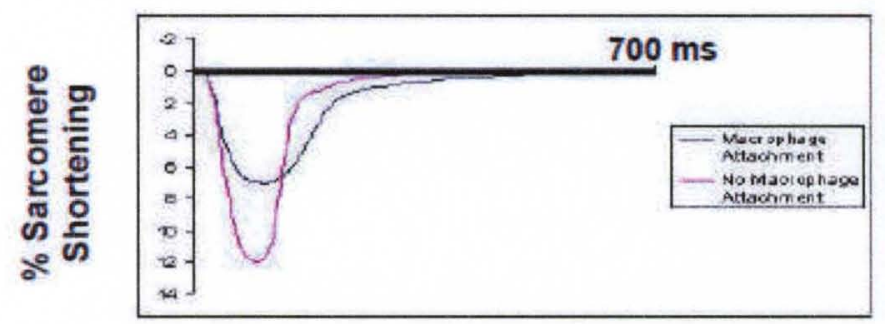

Figure 24. Upper: Movie of normal cardiomyocyte contraction at $1 \mathrm{~Hz}$ in naïve and macrophage-attached cell. Lower: Representative contraction trace depicting both contractile depression and lengthening of the time of contraction upon macrophage attachment. 


\section{LPS-Stimulated Macrophages cause Myocyte Dysfunction in a Juxtacrine}

but not Paracrine Manner

While it was an important finding that macrophage attachment to myocytes induced contractile dysfunction, it was equally important to determine whether these cells can exert detrimental effects in a paracrine fashion in the absence of attachment. This is especially important in the setting of the failing heart, where infiltrating cells may or may not be in direct contact with a given cardiomyocyte. In fact, in Aim 1 we have shown that while macrophages infiltrate the failing heart and are active, they do so in small but sufficient numbers. Therefore, one could conclude that macropahges are able to either: 1) exert influences in small numbers via paracrine effects in the local microenvironment or 2) exert effects in the local environment via process extension and direct contact with cardiomyocytes. Sarcomeric shortening in cardiomyocytes both in close approximation to, but not in contact with, and in direct physical contact with LPSactivated macrophages was measured via co-culture field stimulation and lonOptix imaging software. Group data revealed that while cardiomyocyte sarcomeric shortening was significantly depressed from baseline levels upon direct physical contact with LPS stimulated macrophages $(10.19 \pm 2.74$ vs. 4.96 $\pm 1.97 \%$ shortening) there was no significant difference in the unattached group (10.19 \pm 2.74 vs. $9.26 \pm 3.54 \%$ shortening) despite cell-cell proximity between macrophages and cardiomyocytes in this group. (Figure 25) This finding 
represents one of the first reports detailing the significant role of physical cell-tocell contact in mycoyte dysfunction.

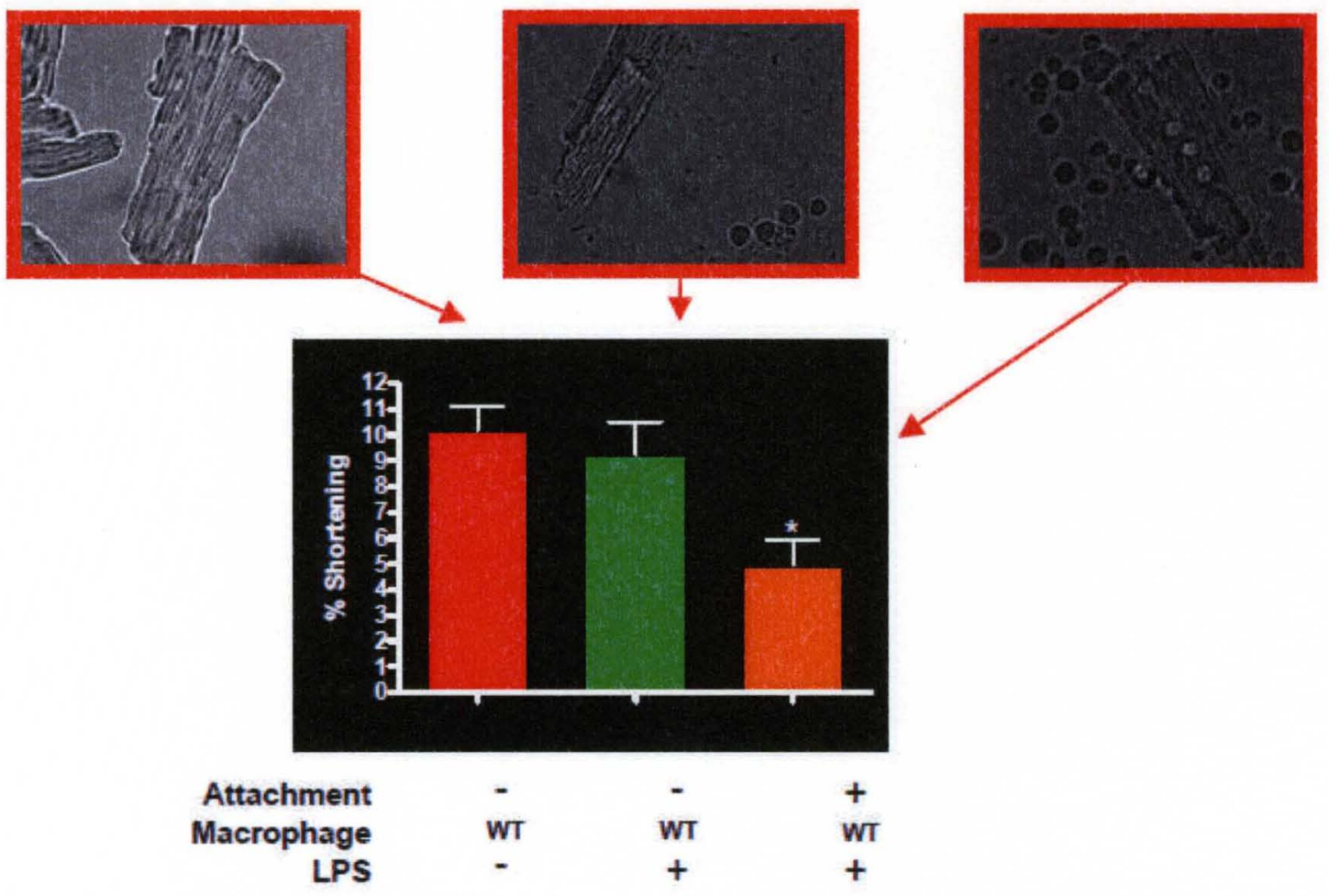

Figure 25. Representative images and group data for myocyte sarcomeric shortening at baseline (left), upon close proximity of macrophages but no attachment (paracrine response, center), and upon macrophage attachment (juxtacrine response, right).

Importantly, no significant change in cardiomyocyte function was noted from baseline levels when non-stimulated, naïve macrophages were physically attached to myocytes (data not shown). This important distinction clearly 
implicates the role of the activated macrophage in the pathogenesis of myocyte dysfunction and correlates closely with our previous data implicating the activated, infiltrating peripheral blood macrophages in the pathogenesis of cardiac dysfunction in HF.

\section{Heart Failure-Derived Macrophages are Sufficiently Activated to Induce Cardiomyocyte Contractile Depression}

Having shown that LPS-stimulated macrophages induce contractile dysfunction, we next examined whether tissue macrophages in heart failure are sufficiently activated to mirror this response. As shown in Figure 26A, in the absence of cell attachment, wild-type heart failure-derived macrophages did not depress myocyte contraction over baseline (11.6 \pm 1.3 vs. $9.6 \pm 3.1 \%$ shortening), again suggesting the lack of a paracrine effect. However, direct physical contact of wild-type, heart failure-derived macrophages induced severe contractile depression analogous to the effects of LPS-stimulated macrophages (4.5 \pm 2.8 vs. $9.6 \pm 3.1 \%$ shortening). Figure $26 \mathrm{~B}$ shows a representative image of macrophage (white arrowhead) attachment to a myocyte using bright field microscopy. 
A.

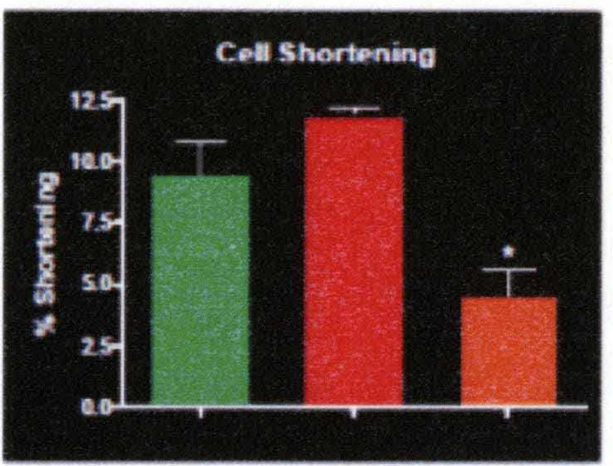

B.

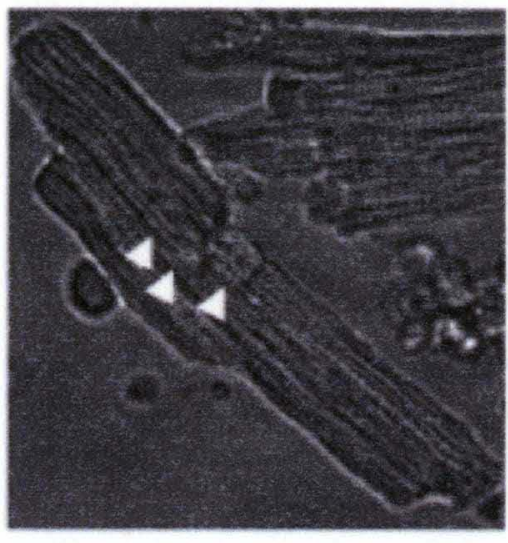

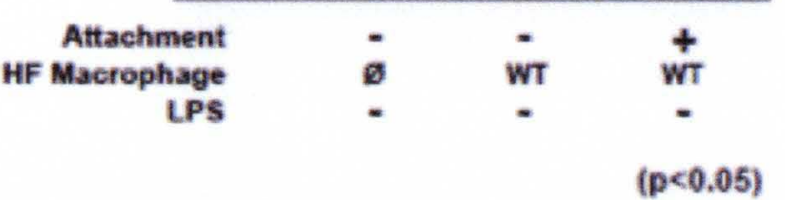

Figure 26. A: Group myocyte contraction data reveal a significant depression in sarcomeric shortening in the attached, WT HF-derived macrophage treated group (orange bar) ( $p=0.001$ vs WT HF unattached). B: Representative example of macrophage (white arrows) attachment to cardiomyocyte. 


\section{HF-Derived Macrophage-Myocyte Physical Interaction Induces Contractile Dysfunction in a TNFR-Divergent Manner}

As our in vivo studies (Aim 1) implicated changes in inflammatory cell-localized TNF receptors 1 and 2 in the pathogenesis of LV remodeling from the molecular level to gross function, we next sought to investigate TNFR specificity in the in vitro cell co-culture model. WT, TNFR $1^{+-}$and TNFR2 ${ }^{-1-}$ mice were subjected to coronary ligation or sham operation. After 4 weeks peritoneal macrophages were isolated via thioglycollate elucidation. Isolated $\mathrm{R}^{-1-}$ and $\mathrm{R} 2^{-1-}$ macrophages were co-cultured with wild-type cardiomyocytes thereby yielding in vitro replicas of our in vivo mouse models. As seen in Figure 27 and in corroboration with our in vivo experiments, ablation of macrophage specific TNFR1 significantly alleviated macrophage-induced myocyte dysfunction. While still significantly depressed from baseline levels, cardiomyocte function was improved from WT HF macrophage attachment levels $(7.06 \pm 1.44$ vs. $5.00 \pm$ $1.54 \%$ shortening). Conversely and still in support of our in vivo data from Aim 1 , specific ablation of TNF receptor 2 exacerbated macrophage-induced cardiomyocyte dysfunction. Specifically, upon attachment of TNFR2 ${ }^{\text {- }}$ macrophages to WT myocytes, myocyte function significantly decreased from both baseline and WT HF macrophage attachment levels $(2.80 \pm 0.19$ vs. $9.39 \pm$ 2.85 vs. $5.00 \pm 1.54 \%$ shortening, respectively). 


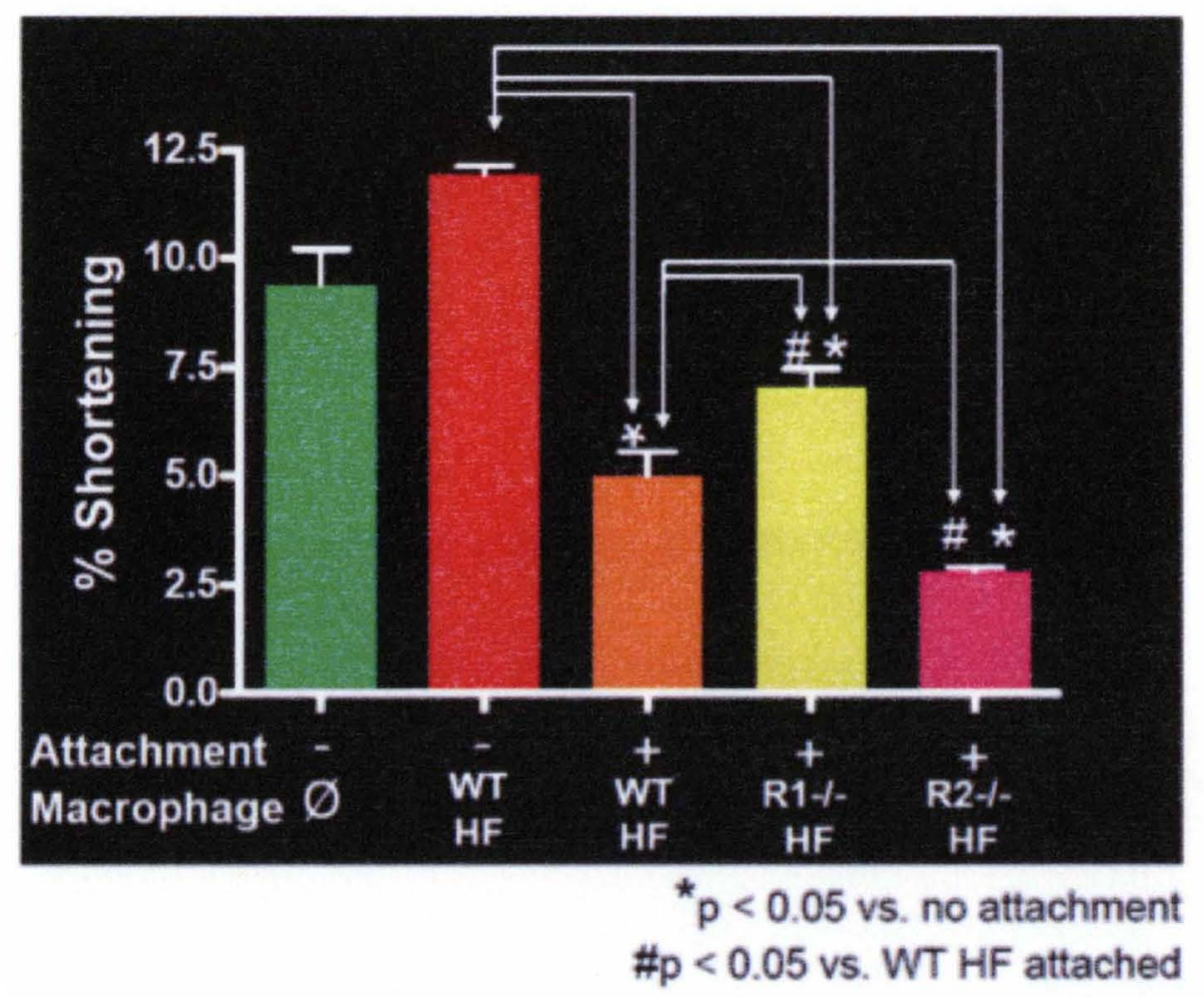

Figure 27: Attachment of wild type HF-derived macrophages imparts a significant dysfunction as compared to baseline cardiomyocyte function. Attachment of $\mathrm{R} 1^{-1} \mathrm{HF}$-derived macrophages improves this dysfunction as compared to WT HF-derived, and attachment of R2-1- HF-derived macrophages exacerbates the inflammatory cell derived dysfunction. 
Taken together these data provide the first known report delineating the role of inflammatory cell-specific TNF receptors on cardiomyocyte function in the in vitro co-cultured macrophage/myocyte functional model. Excitingly, these data corroborate our in vivo, whole animal data thereby further implicating unique TNF receptor-specific effects as central mediators of heart failure pathophysiology.

Heart Failure-Derived Macrophages Stimulate Cardiomyocyte Free Radical Production

While the presented data presented implicate TNF receptors as central mediators in the failing heart they do not uncover the mechanism by which this dysfunction occurs. As generation of free radicals has long been studied as a central and crucial underlying mechanism of cardiomyocyte dysfunction, we studied the production of myocyte ROS in our model. Specifically, we examined the immediate effects of macrophage attachment on the generation of oxygen free radicals within the cardiomyocyte. First, LPS-stimulated macrophages were co-cultured with DCF-loaded myocytes, and fluorescence was observed over the short-term. Macrophage attachment rapidly induced myocyte ROS generation within 15 minutes.(Figure 28) We then performed similar experiments with heart failure derived macrophages and DCF-loaded myocytes. As seen in Figure 30, analogous to the contractile responses, despite close cell-to-cell proximity, wildtype heart failure derived macrophages did not significantly induce myocyte ROS in the absence of cell contact. Conversely, upon physical attachment, there was 


\section{DCF Fluorescence}

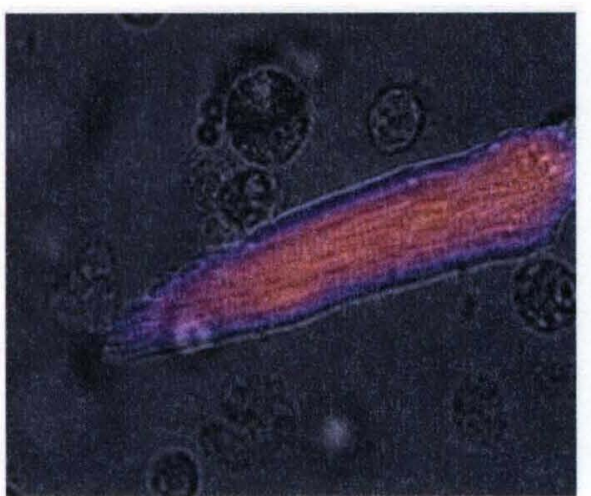

Baseline

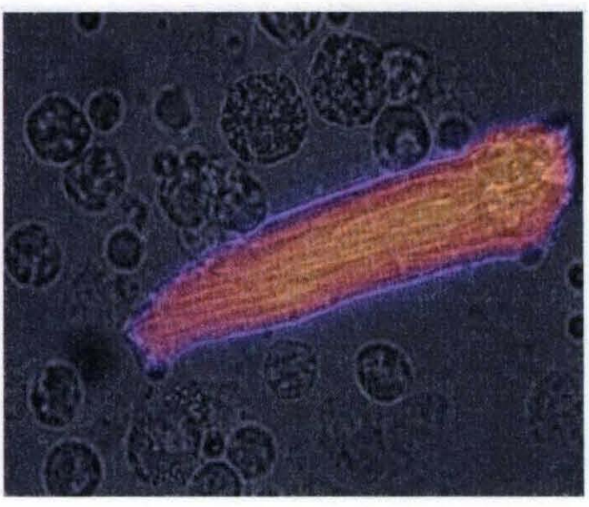

$\square^{170}$

152

134

115

Figure 28: Attachment of wild type HF-derived macrophages to wild type cardiomyocytes induces reactive oxygen species production in the cardiomyocyte 15 minutes post-attachment.

rapid myocyte ROS generation with an increase in DCF fluorescence, as seen in the second row. In contrast, the increase in myocyte ROS was not evident with the attachment of macrophages derived from TNFR $1^{-1}$ heart failure mice, as seen in the third row. Finally, attachment of TNFR2 ${ }^{--}$HF macrophages induced cardiomyocyte free radical production to the same degree as that induced by WT HF macrophages. Interestingly, increases in cardiomyocyte fluorescence occurred in close approximation to the sites of macrophage attachment, as seen in Figure 29, implying a direct, localized activation of the cardiomyocyte by the macrophage and not a more generalized effect. The group data, confirmed the qualitative images (Figure 31). DCF fluorescence was not significantly different from baseline with the attachment of macrophages from wild-type sham mice (- 
$3.21 \pm 3.12)$ or with unattached wild-type heart failure macrophages $(5.19 \pm$ 3.675). However, attachment of wild-type heart failure macrophages significantly augmented myocyte ROS $(31.25 \pm 7.92)$, which was abrogated with the loss of macrophage TNFR1 $(4.85 \pm 2.52)$ and similar upon loss of macrophage TNFR2 $(19.52 \pm 6.94)$. Interestingly, additional stimulation of TNFR $1^{-1-} \mathrm{HF}$ macrophages with LPS still did not result in significant production of ROS upon attachment to myocytes $(1.857 \pm 0.60)$ indicating a TNFR1 inflammatory cell dependent mechanism involved in myocyte ROS production. Hence, heart failure-derived macrophages induced myocyte ROS in a juxtacrine and TNF receptor-dependent manner (Figure 31). These data represent the first known report implicating the role of inflammatory cell specific TNF receptor expression in the production of cardiomyocyte free radical production in heart failure. 


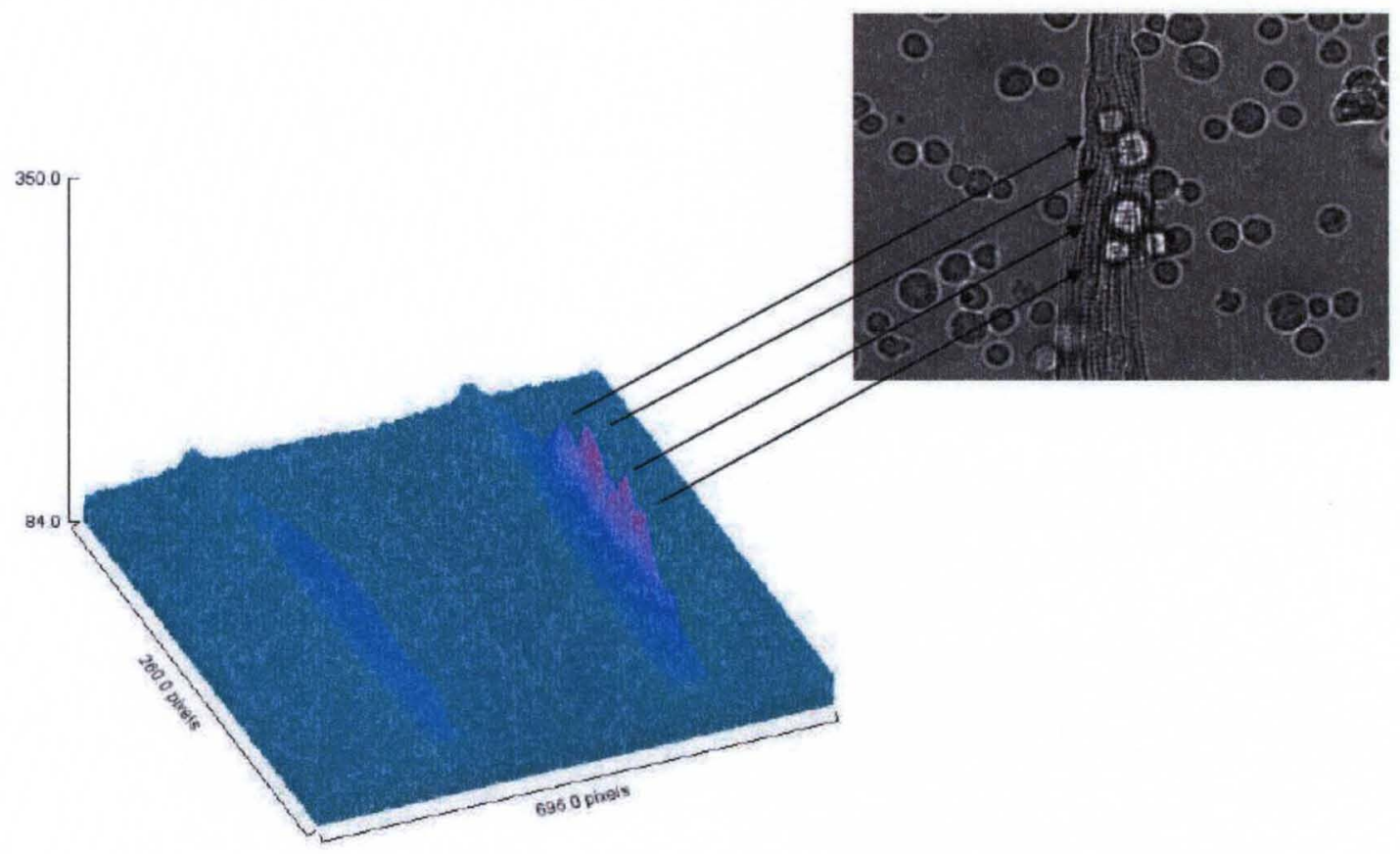

Figure 29: Representative three dimensional computer generated color map depicting increases in cardiomyocyte DCF fluorescence localized to areas of macrophage attachment. 


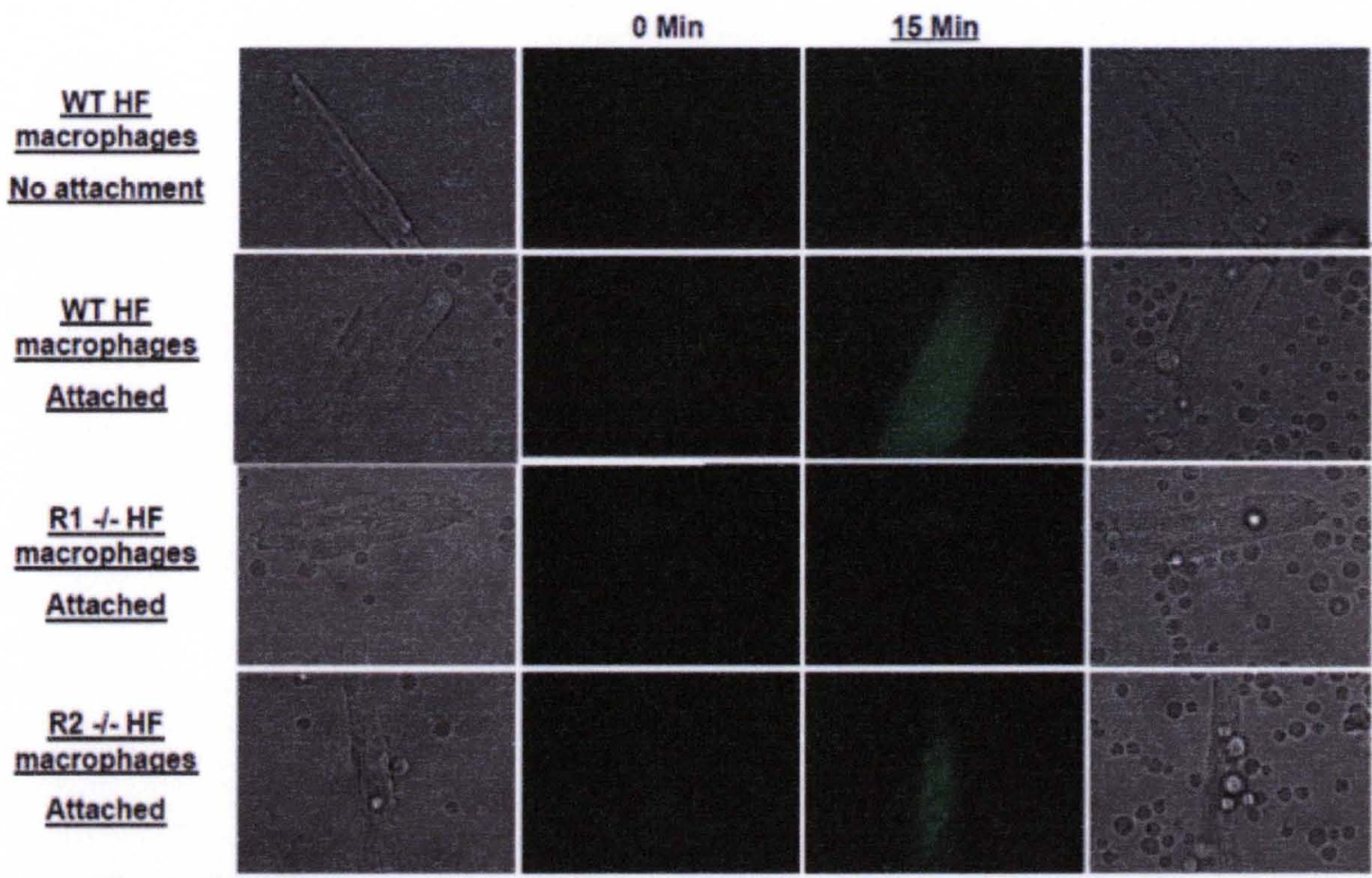

Figure 30: Representative brightfield and DCF fluorescent pictures of cardiomyocytes at baseline and $15 \mathrm{~min}$ post macrophage introduction. At top, WT HF paracrine interaction showed no effect on cardiomyocyte free radical production. Second, upon attachment of WT HF macrophages, myocyte free radical production drastically increased. Third, upon attachment of TNFR1\% HF macrophages, no significant change was seen. Bottom, upon attachment of TNFR2 $2^{-/} \mathrm{HF}$ macrophages, myocytes free radical production was elevated to a level equivalent to WT HF macrophage attachment. 


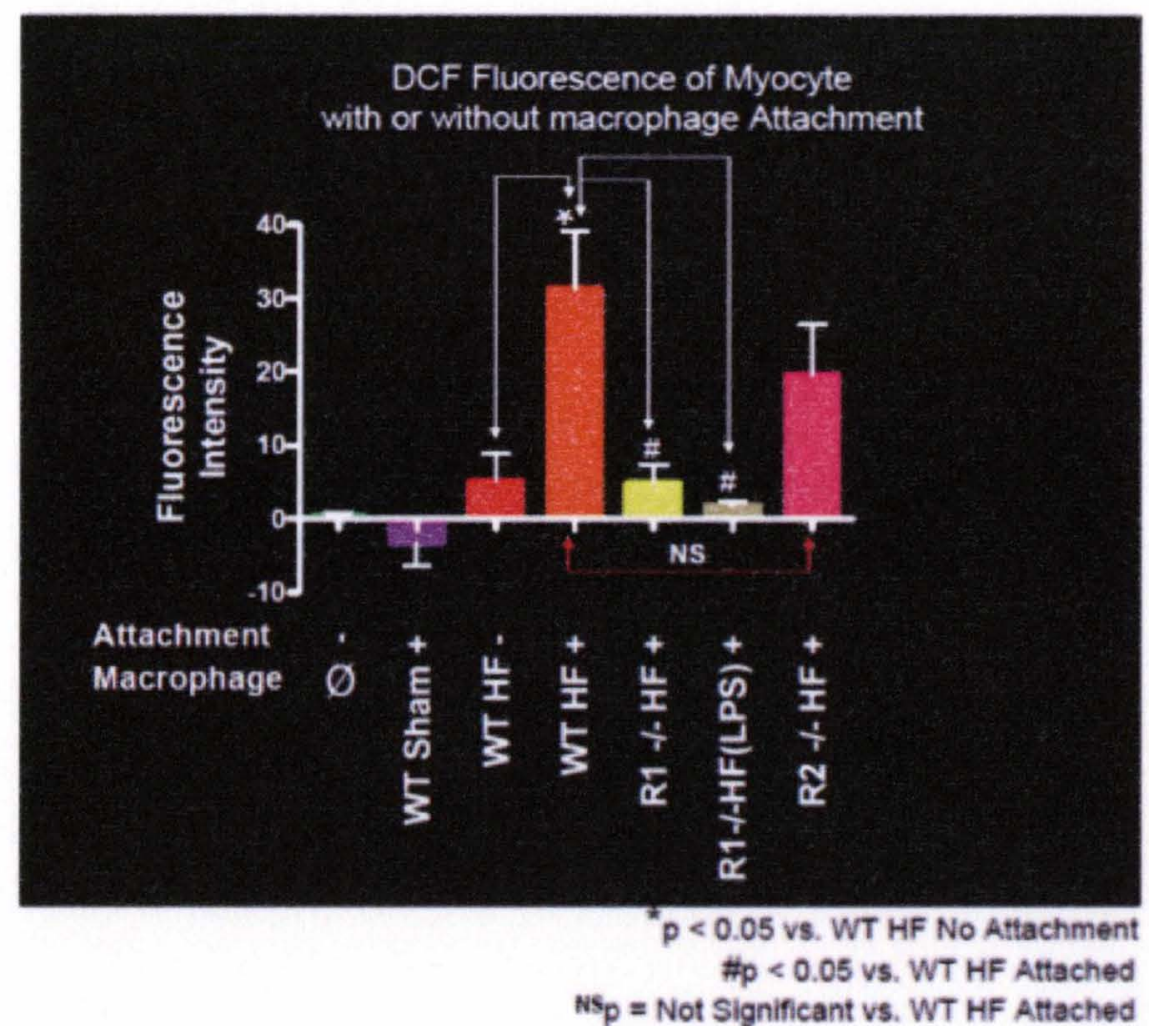

Figure 31: Group quantitative data reveal that upon attachment of WT HF macrophages, a significant increase in fluorescence was observed $\left({ }^{*} \mathrm{p}=0.0147\right)$ within the cardiomyocyte. This increase was present to an equivalent degree upon attachment of TNFR2 ${ }^{-1}$ HF macrophages $(p<0.05)$ but abolished upon attachment of TNFR1 1 macrophages $(p=N S)$. 


\section{Wild Type, TNFR1', and TNFR2 ${ }^{-1}$ Macrophages Attach to Myocytes in Equivalent Numbers}

Stimulation of the membrane TNF receptor has a myriad of downstream effects with one of the most important being the augmented production of several proinflammatory cytokines including TNF. These inflammatory mediators, are also known modulators of cellular adhesion receptors and molecules. Hence, it is possible that alterations in macrophage-induced myocyte dysfunction was related to changes in the magnitude macrophage attachment. To investigate this, we obtained brightfield images at the initiation of macrophage/myocyte contact and 15 minutes post-attachment. The numbers of attached macrophages was determined in the 15 minute post-attachment group and reported as the final number of attached macrophages. As can be seen in Figure 32 there was no significant difference in number of macrophages attached between either the WT, TNFR $1^{\text {t- }}$, or TNFR2 $2^{-1}$ groups, thereby ruling out that these effects were related to greater or fewer macrophages attached to the myocyte. Interestingly, the average number of macrophages attached, four, has previously been reported in our lab in separate studies and suggests a possible "maximal upper limit" of macrophage load carrying ability by the cardiomyocyte. 


\section{Number of Macrophages Attached to Myocyte}

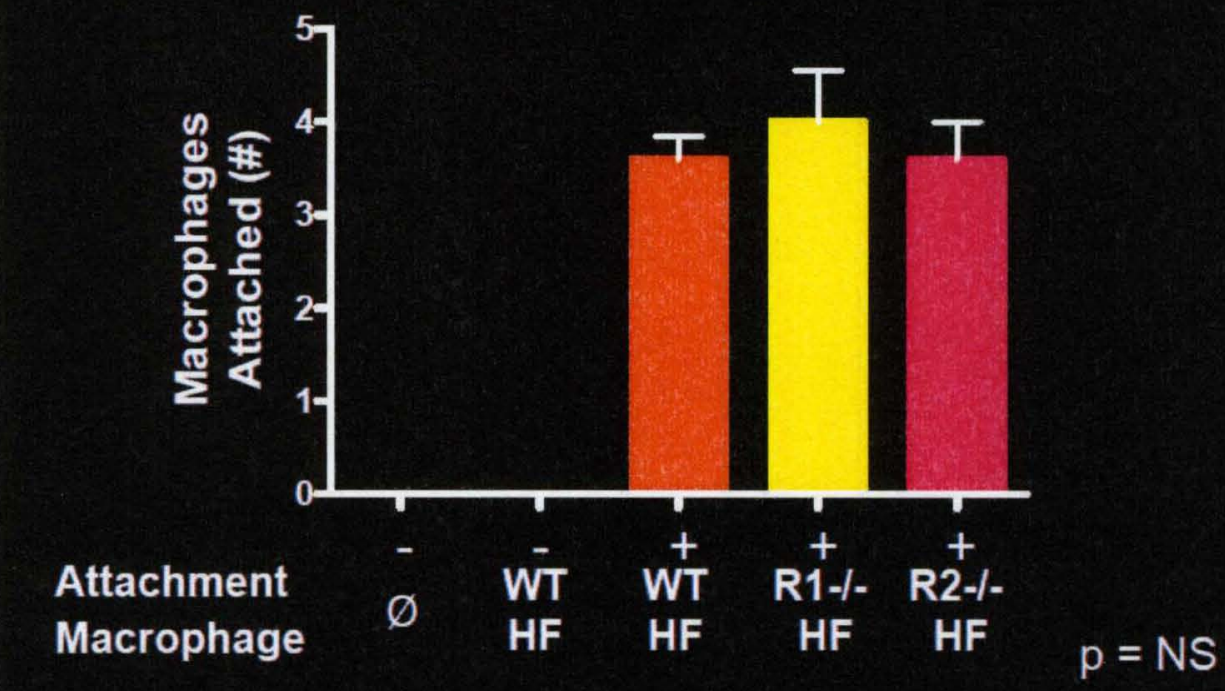

Figure 32: Group data reveal no significant differences in number of macrophages attached to myocytes in WT, TNFR1 $1^{--}$, or TNFR2 ${ }^{--}$groups $(p=N S)$. 


\section{CONCLUSION}

This study demonstrates for the first time that activated macrophages, whether stimulated via LPS or by the HF state, induce contractile depression and oxidative stress in a juxtacrine, but not paracrine manner. In addition, this cell-tocell contact is dependent not only upon physical contact, but also on inflammatory cell TNF receptor signaling. Whereas TNFR1 augments the detrimental inflammatory cell-cardiomyocyte interaction, TNFR2 attenuates the contractile dysfunction but has no effect on ROS production. This suggests that analogous interactions could occur in human HF and that such juxtacrine, receptor dependent responses may represent a therapeutic target in patients. Upon physical attachment, activated macrophages enact detrimental cascades. Free radical production is immediately induced within the cardiomyocyte, which, in turn, leads to cardiomyocyte dysfunction. Whether this is the sole mechanism of dysfunction is still not completely defined; however, this work provides an important step in the quest for this answer. In support of this theory are reports that oxidant radicals inhibit cardiomyocyte contraction via interference with contractile proteins [101]. In order to fully elucidate this mechanism, future studies could be done using antioxidant pre-loaded cardiomyocytes. Overall, these data provide an exciting and important piece of the heart failure puzzle and suggest that modulation of immune cell, specifically macrophage, TNF receptor expression may be an important part of the complex pathological mechanism of the failing heart. 


\section{CHAPTER VI}

\section{SUMMARY OF FINDINGS AND FUTURE DIRECTIONS}

\section{Summary of Findings}

The significance of TNF and inflammation in the pathophysiology of myocardial dysfunction is not an uniformly accepted principle. While the preclinical data regarding the influence of TNF in HF has been overwhelmingly positive, in that antagonism of TNF in various animal models has shown significant protective effects, the clinical data has not been so promising. How could the preclinical and clinical experiments have such dichotomously opposing results? It is likely that TNF has more complex inter and intracellular effects than previously appreciated. Previous work in the Prabhu lab has delineated the dichotomous relationship of the TNF receptors in whole body knockout animals, in that TNFR1 signaling appears detrimental and TNFR2 signaling, on some level beneficial. This study serves to unravel the mystery of TNF even further by determining the influence of inflammatory cell specific TNF receptor expression in HF physiology. The data demonstrated here indicates that modulation of the TNF receptors in the inflammatory compartment can have significant influence over the 
pathological processes involved in post ischemic remodeling. Specifically, loss of TNFR1 in inflammatory cells demonstrated beneficial influences in cardiac remodeling and many of the deleterious processes that define the pathology of HF. Conversely, selective loss of TNFR2 in inflammatory cells did not significantly influence post-infarction cardiac remodeling, or inflammatory cell activation.

Nonetheless, loss of either TNFR1 or TNFR2 in inflammatory cells improved post-infarction survival. This is interesting given that the loss of TNFR2 does not significantly change the phenotype observed in chronic HF. This is of further interest in that it correlates with previously reported data [63] that showed a similar survival benefit in TNFR1 and R2 whole body knockouts.

We also delineated the importance of inflammatory cell and myocyte juxtracrine interactions in myocardial dysfunction and cellular damage. We developed a unique co-culture mechanism to study, in an in vitro manner, the interactions between isolated myocytes and activated macrophages. This technique allows for real time measurement of myocyte function and the generation of reactive oxygen species in response to interactions to macrophages. Using this method we determined that peritoneal macrophages activated by exposure to LPS elicited myocyte contractile dysfunction and ROS generation in a juxtacrine but not paracrine manner. This is interesting from two standpoints. First it shows that activated inflammatory cells can induce significant myocyte dysfunction. 
Secondly, this interaction is dependent on cell-to-cell contact. This finding suggests that pro-inflammatory states in $\mathrm{HF}$ are more than just an epiphenomenon, and actively participate in myocardial dysfunction on the cellular level. Perhaps more interestingly, we found that HF derived macrophages produced a similar level of myocyte dysfunction as LPS-stimulated cells.

Taking this one step further, we examined the selective role of TNF receptors in the macrophage-myocyte interactions. In line with our findings in the in vivo model, selective loss of the TNFR1 receptor in inflammatory cells resulted in less myocyte dysfunction and less ROS production than inflammatory cells possessing either both TNF receptors or those possessing only the TNFR1 receptor. When considered in conjunction with the in vivo studies our finding demonstrates that the inflammatory cell serves as a significant source of myocyte dysfunction observed in $\mathrm{HF}$ and that, at least to some extent, direct cellular interactions between macrophages and myocytes are required for this effect to take place. This work demonstrates the fundamental role of the inflammatory cell in the pathophysiology of chronic HF, as well as the importance of TNF receptor signaling in mediating these effects. Selective modulation of the TNF receptors in the inflammatory compartment can yield dichotomous effects on cardiac remodeling and function following myocardial injury. We have demonstrated that inflammatory cell-localized TNFR1 exacerbates post-infarction remodeling in chronic HF and is required for myocardial pro-inflammatory cytokine generation. Conversely, inflammatory cell-localized TNFR2 yields modest beneficial effects. 


\section{Future Directions}

Heart failure is of paramount importance from a public health standpoint in the U.S., in terms of both patient lives and dollars spent. There are approximately 5 million Americans living with clinically documented HF representing a large percentage of health care expenditure, many times for repeated admissions for the most decompensated patients. In fact, it is the number one Medicare discharge diagnosis. Many of these patients not only spend many of their last months or years in a downward spiral in and out of the hospital but also face a prognosis worse than many cancers. It is therefore of the utmost importance to develop new therapies to combat this malignant condition [100].

This study provides insights into the role of TNF in the failing heart. With the robust nature of the benefit demonstrated in animal models, it is hard to believe that some element of protection is not derived from modulation of TNF expression and signaling. Yet several clinical studies were overwhelmingly negative, showing completely opposite outcomes from those expected. As has been demonstrated in previous work in the Prabhu lab and now with this study, all TNF signaling is not equal, and the cellular interactions and signaling mechanisms at play are much more complicated than previously believed. Discovery of the harmful effects of TNFR1 signaling offer ripe ground to reopen the possibility of using TNF antagonism as a therapeutic approach to chronic HF. 
The development of selective TNFR1 blocking agents in the future could serve to re-establish this potential mode of HF therapy. Other options along this line would be a method by which to negate sTNF, taking advantage of the differences in the two receptors, as TNFR1 binds both sTNF and mTNF and TNFR2 binds primarily mTNF. While this would not be as effective as a TNFR1 antagonist, it would help to switch the balance more in favor of TNFR2 signaling and hopefully improved clinical outcomes.

From a more mechanistic standpoint, our understanding of the role of inflammation in chronic HF is still in its infancy, in that our understanding of the inflammatory compartment and its influence on other organ systems is increasing exponentially from day to day. The data in this study, while unique and groundbreaking, is an early and basic explanation of the interplay between inflammatory cells and the failing myocardium. 


\section{REFERENCES}

1. Eichhorn EJ, Bristow MR. Medical therapy can improve the biological properties of the chronically failing heart: a new era in the treatment of heart failure. Circulation. 1996;94:2285-2296.

2. Mann DL. Mechanisms and models in heart failure: a combinatorial approach. Circulation. 1999;100:999-1008.

3. Jessup M, Brozena S. Heart failure. N Engl J Med. 2003;348:2007-2018.

4. Mann DL, Kent RL, Parsons B, Cooper G IV. Adrenergic effects on the biology of the adult mammalian cardiocyte. Circulation. 1992;85:790-804.

5. Bozkurt B, Kribbs SB, Clubb FJ, Michael LH, Didenko VV, Hornsby PJ, Seta Y, Oral H, Spinale FG,Mann DL. Pathophysiologically relevant concentrations of tumor necrosis factor-a promote progressive left ventricular dysfunction and remodeling in rats. Circulation. 1998;97:1382-1391.

6. Communal C, Singh K, Pimentel DR, Colucci WS. Norepinephrine stimulates apoptosis in adult rat ventricular myocytes by activation of the $\beta$-adrenergic pathway. Circulation. 1998;98:1329-1334.

7. Fraccarollo D, Galuppo P, Schraut S, Kneitz S, van Rooijen N, Ertl G, Bauersachs J. Immediate Mineralocorticoid Receptor Blockade Improves Myocardial Infarct Healing by Modulation of the Inflammatory Response. Hypertension. 2008;51:905-914.

8. Frangogiannis NG, Smith CW, Entman ML. The inflammatory response in myocardial infarction. Cardiovasc Res. 2002;53:31-47.

9. Kang PM, Izumo S. Apoptosis and heart failure: A critical review of the literature. Circ Res. 2000;86:1107-1113.

10. Cesselli D, Jakoniuk I, Barlucchi L, Beltrami AP, Hintze TH, Nadal-Ginard B, Kajstura J, Leri A, Anversa P. Oxidative stress-mediated cardiac cell death is a major determinant of ventricular dysfunction and failure in dog dilated cardiomyopathy. Circ Res. 2001;89:279-286. 
11. Prabhu SD, Wang G, Luo J, Gu Y, Ping P, Chandrasekar B. Beta-adrenergic receptor blockade modulates $\mathrm{Bcl}-\mathrm{X}(\mathrm{S})$ expression and reduces apoptosis in failing myocardium. J Mol Cell Cardiol. 2003;35:483-493.

12. Nishigaki K, Minatoguchi S, Seishima M, Asano K, Noda T, Yasuda N, Sano $H$, Kumada $H$, Takemura M, Noma A, Tanaka T, Watanabe S, Fujiwara $H$.

Plasma Fas ligand, an inducer of apoptosis, and plasma soluble Fas, an inhibitor of apoptosis, in patients with chronic congestive heart failure. J Am

Coll Cardiol. 1997;29:1214-1220.

13. Prabhu SD. Post-infarction ventricular remodeling: an array of molecular events. J Mol Cell Cardiol. 2005;38:547-550.

14. Beuckelmann DJ, Nabauer M, Erdmann E. Intracellular calcium handling in isolated ventricular myocytes from patients with terminal heart failure. Circulation. 1992;85:1046-1055.

15. Bing OHL, Brooks WW, Conrad CH, Sen S, Perreault CL, Morgan JP. Intracellular calcium transients in myocardium from spontaneously hypertensive rats during the transition to heart failure. Circ Res.1991;68:1390-1400.

16. O'Rourke B, Kass DA, Tomaselli GF, Kääb S, Tunin R, Marbán E. Mechanisms of altered excitationcontraction coupling in canine tachycardia-induced heart failure, I: Experimental studies. Circ Res. 1999;84:562-570.

17. Pieske B, Kretschmann B, Meyer M, Holubarsch C, Weirich J, Posival H, Minami $\mathrm{K}$, Just $\mathrm{H}$, Hasenfuss $\mathrm{G}$. Alterations in intracellular calcium handling associated with the inverse force-frequency relation in human dilated cardiomyopathy. Circulation. 1995;92:1169-1178.

18. Prabhu SD, Freeman GL. Effect of tachycardia heart failure on the restitution of left ventricular function in closed-chest dogs. Circulation. 1995;91:176-185.

19. Bristow MR. Mechanism of action of beta-blocking agents in heart failure. Am J Cardiol.1997;80(11A):26L-40L.

20. Maurice JP, Shah AS, Kypson AP, Hata JA, White DC, Glower DD, Koch WJ. Molecular $\beta$-adrenergic signaling abnormalities in failing rabbit hearts after infarction. Am J Physiol. 1999;276:H1853-H1860.

21. Kiuchi K, Shannon RP, Komamura K, Cohen DJ, Bianchi C, Homcy CJ, Vatner SF, Vatner DE. Myocardial $\beta$-adrenergic receptor function during the development of pacing-induced heart failure. J Clin Invest. 1993;91:907-914. 
22. Sawyer DB, Siwik DA, Xiao L, Pimentel DR, Singh K, Colucci WS. Role of oxidative stress in myocardial hypertrophy and failure. J Mol Cell Cardiol. 2002;34:379-388.

23. Mak S, Lehotay DC, Yazdanpanah M, Azevedo ER, Liu PP, Newton GE. Unsaturated aldehydes including 4-OH-nonenal are elevated in patients with congestive heart failure. J Cardiac Failure. 2000;6:108-114.

24. Mallat Z, Philip I, Lebret M, Chatel D, Maclouf J, Tedgui A. Elevated levels of 8-iso-prostaglandin $F 2 \alpha$ in pericardial fluid of patients with heart failure: $A$ potential role for in vivo oxidant stress in ventricular dilatation and progression to heart failure. Circulation. 1998;97:1536-1539.

25. Ide T, Tsutsui H, Kinugawa S, Suematsu N, Hayashidani S, Ichikawa K, Utsumi H, Machida Y, Egashira K, Takeshita A. Direct evidence for increased hydroxyl radicals originating from superoxide in the failing myocardium. Circ Res. 2000;86:152-157.

26. Kinugawa S, Tsutsui H, Hayashidani S, Ide T, Suematsu N, Satoh S, Utsumi $H$, Takeshita A. Treatment with dimethylthiourea prevents left ventricular remodeling and failure after experimental myocardial infarction in mice: role of oxidative stress. Circ Res. 2000;87:392-398.

27. Conraads VM, Bosmans JM, Vrints CJ. Chronic heart failure: an example of a systemic chronic inflammatory disease resulting in cachexia. Int J Cardiol. 2002;85:33-49.

28. Mann DL. Inflammatory mediators and the failing heart: past, present, and the foreseeable future. Circ Res. 2002;91:988-998.

29. Torre-Amione G, Kapadia S, Lee J, Durand J-B, Bies RD, Young JB, Mann $D L$. Tumor necrosis factor- $\alpha$ and tumor necrosis factor receptors in the failing human heart. Circulation. 1996;93:704-711.

30. Testa M, Yeh M, Lee P, Fanelli R, Loperfido F, Berman JW, LeJemtel T. Circulating levels of cytokines and their endogenous modulators in patients with mild to severe congestive heart failure due to coronary artery disease or hypertension. J Am Coll Cardiol. 1996;28:964-971.

31. Tsutamoto T, Hisanaga T, Wada A, Maeda K, Ohnishi M, Fukai D, Mabuchi N, Sawaki M, Kinoshita M. Interleukin-6 spillover in the peripheral circulation increases with the severity of heart failure, and the high plasma level of interleukin- 6 is an important prognostic predictor in patients with congestive heart failure. J Am Coll Cardiol. 1998;31:391-398. 
32. Stumpf C, Lehner C, Yilmaz A, Daniel WG, Garlichs CD. Decrease of serum levels of the anti-inflammatory cytokine interleukin-10 in patients with advanced chronic heart failure. Clin Sci (Lond) 2003;105:45-50.

33. Bolger AP, Sharma R, von Haehling S, Doehner W, Oliver B, Rauchhaus $M$, Coats AJ, Adcock IM, Anker SD. Effect of interleukin-10 on the production of tumor necrosis factor-alpha by peripheral blood mononuclear cells from patients with chronic heart failure. Am J Cardiol 2002;90:384-389.

34. Kapadia S, Dibbs Z, Kurrelmeyer K, Kalra D, Seta Y, Wang F, Bozkurt B, Oral $\mathrm{H}$, Sivasubramanian N, Mann DL. The role of cytokines in the failing human heart. Cardiol Clin.1998 Nov;16(4):645-56, viii.

35. Oral H, Kapadia S, Nakano M, Torre-Amione G, Lee J, Lee-Jackson D, Young JB, Mann DL. Tumor necrosis factor-alpha and the failing human heart. Clin Cardiol. 1995 Sep;18 (9 Suppl 4):IV20-7.

36. Francis SE, Holden H, Holt CM, Duff GW. Interleukin-1 in myocardium and coronary arteries of patients with dilated cardiomyopathy. J Mol Cell Cardiol. 1998;30:215-223.

37. Prabhu SD, Chandrasekar B, Murray DR, Freeman GL. $\beta$-Adrenergic blockade in developing heart failure: effects on myocardial inflammatory cytokines, nitric oxide, and remodeling. Circulation 2000;101:2103-2109.

38. Ono K, Matsumori A, Shioi T, Furukawa Y, Sasayama S. Cytokine gene expression after myocardial infarction in rat hearts. Possible implication in left ventricular remodeling. Circulation. 1998;98:149-156.

39. Deswal A, Petersen NJ, Feldman AM, Young JB, White BG, Mann DL. Cytokines and cytokine receptors in advanced heart failure: an analysis of the cytokine database from the Vesnarinone trial (VEST). Circulation.

2001;103:2055-2059.

40. Rauchhaus M, Doehner W, Francis DP, Davos C, Kemp M, Liebenthal C, Niebauer J, Hooper J, Volk HD, Coats AJ, Anker SD. Plasma cytokine parameters and mortality in patients with chronic heart failure. Circulation. 2000;102:3060-3067.

41. Finkel MS, Oddis CV, Jacob TD, Watkins SC, Hattler BG, Simmons RL. Negative inotropic effects ofcytokines on the heart mediated by nitric oxide. Science. 1992;257:387-9.

42. Yokoyama T, Vaca L, Rossen RD, Durante W, Hazarika P, Mann DL. Cellular basis for the negative inotropic effects of tumor necrosis factor- $\alpha$ in the adult mammalian heart. J Clin Invest. 1993;92:2303-12. 
43. Prabhu SD. Cytokine-induced modulation of cardiac function. Circ Res. 2004;95:1140-1153.

44. Yokoyama T, Nakano M, Bednarczyk JL, Mclntyre BW, Entman M, Mann DL. Tumor necrosis factor- $\alpha$ provokes a hypertrophic growth response in adult cardiac myocytes. Circulation. 1997;95:1247-1252.

45. Krown KA, Page MT, Nguyen C, Zechner D, Gutierrez V, Comstock KL, Glembotski CC, Quintana PJE,Sabbadini RA. Tumor necrosis factor- $\alpha$-induced apoptosis in cardiac myocytes. Involvement of the sphingolipid signaling cascade in cardiac cell death. J Clin Invest. 1996;98:2854-2865.

46. Moe, GW, Marin-Garcia,J, Konig,A, Goldenthal,M, Lu,X, Feng,Q. In vivo TNF$\alpha$ inhibition ameliorates cardiac mitochondrial dysfunction, oxidative stress, and apoptosis in experimental heart failure. Am JPhysiol Heart Circ Physiol. 2004;287:1813-1820.

47. Sivasubramanian N, Coker ML, Kurrelmeyer KM, MacLellan WR, DeMayo FJ, Spinale FG, Mann DL. Left ventricular remodeling in transgenic mice with cardiac restricted overexpression of tumor necrosis factor. Circulation. 2001; $104: 826-831$.

48. Kubota T, McTiernan CF, Frye CS, Slawson SE, Lemster BH, Koretsky AP, Demetris AJ, Feldman AM. Dilated cardiomyopathy in transgenic mice with cardiac-specific overexpression of tumor necrosis factor- $\alpha$. Circ Res. 1997;81:627-635.

49. Bryant D, Becker L, Richardson J, Shelton J, Franco F, Peshock R, Thompson M, Giroir B. Cardiac failure in transgenic mice with myocardial expression of tumor necrosis factor-a. Circulation. 1998;97:1375-1381.

50. Feldman,AM, Kadokami,T, Higuichi,Y, Ramani,R, McTiernan,CF. The role of anticytokine therapy in heart failure: recent lessons from preclinical and clinical trials? Med Clin North Am. 2003;87:419-440.

51. Tracey KJ, Vlassara $\mathrm{H}$, Cerami A. Cachectin/tumour necrosis factor. Lancet. 1989;1(8647):1122-1126.

52. Li, YY, Feng, YQ, Kadokami,T, McTiernan,CF, Draviam,R, Watkins,SC, Feldman,AM. Myocardial extracellular matrix remodeling in transgenic mice overexpressing tumor necrosis factor- $\alpha$ can be modulated by anti-tumor necrosis factor- $\alpha$ therapy. Proc Natl Acad Sci USA. 2000;97:12746-51.

53. Iversen PO, Nicolaysen G, Sioud M. DNA enzyme targeting TNF- $\alpha$ mRNA improves hemodynamic performance in rats with postinfarction heart failure. Am J Physiol Heart Circ Physiol. 2001;281:H2211-H2217. 
54. Berthonneche C, Sulpice T, Boucher F, Gouraud L, de Leiris J, O'Connor SE, Herbert JM, Janiak P. New insights into the pathological role of TNF-a in early cardiac dysfunction and subsequent heart failure after infarction in rats. Am J Physiol Heart Circ Physiol. 2004;287:H340-H350.

55. Sugano $M$, Tsuchida $K$, Hata T, Makino N. In vivo transfer of soluble TNFalpha receptor 1 gene improves cardiac function and reduces infarct size after myocardial infarction in rats. FASEB J. 2004;18:911-913.

56. Berry MF, Woo YJ, Pirolli TJ, Bish LT, Moise MA, Burdick JW, Morine KJ, Jayasankar V, Gardner TJ, Sweeney HL. Administration of a tumor necrosis factor inhibitor at the time of myocardial infarction attenuates subsequent ventricular remodeling. J Heart Lung Transplant. 2004;23:1061-1068.

57. Gurantz D, Yndestad A, Halvorsen B, Lunde OV, Omens JH, Ueland T, Aukrust P, Moore CD, Kjekshus J, Greenberg BH. Etanercept or intravenous immunoglobulin attenuates expression of genes involved in post-myocardial infarction remodeling. Cardiovasc Res. 2005;67:106-115.

58. Anker SD, Coats AJ. How to RECOVER from RENAISSANCE? The significance of the results of RECOVER, RENAISSANCE, RENEWAL and ATTACH. Int J Cardiol. 2002;86:123-130.

59. Kurrelmeyer K, Michael L, Baumgarten G, Taffet G, Peschon J, Sivasubramanian N, Mann DL. Endogenous myocardial tumor necrosis factor protects the adult cardiac myocyte against ischemicinduced apoptosis in a murine model of acute myocardial infarction. Proc Natl Acad Sci USA. 2000;290:5456-5461.

60. Lecour S, Smith RM, Woodward B, Opie LH, Rochette L, Sack MN. Identification of a novel role for sphingolipid signaling in TNF- $\alpha$ and ischemic preconditioning mediated cardioprotection. J Mol Cell Cardiol. 2002;34:509-518.

61. Machado FS, Martins GA, Aliberti JC, Mestriner FL, Cunha FQ, Silva JS. Trypanosoma cruzi-infected cardiomyocytes produce chemokines and cytokines that trigger potent nitric oxide-dependent trypanocidal activity. Circulation. 2000;102:3003-3008.

62. Wada,H, Saito,K, Kanda,T, Kobayashi,I, Fujii,H, Fujigaki,S, Maekawa,N, Takatsu,H, Fujiwara,H, Sekikawa,K, Seishima,M. Tumor necrosis factor-a (TNFa) plays a protective role in acute viralmyocarditis in mice: A study using mice lacking TNF- $\alpha$. Circulation 2001;103:743-9. 
63. Hamid T, Gu Y, Ortines R, Bhattacharya C, Wang GW, Xuan YT, Prabhu SD. Divergent TNF receptor-related remodeling responses in heart failure: role of NFKB and inflammatory activation. Circulation. 2009;119:1386-97.

64. Wajant $\mathrm{H}$, Pfizenmaier $\mathrm{K}$, Scheurich $\mathrm{P}$. Tumor necrosis factor signaling. Cell Death Differ. 2003;10:45-65.

65. MacEwan DJ. TNF receptor subtype signalling: differences and cellular consequences. Cell Signal. 2002;14:477-492.

66. Aggarwal BB. Signalling pathways of the TNF superfamily: a double-edged sword. Nat Rev Immunol. 2003;3:745-756.

67. Varfolomeev EE, Ashkenazi A. Tumor necrosis factor: an apoptosis JuNKie? Cell. 2004;116:491-497.

68. Muppidi JR, Tschopp J, Siegel RM. Life and death decisions: secondary complexes and lipid rafts in TNF receptor family signal transduction. Immunity. 2004;21:461-465.

69. Gupta S. Molecular steps of tumor necrosis factor receptor-mediated apoptosis. Curr Mol Med. 2001;1:317-324.

70. Grell M, Douni E, Wajant H, Lohden M, Clauss M, Maxeiner B, Georgopoulos S, Lesslauer W, Kollias G, Pfizenmaier K, Scheurich P. The transmembrane form of tumor necrosis factor is the prime activating ligand of the $80 \mathrm{kDa}$ tumor necrosis factor receptor. Cell. 1995;83:793-802.

71. Torre-Amione G, Kapadia S, Lee J, Bies RD, Lebovitz R, Mann DL. Expression and functional significance of tumor necrosis factor receptors in human myocardium. Circulation. 1995;92:1487-1493.

72. Diwan A, Dibbs Z, Nemoto S, Defreitas G, Carabello BA, Sivasubramanian N, Wilson EM, Spinale FG, Mann DL. Targeted overexpression of noncleavable and secreted forms of tumor necrosis factor provokes disparate cardiac phenotypes. Circulation 2004;109:262-268.

73. Fontaine V, Mohand-Said S, Hanoteau N, Fuchs C, Pfizenmaier K, Eisel U. Neurodegenerative and neuroprotective effects of tumor Necrosis factor (TNF) in retinal ischemia: opposite roles of TNF receptor 1 and TNF receptor 2. J Neurosci. 2002;22:RC216:1-7.

74. Kontoyiannis D, Pasparakis M, Pizarro TT, Cominelli F, Kollias G. Impaired on/off regulation of TNF biosynthesis in mice lacking TNF AU-rich elements: implications for joint and gut-associated immunopathologies. Immunity. 1999;10:387-398. 
75. Yndestad A, Damas JK, Geir Eiken H, Holm T, Haug T, Simonsen S, Froland SS, Gullestad L, Aukrust P. Increased gene expression of tumor necrosis factor superfamily ligands in peripheral blood mononuclear cells during chronic heart failure. Cardiovasc Res. 2002;54:175-82.

76. Devaux B, Scholz D, Hirche A, Klovekorn WP, Schaper J. Upregulation of cell adhesion molecules and the presence of low grade inflammation in human chronic heart failure. Eur Heart J. 1997;18:470-479.

77. Kuhl U, Noutsias M, Schultheiss HP. Immunohistochemistry in dilated cardiomyopathy. Eur Heart J. 1995;16 Suppl O:100-106.

78. Shioi $T$, Matsumori A, Kihara $Y$, Inoko M, Ono K, Iwanaga $Y$, Yamada $T$, Iwasaki A, Matsushima K, Sasayama S. Increased expression of interleukin-1 $\beta$ and monocyte chemotactic and activating factor/monocyte chemoattractant protein-1 in the hypertrophied and failing heart with pressure overload. Circ Res. 1997;81:664-671.

79. Badorff C, Noutsias M, Kuhl U, Schultheiss HP. Cell-mediated cytotoxicity in hearts with dilated cardiomyopathy: correlation with interstitial fibrosis and foci of activated T lymphocytes. J Am Coll Cardiol 1997;29:429-434.

80. Kuhl U, Noutsias M, Seeberg B, Schultheiss HP. Immunohistological evidence for a chronic intramyocardial inflammatory process in dilated cardiomyopathy. Heart. 1996;75:295-300.

81. Kherani AR, Moss GW, Zhou H, Gu A, Zhang G, Schulman AR, Fal JM, Sorabella R, Plasse T, Rui L, Homma S, Burkhoff D, Oz MC, Wang J. Macrophage inhibitor, semapimod, reduces tumor necrosis factor-alpha in myocardium in a rat model of ischemic heart failure. J Cardiovasc Pharmacol. 2004;44:665-71.

82. Gordon S, Taylor PR. Monocyte and macrophage heterogeneity. Nat Rev Immunol. 2005;5:953-64.

83. Klimp AH, de Vries EG, Scherphof GL, Daemen T. A potential role of macrophage activation in the treatment of cancer. Crit Rev Oncol Hematol. 2002;44:143-61.

84. Tavener SA, Long EM, Robbins SM, McRae KM, Van Remmen $H$, Kubes $P$. Immune cell Toll-like receptor 4 is required for cardiac myocyte impairment during endotoxemia. Circ Res. 2004;95:700-7. 
85. Luoma JS, Stralin P, Marklund SL, Hiltunen TP, Sarkioja T, Yla-Herttuala S. Expression of extracellular SOD and iNOS in macrophages and smooth muscle cells in human and rabbit atherosclerotic lesions: colocalization with epitopes characteristic of oxidized LDL and peroxynitrite-modified proteins.

Arterioscler Thromb Vasc Biol. 1998;18:157-167.

86. White CR, Brock TA, Chang LY, Crapo J, Briscoe P, Ku D, Bradley WA, Gianturco SH, Gore J, Freeman BA, et al. Superoxide and peroxynitrite in atherosclerosis. Proc Natl Acad Sci U S A. 1994;91:1044-1048.

87. Poon BY, Ward CA, Cooper CB, Giles WR, Burns AR, Kubes P. Alpha(4)integrin mediates neutrophilinduced free radical injury to cardiac myocytes. $J$ Cell Biol. 2001;152:857-866.

88. Johnston RB Jr, Kitagawa S. Molecular basis for the enhanced respiratory burst of activated macrophages. Fed Proc. 1985;44:2927-32.

89. Poon BY, Raharjo E, Patel KD, Tavener S, Kubes P. Complexity of inducible nitric oxide synthase: cellular source determines benefit versus toxicity.

Circulation. 2003;108:1107-1112.

90. Pfeffer K; Matsuyama T; Kundig TM; Wakeham A; Kishihara K; Shahinian A; Wiegmann K; Ohashi PS; Kronke M; Mak TW. 1993. Mice deficient for the $55 \mathrm{kd}$ tumor necrosis factor receptor are resistant to endotoxic shock, yet succumb to L. monocytogenes infection. Cell 73(3):457-67.

91. Erickson SL; de Sauvage FJ; Kikly K; Carver-Moore K; Pitts-Meek S; Gillett N; Sheehan KC; Schreiber RD; Goeddel DV; Moore MW. 1994. Decreased sensitivity to tumour-necrosis factor but normal T-cell development in TNF receptor-2-deficient mice. Nature 372(6506):560-3.

92. Wang G, Hamid T, Keith RJ, Zhou G, Partridge CR, Xiang X, Kingery JR, Lewis RK, Li Q, Rokosh DG, Ford R, Spinale FG, Riggs DW, Srivastava S, Xuan Y-T, Bhatnagar A, Bolli R, Prabhu SD. Cardioprotective and anti-apoptotic effects of heme oxygenase-1 in the failing heart. Circulation. 2010 May: 4;121(17):191225.

93. Livak KJ, Schmittgen TD. Analysis of relative gene expression data using real-time quantitative PCR and the 2-DDCT method. Methods. 2001;25;402-408.

94. American Association for Laboratory Animal Science. Animal Care and Use in Research and Education. https://www.aalaslearninglibrary.org. 2005.

95. Urban JL, Shepard HM, Rothstein JL, Sugarman BJ, Schreiber H. Tumor necrosis factor: a potent effector molecule for tumor cell killing by activated macrophages. Proc Natl Acad Sci U S A. 1986 Jul;83(14):5233-7. 
96. Kohlhaas M, Liu T, Knopp A, Zeller T, Ong MF, Böhm M, O'Rourke B, Maack C. Elevated Cytosolic $\mathrm{Na}+$ Increases Mitochondrial Formation of Reactive Oxygen Species in Failing Cardiac Myocytes. Circulation. 2010 Mar 29.

97. Dhalla NS, Saini-Chohan HK, Rodriguez-Leyva D, Elimban V, Dent MR, Tappia PS. Subcellular remodelling may induce cardiac dysfunction in congestive heart failure. Cardiovasc Res. 2009 Feb 15;81(3):429-38.

98. Nelson, D.S. Macrophages and Immunity. New York N.Y: American Elsevier Publishing Company. 1969.

99. Smith KA, Lachman LB, Oppenheim JJ, Favata MF. The functional relationship of the interleukins. J Exp Med. 1980 Jun 1;151(6):1551-6.

100. Bui AL, Horwich TB, Fonarow GC. Epidemiology and risk profile of heart failure. Nat Rev Cardiol. 2010 Nov 9. (in press).

101. Lou J, Xuan Y, Gu Y, Prabhu SD. Prolonged oxidative stress inverts the cardiac force-frequency relation: role of altered calcium handling and myofilament calcium responsiveness. J Mole Cell Cardio. 2006 Jan; (40):64-75. 


\section{CURRICULUM VITAE}

\section{Robert Kenneth Lewis, M.D., M.S., M.B.A.}

\section{Current Position}

Chief Fellow Division Cardiovascular Medicine

University of Louisville

Louisville, Kentucky

\section{University of Louisville Hospital}

Department of Internal Medicine

Division Cardiovascular Medicine

University of Louisville

550 S. Jackson St.

ACB, $3^{\text {rd }}$ Floor

Louisville, Kentucky 40202

(502) 852-1845

Home Address

16811 Polo Fields Lane

Louisville, Kentucky 40245

Email

Robert.Lewis@Louisville.edu

Telephone

(502) 931-7333 (cell)

(502) 332-8586 (pager)

Nationality

United States of America

Date of Birth

September 10, 1977

Louisville, Kentucky

Marital Status

Married, no children 


\section{Education}

Graduate

2007-Present

University of Louisville School of Medicine Louisville, Kentucky

Doctor of Philosophy, Ph.D.

Physiology and Biophysics

Advisor, Sumanth D. Prabhu, M.D.

2007-2008

University of Louisville School of Medicine Louisville, Kentucky

Master of Science, M.S.

Physiology and Biophysics

1999-2004

University of Louisville School of Medicine Louisville, Kentucky

Doctor of Medicine, M.D.

1999-2002 University of Louisville College of Business Louisville, Kentucky

Master of Business Administration, M.B.A.

Concentration in entrepreneurship

Undergraduate 1995-1999

University of Louisville College of Arts and Sciences

Louisville, Kentucky

Bachelor of Arts

Biology

\section{Post Graduate Training}

2010-Present University of Louisville School of Medicine Louisville, Kentucky

Chief Fellow, Cardiovascular Medicine

Chief, Roberto Bolli, M.D.

\section{7- Present}

University of Louisville School of Medicine Louisville, Kentucky Fellowship, Cardiovascular Medicine, Investigator Track 4-Year combined clinical-research program Chief, Roberto Bolli, M.D. 
2007-2009

University of Louisville School of Medicine

Louisville, Kentucky

Postdoctoral Research Fellow

Division of Cardiovascular Medicine and Department

of Physiology and Biophysics

Mentor, Sumanth D. Prabhu, M.D.

2004-2007

University of Louisville School of Medicine

Louisville, Kentucky

Residency, Categorical Internal Medicine

Chairman, Richard Redinger, M.D.

\section{Professional}

\section{Licensure}

2007-Present

Kentucky \#41735

2007-2011

DEA \#FL0832685

Current

NPI \# 1164542221

\section{Certification}

2007-2017

American Board of Internal Medicine Internal Medicine

Board Eligible 2011

American Board of Internal Medicine Cardiovascular Medicine

\section{Awards}

2006

Excellence in Clinical Education Award Best resident instructor in Internal Medicine Voted by $3 \mathrm{rd}$ and 4 th year medical students

Basic Cardiovascular Science Award (BCVS) Voted top $20 \%$ abstract submitted American Heart Association Scientific Sessions 


\title{
Lecturer
}

\author{
University School of Medicine \\ Clinical Practical Sciences \\ 3rd and 4th year medical students \\ Problem Based Learning \\ 1 st and 2nd year medical students \\ Didactics in Cardiovascular Medicine \\ Internal Medicine residents \\ Research Seminar \\ Department of Physiology and Biophysics
}

\section{Memberships}

\author{
American Medical Association \\ American Heart Association \\ American College of Cardiology \\ American College of Physicians
}

\section{Research}

\section{Clinical}

Graduate

Co-Investigator:

Myocardial Regeneration Using Cardiac Stem Cells Harvested From

Right Atrial Appendages in Patients with Ischemic Cardiomyopathy.

FDA approval January, 2007; Serial $N^{0} 0002$.

\section{Basic Science}

Undergraduate

University of Louisville School of Medicine

1995-1999

Chemotherapeutic delivery techniques for colorectal cancer

Department of Surgery, Mentor, Hiram C. Polk, Jr, M.D.

\section{Medical School}

University of Louisville School of Medicine

Genetic characterization of Inflammatory Bowel Disease

Department of Surgery, Mentor, Hiram C. Polk, Jr, M.D. 
Graduate

University of Louisville School of Medicine

2007-Present

Doctoral Thesis Project "Inflammatory Cell-Localized Tumor Necrosis Factor

Receptors 1 and 2 Have Divergent Effects on Post-Infarction Left Ventricular

Remodeling". Division of Cardiovascular Medicine, Department of Physiology and Graduate

Biophysics Mentor, Sumanth D. Prabhu, M.D.

University of Louisville School of Medicine 2007-Present

The role of inflammatory cell localized iNOS in the pathogenesis of chronic ischemic heart failure.

Division of Cardiovascular Medicine, Department of Physiology and Biophysics

Mentor, Sumanth D. Prabhu, M.D.

\section{Publications}

\section{Scientific Papers (Peer-Reviewed Journals)}

1. Pokorny RM, Wrightson WR, Lewis RK, Paris KJ, Hofmeister A, LaRocca R, Myers SR, Ackerman D, Galandiuk S. Suppository administration of chemotherapeutic drugs with concomitant radiation for rectal cancer. Dis Colon Rectum. 1997 Dec;40(12):1414-20.

2. Uthoff SM, Eichenberger MR, Lewis RK, Fox MP, Hamilton CJ, McAuliffe $\mathrm{TL}$, Grimes HL, Galandiuk S. Identification of candidate genes in ulcerative colitis and Crohn's disease using cDNA array technology.Int J Oncol. 2001 Oct;19(4):803-10.

3. Crawford NP, Eichenberger MR, Colliver DW, Lewis RK, Cobbs GA, Petras RE, Galandiuk S. Evaluation of SLC11A1 as an inflammatory bowel disease candidate gene. BMC Med Genet. 2005 Mar 9;6:10.

4. Makkar A, Siddiqui TS, Stoddard MF, Lewis RK, Dawn B. Impact of valvular calcification on the diagnostic accuracy of transesophageal echocardiography for the detection of congenital aortic valve malformation. Echocardiography. 2007 Aug;24(7):745-9.

5. Guangwu Wang, MD, PhD; Tariq Hamid, PhD; Rachel J. Keith, MS; Guihua Zhou, MD, PhD; Charles R. Partridge, PhD; Xilin Xiang, MD, PhD; Justin R. Kingery, BS; Robert K. Lewis, MD; Qianhong Li, MD, PhD; D. Gregg Rokosh, PhD; Rachael Ford, BS; Francis G. Spinale, MD, PhD; Daniel W. Riggs, BS; Sanjay Srivastava, PhD; Aruni Bhatnagar, PhD; Roberto Bolli, MD; Sumanth D. Prabhu, MD. Cardioprotective and AntiApoptotic Effects of Heme Oxygenase-1 in the Failing Heart. Circulation. 2010;121:1912-1925. 


\section{Manuscripts in Progress}

1. Buddhadeb Dawn, Tariq S. Siddiqui, Akash Makkar, Robert K. Lewis, Marcus F. Stoddard, Transesophageal Echocardiographic Direct Measurement of Left Ventricular Outflow Tract Area Improves Accuracy of Aortic Valve Area Determination by the Continuity Equation in Aortic Stenosis. (manuscript in preperation).

2. Robert K. Lewis, Tariq S. Siddiqui, Buddhadeb Dawn, Akash Makkar, Markus F. Stoddard, Detection of Coronary Artery Disease by Dobutamine Stress Transesophageal Echocardiography in Patients with Aortic Stenosis. (manuscript in preperation).

3. Lewis RK, Kingery JR, Hamid T, Keskey AL, Ishamil MA, Guo SZ, Bhatnagar A, Bolli RB, Prabhu SD. Myocyte-localized iNOS is Cardioprotective against Pathologic Remodeling in Heart Failure.

4. Lewis RK, Kingery JR, Ismahil MA, Guo SZ, Clair HB, Brittian KR, Henning, Hamid T, Prabhu SD. Inflammatory Cell-Localized Tumor Necrosis Factor Receptors 1 and 2 Have Divergent Effects on PostInfarction Left Ventricular Remodeling.

\section{Abstracts}

1. Transesophageal Echocardiographic Direct Measurement of Left Ventricular Outflow Tract Area Improves Accuracy of Aortic Valve Area Determination by the Continuity Equation in Aortic Stenosis. Buddhadeb Dawn, Tariq S. Siddiqui, Akash Makkar, Robert K. Lewis, Marcus F. Stoddard, Division of Cardiology, University of Louisville, Louisville, KY: American College of Cardiology, 56th Annual Scientific Sessions, New Orleans, LA, March 24-27, 2007.

2. Detection of Coronary Artery Disease by Dobutamine Stress

Transesophageal Echocardiography in Patients with Aortic Stenosis. Tariq S. Siddiqui, Buddhadeb Dawn, Robert K. Lewis, Akash Makkar, Marcus F. Stoddard, Division of Cardiology, University of Louisville, Louisville, KY: $13^{\text {th }}$ World Congress on Heart Disease, International Academy of Cardiology, Annual Scientific Sessions 2007, Vancouver, B.C., Canada, July 28-31, 2007.

3. Loss of Nrf2 Exacerbates Cardiac Hypertrophy and Dysfunction in Response to Pressure-Overload Charles R Partridge, Robert K Lewis, Justin R Kingery, Kenneth S Ramos, Sumanth D Prabhu,University of Louisville and Louisville VAMC, Louisville, KY: American Heart Association Scientific Sessions, Orlando, FL, November 4-7, 2007. 
4. Heart Failure-Derived Macrophages Induce Myocyte Oxidative Stress and Contractile Dysfunction in a Juxtacrine and iNOS-Dependent Manner. Justin R Kingery, Robert K Lewis, Charles R Partridge, M. Ameen Ismahil, Ernest Cardwell, Tariq Hamid, Steven P Jones, Sumanth D Prabhu, Univ of Louisville and Louisville VAMC, Louisville, KY: American Heart Association Scientific Sessions, New Orleans, LA, November 8-12, 2008.

5. Inflammatory Cell-Localized Tumor Necrosis Factor Receptors 1 and 2 Have Divergent Effects on Post-Infarction Left Ventricular Remodeling. Robert K Lewis, Justin R Kingery, Mohamed A Ismahil, Shang Z Guo, Heather Clair, Kenneth Brittian, Alexandria Henning, Tariq Hamid, Sumanth D Prabhu, Univ of Louisville and Louisville VAMC, Louisville, KY: American Heart Association Scientific Sessions, Orlando, FL, November 14-18, 2009.

6. Tumor Necrosis Factor Signaling in Macrophages Modulates Juxtacrine Macrophage-Myocyte Interactions in Heart Failure. Robert K Lewis, Justin R Kingery, Tariq Hamid, Mohamed A Ismahil, Shang Z Guo, Steven $P$ Jones, Sumanth D Prabhu, Univ of Louisville and Louisville VAMC, Louisville, KY: American Heart Association Scientific Sessions, Orlando, FL, November 14-18, 2009.

7. Inflammatory Cell-Localized iNOS Exacerbates Post-infarction LV Remodeling. Justin R Kingery, Robert K Lewis, Mohamed A Ismahil, Shang Z Guo, Heather Clair, Tariq Hamid, Sumanth D Prabhu, Univ of Louisville and Louisville VAMC, Louisville, KY: American Heart Association Scientific Sessions, Orlando, FL, November 14-18, 2009.

\section{Presentations}

1. Loss of Nrf2 Exacerbates Cardiac Hypertrophy and Dysfunction in Response to Pressure-Overload Charles R Partridge, Robert K Lewis, Justin R Kingery, Kenneth S Ramos, Sumanth D Prabhu,University of Louisville and Louisville VAMC, Louisville, KY: American Heart Association Scientific Sessions, Orlando, FL, November 4-7, 2007.

2. Inflammatory Cell-Localized Tumor Necrosis Factor Receptors 1 and 2 Have Divergent Effects on Post-Infarction Left Ventricular Remodeling. Robert K Lewis, Justin R Kingery, Mohamed A Ismahil, Shang Z Guo, Heather Clair, Kenneth Brittian, Alexandria Henning, Tariq Hamid, Sumanth D Prabhu, Univ of Louisville and Louisville VAMC, Louisville, KY: Oral presentation at American Heart Association Scientific Sessions, Orlando, FL, November 14-18, 2009. 
3. Tumor Necrosis Factor Signaling in Macrophages Modulates Juxtacrine Macrophage-Myocyte Interactions in Heart Failure. Robert K Lewis, Justin R Kingery, Tariq Hamid, Mohamed A Ismahil, Shang Z Guo, Steven $P$ Jones, Sumanth D Prabhu, Univ of Louisville and Louisville VAMC, Louisville, KY: Oral presentation at American Heart Association Scientific Sessions, Orlando, FL, November 14-18, 2009.

\section{References}

Roberto Bolli, MD

Chief, Division of Cardiovascular Medicine

Vice Chairman for Research, Department of Medicine

Professor of Medicine, Physiology \& Biophysics

Distinguished University Scholar

Division of Cardiology

University of Louisville Health Sciences Center

$\mathrm{Ph}:$ (502) 852-1837

\section{Sumanth D. Prabhu, MD}

Professor of Medicine, and Physiology \& Biophysics

Division of Cardiology

University of Louisville Health Sciences Center

Ph: (502) 852-7959

William B. Wead, Ph.D.

Associate Professor and Vice Chairman

Department of Physiology \& Biophysics

University of Louisville Health Sciences Center

Ph: (502) 852-5371

\section{Stephen Wagner, MD}

Associate Professor of Medicine

Program Director, Cardiology Fellowship

Chief of Cardiology, Louisville VA Medical Center

Division of Cardiology

University of Louisville Health Sciences Center

$\mathrm{Ph}$ : (502) 852-7959

\section{A. Gregory Deam, M.D.}

Assistant Professor of Medicine

Director, Cardiac Electrophysiology

Division of Cardiology

University of Louisville Health Sciences Center

Ph: (502) 852-7959 